\title{
II. Kollektives Handeln: Ein praxistheoretisches Konzept
}

Die im Folgenden entwickelte Heuristik kollektiven Handelns basiert auf einem strukturationstheoretisch informierten Begriff der Agency. In einem ersten Schritt wird das Konzept systematisiert und verschiedene Aspekte sowie Formen von Agency unterschieden. In einem zweiten Schritt erfolgt dann eine Übertragung dieser Aspekte und Formen von Agency auf die Ebene des Kollektivhandelns. Abschließend wird die Abgrenzung des so entstandenen Konzepts des Kollektivhandelns zu anderen Kollektivbegriffen diskutiert. Neben einer Vielzahl kleinerer Beispiele wird dabei für eine komplexere Illustration der bereits eingangs erwähnte Fall eines interorganisationalen Netzwerks in der Katalyseforschung herangezogen.

\section{Handeln als Agency: Dezentrierung von Subjekt und Intention}

Mit dem Begriff der Agency verleiht Giddens seiner Handlungstheorie eine spezifisch antiindividualistische, antiidealistische und antirationalistische Richtung unter Betonung des ausführenden Charakters des Handelns. Seine Bestimmung erfolgt unter Bezug auf das Grundkonzept der Praxis:

„I shall define action or agency as the stream of actual or contemplated causal interventions of corporal beings in the ongoing process of events-in-the-world. The notion of agency connects directly with the concept of Praxis "(Giddens 1993: 81; Herv. RJ)

Agency $^{82}$ bedeutet für Giddens eine kausale körperliche Intervention in die Praxis hinein, er bindet sie an körperliche Bewegungen und physisch-materiale

82 Giddens verwendet Agency und Handeln, wie im Zitat ersichtlich, synonym. Ein weiteres Äquivalent ist der Term der Aktivität. Diese Gleichsetzung geschieht auch im Verlaufe dieser Arbeit. Dennoch möchte ich in den einführenden Kapiteln den spezifischen Zuschnitt einer 
Effekte, die direkt oder vermittelt kausale Wirkungen auf das beständige Verlaufen der Praxis haben. Somit denkt er das Handeln zuvorderst als praktisches Ausführen. Sozialtheorie fokussiert für Giddens (1984: xvii) dabei auf die Spezifika menschlicher Aktivitäten. Diese sind wirksame Agenturen für eine Vielzahl an Prinzipien, auch jenseits eigener Interessen, Pläne oder Vorstellungen (ebd.: 9). Dabei nimmt er die Trennung von Agency und Verhalten aus der Webertradition mit und spezifiziert dieses Einwirken, anders als Latour, noch einmal deutlich. Agency meint, zu kontrollierten Aktivitäten fähig zu sein, Aktivitäten reflexiv unter Einbezug der sozio-materialen Situiertheit und den im Handeln vergegenwärtigten Gedächtnisspuren der Handelnden zu orientieren und auszurichten (ebd.: 5ff.), ebenso sozial anerkannt zu handeln und als Verursacher eigener Aktivitäten zu gelten (Giddens 1993: 78).

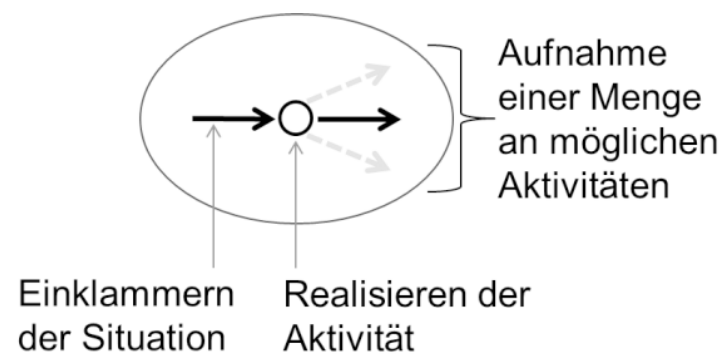

Abb. 2: Agency als realisierte Intervention im Fluss der Praxis, eigene Darstellung

Agency bezeichnet für Giddens des Weiteren, wie in Abb. 2. dargestellt, das praktische Realisieren einer Aktivität vor dem Hintergrund eines möglichen

praxisbezogenen Handlungstheorie betonen, sodass ich hier von Aktivitäten spreche oder den nicht übersetzbaren Originalterm der Agency beibehalte. Zu einem ebenso schillernden wie schwierigen Begriff wird Agency durch seine vielfältige und doch scheinbar immer ähnliche Verwendung. Die Ähnlichkeiten täuschen, und es lohnt sich, die Traditionen näher zu beleuchten, denen die Konzepte entspringen. Fundamentale Unterschiede in den Bestimmungen werden häufig erst vor dem Hintergrund ihrer Einbindung und Bedeutung für die konzeptionelle Architektur des Ansatzes, in der sie verwendet werden, deutlich. Giddens geht, wie es so typisch ist für sein Werk, radikal eklektizistisch vor und verbindet verschiedene Traditionen, dies allerdings, und ebenso kennzeichnend, unter striktem Bezug auf die von ihm verfolgte praxistheoretische Perspektivität, seinem vor allem durch den frühen Marx geprägten Blick auf die Welt. 
Spektrums anderer Aktivitäten bzw. des Unterlassens von Aktivität. Nach all den vielfältigen Prägungen, die dem Handelnden als gegebene, nicht selbst gewählte Bedingungen im Tun begegnen, wohnt Handeln dennoch stets ein Moment aktiver Produktion inne. Um von einem Agency-Ereignis sprechen zu können, muss das Tun also durch einen Handelnden zumindest zu einem gewissen Grade kontrollierbar und praktisch gerichtet sein. Dies meint keineswegs ein Ausrichten an einem Nutzen oder Interessen, wie etwa bei Coleman, sondern vielmehr, dass wir unserem Tun im Alltag meist routinehaft eine Richtung geben. Es ist weiterhin an ein gesellschaftlich wie situativ konstituiertes Wissen und Können des Handelnden gebunden, an seine Fähigkeit, etwas zu machen (zu ,powern“), sowie an seine spezifische Aufnahme von Welt (Reflexivität). Die Aktivität wird dabei in sozialen Kontexten als vom Handelnden verursacht interpretiert, bewertet und praktisch behandelt, egal ob dieser den Effekt erzielen wollte oder nicht.

Im Ergebnis ist Handeln steht verbunden mit einer transformativen Kapazität (Giddens 1984: 15), die sowohl zur Produktion des Neuen als auch zur Reproduktion des Bestehenden aktiv eingesetzt wird. Agency ist damit zugleich Produkt und Produzierendes gesellschaftlicher Praxis unter Rekurs auf soziale Praktiken. Anders als Coleman und Meyer greift Giddens die Agency-Debatte also radikal prozessual vom andauernden Fluss der Praxis her auf. ${ }^{83}$

Diese Bestimmung erscheint zunächst sehr allgemein. Aber: Agency ist ein zentraler Begriff der philosophischen, sozialwissenschaftlichen (insbesondere ökonomischen, rechtswissenschaftlichen und politologischen) sowie psychologischen Debatte. Was hier so unscheinbar daherkommt, bedeutet nichts weniger als einen radikalen Bruch mit dem philosophischen Mainstream und der postparsonsianischen Handlungstheorie in der Soziologie. Giddens Impetus kann man dabei unter einer großen Überschrift zusammenfassen: Es geht um eine Dezentrierung von Subjekt und Intention (ebd.: xxii) in existentialistischer Atti-

83 Auf den ersten Blick ergeben sich Ähnlichkeiten zum Agency-Begriff bei Latour, was nicht verwundert, da sich beide mehr oder minder explizit auf Gregory Bateson (1981) beziehen, um zunächst ein wenig voraussetzungsvolles Verständnis zu entwickeln: Jedes Element, das für die Situation einen Unterschied macht, übt nach diesem Verständnis eine prinzipielle Form von Agency aus. Latour fasst dies mit einem Gedankenexperiment (Latour 2007: 123) zusammen, wonach sich der Forscher vorstellen möge, was an einer bestehenden Situation anders wäre, wenn man sich das jeweilige Element wegdenkt. Bateson versteht unter Information ,einen Unterschied, der bei einem späteren Ereignis einen Unterschied ausmacht“ (zitiert nach Luhmann 2009: 30). 
tude. Ihm ist es um ein Denken des Handelns nicht vom intentional steuernden Subjekt oder dieses bestimmenden Institutionen her bestellt, sondern von der relationalen, nie isolierten und stets schon gesellschaftlichen Praxis. Handeln ist praktisches Produzieren in Auseinandersetzung mit Welt. Nichtsdestoweniger möchte er in einem ganz basalen Sinne an einem existentialistischen Menschenbild à la Sartre (1993) festhalten, das die Besonderheit dieses Wesens in seiner ganz prinzipiellen Fähigkeit zum Unterlassen eigenen Handelns begründet, selbst wenn dies in letzter Konsequenz bedeutet, dem eigenen Leben ein Ende zu setzen. Diese Qualifizierung ist ihm analytisch bedeutsam, impliziert sie doch, dass selbst hochgradig systemisch oder institutionell geprägte Momente der Praxis dennoch nie losgelöst von der Unbestimmtheit und Kontingenz des menschlichen Tuns analysiert werden können.

Im Folgenden wird anhand dieser allgemeinen Bestimmung ein praxistheoretisches Handlungsmodell präsentiert. Dies impliziert eine analytische Trennung verschiedener Aspekte von Agency und einer Diskussion ihres Verhältnisses. Insgesamt werden aus der Diskussion des Begriffs bei Giddens drei Spezifika unterschieden, die Agency als spezifische Form kausaler Intervention fundamental in der Praxis begründen ${ }^{84}$ So kann die neuere Debatte um die Fruchtbarkeit von Agency-Konzepten in empirischen Analysen aufgenommen ${ }^{85}$ und um eine praxistheoretische Alternative ergänzt werden. Im Zusammenspiel entsteht eine Heuristik praxistheoretischer Agency, die die Basis für eine Übertragung hin zu kollektiver Agency bietet. ${ }^{86}$

84 Wichtig ist dennoch zu betonen: Agency-Ereignisse sind stets und zugleich Strukturereignisse. Dieser Punkt wird später noch ausgeführt und unterscheidet Giddens Ansatz der Dualität von Struktur und Handeln von stärker auf dem Auseinanderziehen von Agency und Struktur basierenden Ansätzen (vgl. bspw. Archer 1995). Wie im Verlauf noch dargestellt wird, bedeutet dies nicht, dass man in der Analyse nicht einen Punkt expliziter zum Erkenntnisinteresse machen kann; wichtig ist dabei nur, den anderen in der Analyse auch mitzuführen.

85 Siehe prominent Emirbayer/Mische (1998) und die kritische Erwiderung von Fuchs (2001) sowie Hitlin/Elder $(2006,2007)$ und Elder-Vass (2007).

86 Die vielleicht prominenteste Version der Unterscheidung verschiedener Aspekte von Agency im amerikanischen Theoriediskurs ist die Verbindung der Netzwerkforschung soziometrischer Tradition mit dem Pragmatismus und der Phänomenologie bei Emirbayer und Mische (1998). Sie gelangen allerdings zu einer gänzlich anderen Auffassung zu den Aspekten als den eingangs skizzierten. Für sie besteht Agency aus dem iterationalen, also der Geschichtlichkeit des Akteurs (ähnlich Bourdieus Habitus), dem projektiv imaginierenden sowie dem evaluativwertenden Element. Auch wenn man ihnen zustimmen kann, dass all diese Aspekte von Bedeutung für das Handeln sind, wird hier ein zu planvolles und klar auf Transformation zugespitztes Moment von Aspekten, die irgendwie ,aus dem Individuum kommen“, als Gegensatz 


\subsection{Die Fähigkeit zu Handeln}

Ganz basal bindet Giddens die Möglichkeit zur Intervention, so will ich ihn deuten, an eine situative Verfasstheit von Agency-Situationen und den in ihnen handlungsfähigen Menschen. ${ }^{87}$ Die Ko-Konstitution von Handelndem und Situation muss einen gewissen Grad an Kontrolle körperlicher Bewegung, eine Ausrichtung des Tuns und das Erzeugen eines Effekts für späteres Tun ermöglichen. Handlungsfähigkeit meint also die Möglichkeit, qua menschlicher Aktivität zu einem gewissen Grade kontrolliert und praktisch gerichtet kausal auf Praxis einzuwirken oder dies zu unterlassen. Die Handlungsfähigkeit umfasst wiederum drei Elemente:

(i) Hier wäre zunächst ein gewisser Grad körperlicher Kontrolle zu nennen. In seiner praxistheoretischen Handlungstheorie ${ }^{88}$ nimmt Giddens die Steue-

zu Strukturmomenten entworfen. Fuchs (2001) hat hier zu Recht von einer Restkategorie gesprochen, dem alles zugewiesen werden kann, das nicht „,sozial“ ist. Eine weitere Möglichkeit liegt darin, verschiedene Komplexitätsstufen der Agency zu unterscheiden (instruktiv hierfür in Anlehnung an den Diskurs um die Agency der Dinge Rammert/Schulz-Schaeffer 2002 oder in Auseinandersetzung mit der Agency-Debatte der Sozialpsychologie Hitlin/Elder 2006, 2007). Auch diese Idee wird später in abgewandelter Form aufgenommen (siehe Teil IV.).

87 Mit Alkemeyer (2017) kann man betonen, dass mit dem Term des Agenten zugleich die wirkende Kraft, die Bevollmächtigung und das Ausführen im Auftrag (eines umfassenderen Prinzipals) angesprochen wird. Hinzufügen könnte man außerdem die relativ stabile und als stabil herzustellende Reflexivität, der reflexive Kern des Agenten, den Giddens mit seinem Stratifikationsmodell des Agenten andeutet. Generell kann man, wie später noch eingeführt, diese allgemeine Figur des Agenten vom deutlich spezifischeren Begriff des kompetenten Akteurs wie dem des knowledgeable Agenten unterscheiden.

88 Während in der praxistheoretischen Debatte durchaus Fortschritte in der Betonung der Eigendynamiken sozialer Praktiken (vgl. Schatzki 2002 in sehr abstrakter sowie strukturalistischer Manier und insbesondere Shove et al. 2012 in stärker empirisch-analytischer Absicht), der Abgrenzung und Konturierung gegen andere Ansätze sowie Einheit der theoretischen Bewegung (bspw. Reckwitz 2003, Schäfer 2016) oder der Betonung von Praxis und der materialen Situiertheit des Tuns (Pickering 2001) erkennbar sind, ist dies im Bereich eines praxistheoretischen Handlungskonzepts kaum der Fall. Hier ist nach den Statements von Giddens zum Stratifikationsmodell oder Bourdieus Habitusfigur sowie der Diskussion gemeinsamer Bezugspunkte zwischen praxistheoretischer und pragmatistischer Handlungstheorie (Joas 1992, Beckert 1997) kaum neuer Grund erschlossen worden. Der alte Konkurrent des Ansatzes, der sogenannte kritische Realismus, erweist sich als deutlich produktiver und setzt sogar zu einer Vereinnahmung der Reflexivitäts- wie Habitusfigur (vgl. insbesondere Elder-Vass 2007) an. Dies ist insofern problematisch als dass eine Vereinnahmung praxistheoretischen Denkens mit einer völlig differenten ontologischen Basis erfolgt: dem Dualismus von Struktur und Handeln. Die Praxistheorie, befasst vor allem mit den oben angedeuteten Themen, hat dem bislang wenig entgegenzusetzen. 
rungs- und Kontrollfigur vieler Handlungstheorien in der für ihn typischen, eklektizistischen Manier auf, um zugleich die beschriebene Dezentrierung des Subjekts als rationalen oder intentionalen Gestalter zu betonen. Er stellt dabei insbesondere ein einfach kausales Verhältnis der intentionalen Kontrolle des Körpers infrage:

„I am the author of many things I do not intend to do, and may not want to bring about, but none the less $d o$. Conversely, there may be circumstances in which I intend to achieve something, and do achieve it, although not directly through my agency" (Giddens 1984: 9, Herv. i. Orig.).

Das kontrollierte Erzeugen eines Effekts wird von den Absichten des Handelnden entkoppelt. Giddens führt hierzu insbesondere das Standardbeispiel für sogenannte Akkordeoneffekte an (ebd.: 10, siehe für frühere Diskussionen in der Philosophie Feinberg 1970, Davidson 1990a): Ein Handelnder, der eigentlich nur beabsichtigt, das Licht anzuschalten, schreckt mit dieser Fingerbewegung am Lichtschalter einen Dieb in seiner Wohnung auf, der flieht und später verhaftet wird. Sicher war es nicht die Absicht des Handelnden einen Dieb hinter Gitter zu bringen und dennoch erzeugte sein Tun zu einem gewissen Teil und im Verbund mit späteren Aktivitäten diesen Effekt. Diese verallgemeinerte Aufnahme des Themas verbindet er weiterhin mit einer Dialektik der Kontrolle über das Handeln. Aus der eingangs beschriebenen, existentialistischen Tradition übernimmt er dabei die basal menschliche Fähigkeit zum Nein-Sagen. Diese macht es nötig, dass auch in hochgradig durch andere kontrollierten und ohnmächtig erscheinenden Situation für den Ausführenden Potentiale der Kontrolle bestehen. Andersherum handelt der Agent niemals nur im eigenen Sinne. Ohne die vielfältige Verwobenheit und wechselseitigen Kontrollpotentiale Anderer würde er nicht um seiner selbst wissen. ${ }^{89}$

Die beschriebene Fähigkeit zum Andershandeln basiert auf einer Kontrolle einheitlicher Bewegungen des Körpers, die auch die Schaffung der Einheit selbst impliziert. Ohne die Fähigkeit zur Kontrolle einheitlicher Bewegungen wäre Agency undenkbar, könnte ein gemachter Unterschied

89 Vgl. hierzu Hegels (1970) Ausführungen zum Selbstbewusstsein und die Anerkennungstheorie des Selbstbewusstseins bei Honneth (2010). 
kausal nicht zugerechnet werden. Diese Kontrolle ist reflexiv, unmittelbar an das, später eingeführte, Konzept des reflexiven Monitorings geknüpft:

\begin{abstract}
"Action is a continuous process, a flow, in which the reflexive monitoring which the individual maintains is fundamental to the control of the body that actors ordinarily sustain throughout their day-today lives." (Giddens 1984: 15)
\end{abstract}

Auch die für Agency basale Fähigkeit, Wirkungen in Praxis auch unterlassen zu können, basiert auf diesem Vermögen. Dieser Aspekt ist folglich konstitutiv, um überhaupt von Agency sprechen zu können. ${ }^{90}$ Giddens bindet den Agency-Begriff damit unmittelbar an den der Macht und nicht an den der Intention:

,action logically involves power in the sense of transformative capacity, in this sense, the most all-embracing meaning of ,power', power is logically prior to subjectivity, to the constitution of the reflexive monitoring of conduct" (ebd.).

Macht ist also auch in Giddens ' Verständnis stets von einem Machen her zu denken, wie es Popitz (1992) einmal so treffend formuliert hat. ${ }^{91}$ Als spezifische Fähigkeit eines Körpers zum Einwirken ist Macht dabei aber keineswegs individuell, sondern vor dem Hintergrund der Dualität von Struktur und Handeln in Interaktion zu verstehen. Erst die über soziale Praktiken

90 In der Moderne wird diese Fähigkeit zur Selbstzurichtung zum Grundpfeiler und zur Anforderung an das moderne Subjekt (Elias 1979, Foucault et al. 1993, van Krieken 1990), sie wird also noch einmal in die soziale Konstruktion des Akteurs mit eingeführt. Nach der Auflösung der gottgegebenen Ordnung werden wir selbst die Herren unserer Geschichte, und es muss von einer aktiven Gesellschaft (Etzioni 1968) ausgegangen werden. Dies alles basiert aber auf einer eigenen, hochgradig voraussetzungsvollen und erlernten Praxis des Alltags: der Fähigkeit, den Körper als Einheit zu kontrollieren. Bei Säuglingen ist bspw. Mimik und Gestik noch nicht aufeinander eingestellt, und es bedarf einiger Entwicklung, bis wir als in die Gesellschaft Erwachsene sie als einheitliche und aufeinander abgestimmte Bewegungen deuten können.

91 Dabei darf Macht nicht gleichgesetzt werden mit stabilisierten Herrschaftsformen, die ein Element der Ressourcen sozialer Systeme sind. Macht als generatives Vermögen zur Produktion ist konstitutiv, wenn von Handeln gesprochen werden soll. Die Relation von Macht und Ressourcen fasst er wie folgt: ,[...] we can express the duality of structure in power relations in the following way, Resources (focused via signification and legitimation) are structured properties of social systems, drawn upon and reproduced by knowledgeable agents in the course of interaction. Power is not intrinsically connected to the achievement of sectional interests. In this conception the use of power characterizes not specific types of conduct but all action, and power is not itself a resource. Resources are media through which power is exercised, as a routine element of the instantiation of conduct in social reproduction" (Giddens 1984: 15f.). 
bereitgestellten und über Sozialsysteme und Institutionen regulierten Verfahrensweisen ermöglichen die Aktualisierung dieser Kapazitäten (siehe Teil III.1.). Hierbei kann man selten von Situationen der Machtlosigkeit eines Handelnden sprechen, solange er am gesellschaftlichen Leben teilnehmen kann, nicht physisch oder psychisch die Kontrolle über die Bewegungen des eigenen Körpers verloren hat. Im Sinne des Pragmatismus kann man allgemeiner von einer bis zu einem gewissen Grade vorhandenen Primärkoordination sprechen. Dies meint die Erzeugung einer gewissen Einheitlichkeit und Abstimmung zwischen Körper und Situation (vgl. Dewey 1896). Als Agenturen im Sozialen sind wir fähig, einen spezifischen Unterschied zu machen, was nicht nur einen gewissen Grad an Kontrolle der Bewegung umfasst, sondern auch die Wahrnehmung, Interpretation und Bewertung der Situation einschließt. Verlieren wir diese Fähigkeit hören wir nach Giddens auf Handelnde zu sein (Giddens 1984: 14). Diese Annahmen begründen seine latente Anthropologie. Die Herstellung dieser Kontrolliertheit muss stets als bedeutsames Moment von Agency mitbetrachtet werden. Die körperliche Kontrolle ist die Basis, von der aus Giddens Agency denkt. Diese Kapazitäten und Fähigkeiten sind unterschiedlich verteilt. Gleichzeitig kann die Quelle dieser ,autonomy of bodily control“ (ebd.: 50) nicht im Individuum verortet werden, sondern kann nur vor dem Hintergrund erlernter Routinen und Handlungsweisen verstanden und erklärt werden (ebd.).

Die basale Kontrolle körperlicher Bewegung begründet die Dialektik von Kontrolle in Herrschaftsbeziehungen fundamental. Sie ermöglicht die basale Macht der Ohnmächtigen. Dennoch sind wir keineswegs beständig Herren im eigenen Haus. Selbst die einfachsten Bewegungen beruhen auf einem ständig sich neu webenden Netz aus Beziehungen zu anderen, werden erst durch diese Beziehungen erlernt und bedeutsam. Neben der Eigenkontrolle ist also auch Fremdkontrolle zentraler Bestandteil von Agency und relational zu verstehen. Auch wenn Giddens mit dem Term der Dialektik der Kontrolle Konkreteres ${ }^{92}$ fassen möchte, so kann man ihn auch gene-

92 Er bezieht sich meist auf die Wechselseitigkeit der Abhängigkeitsverhältnisse von über- und untergeordneten Positionen in Sozialsystemen (Giddens 1984: 16). Das bietet Anschlüsse an die Prinzipal-Agenten-Theorie (vgl. für einen Überblick Eisenhardt 1989), auf die sowohl das Agency-Verständnis bei Meyer als auch die Theorie des korporativen Akteurs bei Coleman re- 
reller interpretieren. Bezieht man die Figur auf die Einheitlichkeit der Bewegung in Agency-Ereignissen, so kann man allgemeiner davon ausgehen, dass jede Fähigkeit zur Kontrolle eigener Bewegungen auf der Abstimmung mit den (realisierten wie potentiellen) Bewegungen Anderer beruht. Nicht nur ein Selbstbewusstsein (wie bei Hegel), auch Kontrolle selbst entsteht relational aus der ,wechselseitigen Beschränkung der eigenen, egozentrischen Begierde zugunsten des jeweils anderen“ (Honneth 2010: 32), also aus Prozessen wechselseitiger Anerkennung. Man kann die Einheit eigener Bewegung erst in und durch ein konkret-präsentes oder abstraktgeneralisiertes Gegenüber hervorbringen, bewerten und verstehen.

Explizit macht er diese unmittelbare Verknüpfung von Agency und Macht in der Figur der Dialektik von Kontrolle. Der Agency-Begriff im Sinne der Intervention in Praxis ist direkt an den Machtbegriff gekoppelt:

„Power in the sense of transformative capacity of human agency is the capability of the actor to intervene in a series of events so as to alter their course; as such it is the ,can' which mediates between intentions or wants and the actual of outcomes sought after. Power in the narrower relational sense is a property of interaction, and may be defined as the capability to secure outcomes where the realization of these outcomes depends upon the agency of others" (Giddens 1993: 117f.).

In der Thematisierung von Agency als Macht zur Intervention zeigen sich dabei zwei unterschiedliche Aspekte der Kontrolle. Der Erste bezeichnet ein Vermögen zur einheitlichen Bewegung des Körpers, sodass ein Effekt „kontrolliert“ erzielt werden kann. Ein zweiter, relationaler Aspekt verweist darauf, dass diese Kontrollfähigkeit immer auch von den Bewegungen anderer Körper und Dinge abhängt. Praxissituationen werden immer wieder zu einer sozialen Angelegenheit, da wir, und hier kann man Latour zustimmen, stets in Assoziationen handeln. Unsere Aktivitäten sind erst im Zu-

kurriert. Es geht also um Kontrolle in Macht- und Herrschaftsbeziehungen zwischen häufig unterschiedlich interessierten Auftraggebern und Ausführenden. Agency wird sodann zur Handlungsausführung, und dieses Verständnis nimmt Giddens, wenn auch ohne konkreten Verweis, auf. Dieses Ausführen kann im Sinne des eigenen Auftrages oder im Auftrag Anderer geschehen. Wenn Prinzipal und Agent unterschiedliche Personen sind, geht es darum, wie die Kontrolle über die Ausführung eines Tuns ausgestaltet ist, sodass im Sinne eines Prinzipals agiert wird. Es geht um eine Neuauflage einer empirischen und normativen Bestimmung von HerrKnecht-Beziehungen, die schon für Hegel (1952) eine grundlegende Komponente des Sozialen darstellte (siehe Windeler 2001: 173). 
sammenspiel mit anderen Körpern, Dingen, aber auch abstrakten Prinzipien und Symbolen überhaupt wirksam. Die Praxissituationen sind beständig Kontexte der Relationierung. Dieses In-Beziehung-Setzen muss dabei keineswegs in Ko-Präsenz stattfinden. Häufig beziehen sich Handelnde auf die Antizipation eines generalisierten oder physisch abwesenden Anderen bzw. auf abwesende Dinge und Symbole (siehe Cohen 1989: 30). Immer häufiger begeben wir uns zudem in technisch vermittelte, virtuelle Situationen (vgl. etwa Knorr-Cetina 2009).

Die zentrale Rolle in der Vermittlung der damit einhergehenden Dialektik von Fremd- und Eigenkontrolle gesteht Giddens sozialen Praktiken zu. Kontrolle ist damit weder durch das Individuum noch durch die soziale Situation allein zu erklären. Vielmehr ist jeder in Praxis verwendeten sozialen Praktik eine Dialektik aus Fremd- und Eigenkontrolle inhärent. Es sind zumeist typische Handlungsweisen, Routinen und Prozeduren, die uns sowohl die Kontrolle unseres Körpers ermöglichen (und diese beschränken) als auch die Relationierung mit anderen Körpern und Dingen anleiten. Genereller gilt: Auch die Kontrolle körperlicher Bewegung ist zumeist ein hochgradig erlernter und an typischen Arten und Weisen körperlicher Bewegung orientierter Prozess. Soziale Praktiken haben nicht nur eine Wissenskomponente, sondern stets auch eine praktische Ebene. Sie sind zugleich Techniken der körperlichen Selbstzurichtung und Disziplinierung. ${ }^{93}$

(ii) Agency impliziert weiterhin, dass den Aktivitäten zu einem gewissen Grade durch den Handelnden eine Richtung gegeben wird und das Tun gerade nicht von situativen Bedingungen determiniert ist. ${ }^{94}$ Das Konzipieren von Agency als körperlicher Intervention und Vollzug ist so bedeutsam, weil Giddens sich gegen intentionalistische Konzeptionen des Akteurs und des Handelns in der Sozialtheorie richtet, die Handlungen vor dem Hintergrund

93 Diese Dialektik involviert weiterhin nicht nur die Aufnahme von eigenen praktischen Transformationspotentialen und denen Anderer, sondern wird erst in Verbindung mit spezifischen Wahrnehmungs- und Interpretationsmustern sowie Bewertungen in Kraft gesetzt.

94 Giddens selbst verwendet den Begriff der Gerichtetheit nicht. Im Folgenden interpretiere ich seine Ausführungen zum Handlungsbegriff vor dem Hintergrund der existentialistischen Figur einer prinzipiellen Gerichtetheit menschlichen Tuns und der fundamentalen Bedeutung des Unterlassens von Aktivität (siehe Sartre 1993). Den Bezug seines Handlungskonzepts zu dieser Tradition hat Giddens selbst nie explizit hergestellt, wenngleich sein Werk auf eine intensive Rezeption hindeutet. Anmerkungen zu Giddens Beziehung zum Existentialismus finden sich etwa bei Renn (2016). 
individueller Entscheidungen oder von Handlungsentwürfen thematisieren und Intentionen als Ursachen setzen. Giddens geht es um einen anderen Ausgangspunkt:

\begin{abstract}
„Agency refers not to the intentions people have in doing things but to their capability of doing those things in the first place (which is why agency implies power: cf. the Oxford English Dictionary definition of an agent, as ,one who exerts power or produces an effect'). Agency concerns events of which an individual is the perpetrator, in the sense that the individual could, at any phase in a given sequence of conduct, have acted differently" (Giddens 1984: 9, Herv. RJ).
\end{abstract}

Der Fokus liegt auf dem Einwirken auf Welt im Sinne einer Kausalität, die insofern auf menschliche Agenten zurückgeführt werden kann, da sie stets ganz prinzipiell zum Unterlassen fähig wären. Hier kommt der existentialistische Einschlag zur Geltung. Seine ganz prinzipielle Fähigkeit, einzuwirken oder es zu unterlassen, ist die Basis, von der aus Agency analysiert wird. Es geht um ein Konzipieren des Handelns als gerichteter Bewegung, die hochgradig strategisches, planvolles Tun bedeuten kann, häufig aber eher als praktisch bewusst gerichtete, routinierte Bewegung unter vorgefundenen, nicht selbst gewählten Bedingungen daherkommt. Bedeutsam ist ihm, dass auch den eingelebten Handlungsformen des Alltags stets Potentiale zur situativen Abweichung innewohnen, da es eben nie kausal determiniert ist. Im Umkehrschluss gilt: Sind Aktivitäten derart kausal bedingt, verlieren sie ihre Qualität als Handeln.

Dieses balancierte Verständnis der Gerichtetheit von Agency bedeutet, dass die Interventionsmöglichkeit mit einer gewissen Kontingenz im Sinne eines auch Anders-möglich-Seins ausgestattet ist, die durch einen Handelnden in einer bestimmten Hinsicht geschlossen wird. Stehe ich heute Morgen auf und gehe zur Arbeit, bleibe ich liegen und lasse die resultierenden Konsequenzen über mich ergehen, oder wähle ich den Zwischenweg über die nächste Straßenecke zum Arzt? Auch wenn dieses Beispiel eine bewusste Entscheidung impliziert, sind die meisten „kleinen“ Richtungen, die wir unserem Alltag geben, zumeist im praktischen Bewusstsein angesiedelt, erfolgen blitzschnell und ohne eine explizite Entscheidung im Verlauf der Praxis, die auch als Entscheidung im Handeln aufgenommen wird.

Die Gerichtetheit ist zudem nicht nur eine spezifisch-menschliche Fähigkeit, sondern zugleich fundamental konstituiert durch die Handlungssituation: 
„It is analytically to the concept of agency: (1) that a person ,could have acted otherwise' and (2) that the world as constituted by a stream of events-in-process independent of the agent does not hold out a predetermined future" (Giddens 1993: 81).

Agency ist ko-konstituiert durch die Situation und die Handelnden. Wichtig ist hierbei, dass Agency an die Fähigkeit gebunden ist, einen Beitrag auch unterlassen zu können (vgl. ebd.: 82). ${ }^{95}$ Hier finden sich die erwähnten Anleihen an die existentialistische Philosophie, und hier trennen sich auch die Wege von Latour und Giddens. Letzterer schreibt diese Fähigkeit zum Unterlassen ausschließlich Menschen zu. Diese sind, anthropologisch gedeutet, in der Lage, ihre Triebe aufzuschieben und mechanistische Reaktionen im Sinne automatischer Reiz-Reaktions-Ketten zu unterbinden. Existentialistisch gefasst, ist von einer grundlegenden Freiheit des Menschen auszugehen, da er letztlich in jeder noch so ausweglosen Situation immer die Freiheit besitzt, dem Sein ein Ende zu setzen. Giddens (1984: 61ff.) verdeutlicht diese Denkfigur eindrücklich am Beispiel der Konzentrationslager. Er lässt allerdings offen, woher diese menschliche Fähigkeit kommt. Ihm ist es vor allem um einen analytischen Zugriff auf Welt bestellt, der aus dieser folgt:

„To be able to ,act otherwise' means being able to intervene in the world, or to refrain from such intervention, with the effect of influencing a specific process or state of affairs. This presumes that to be an agent is to be able to deploy (chronically, in the flow of daily life) a range of causal powers, including that of influencing those deployed by others. Action depends upon the capability of the individual to ,make a difference' to a pre-existing state of affairs or course of events. An agent ceases to be such if he or she loses the capability to ,make a difference"“ (Giddens 1984: 14).

Nimmt man an, dass Menschen häufig ihr Tun ganz basal unterlassen und somit ganz prinzipiell zu einem gewissen Grade auch kontrollieren können, rückt dies eines ins Zentrum: Wenn wir es mit menschlichen Gesellschaften zu tun haben, haben wir es mit einem Gegenstand zu tun, der nie vollständig kausal determiniert ist. Vor diesem Hintergrund muss die Reproduktion struktureller Zwänge, auch jener, die zum Nachteil der diese Ausübenden gereichen, als Form von Agency verstanden werden. Der Analyst muss verstehen, warum die Handelnden diese aktualisieren, obwohl sie es in ganz 
prinzipieller Weise nicht müssten. Auch das In-Geltung-Setzen eigener Abhängigkeiten ist als Agency zu verstehen, nicht nur Formen des Auflehnens gegen diese.

Dieses Verständnis von Agency als Kapazität zum kausalen Einwirken auf Welt hat philosophiegeschichtlich eine lange Tradition. Agency wird bei Giddens nicht von einem monadischen oder nach freien Willensentscheidungen handelnden Akteur aus gedacht. ${ }^{96}$ Für ihn geht es vielmehr um eine soziologische Wendung des Begriffs, weshalb er auch das Thema der Gerichtetheit vom stetigen Fluss gesellschaftlicher Praxis und den sozialen Praktiken her aufgreift.

Hier folgte Giddens vor allem dem einflussreichen Beitrag Bernsteins (1971), der die Gemeinsamkeiten zwischen verschiedenen Denkbewegungen herausarbeitete, die eine Loslösung der Handlungstheorie vom vorherrschenden, cartesianischen Denken proklamieren. Die hier versammelten Autoren lehnen die Vorstellung einer mentalen oder willentlichen Instanz $\mathrm{ab}$, die dem Handeln zeitlich vorausgeht und dieses ausrichtet. ${ }^{97}$ Auch den

96 Agency wird in der Philosophie häufig mit einer spezifisch menschlichen Fähigkeit zur Ausrichtung des eigenen Handelns durch willentliche Entscheidungen verbunden (vgl. McCann 1998). So argumentiert zumindest die „Standardtheorie“ der Agency in der analytischen Philosophie. Diese setzt zudem meist ein intentionales Einwirken voraus (vgl. Schlosser 2015). Auch Giddens (1993: 77ff.) nimmt die Debatte der analytischen Philosophie in der Folge des Spätwerks Wittgensteins auf, die vor allem durch Anscombe und Davidson geprägt ist, kritisiert aber ihren intentionalistischen Zungenschlag und die vorausgesetzte freiheitlichmonadische Person.

97 Dieser Punkt scheint in einigen neueren, sozialwissenschaftlichen Konzeptualisierungen von Agency weitgehend vergessen. Es ist eine Ironie der Theoriegeschichte, dass heute vielfältig und an prominenter Stelle (u.a. bei Emirbayer/Mische 1998) Agency im Sinne eines Ereignisses unter willentlicher, kreativer oder freier Entscheidung in unterschiedliche Theorien aufgenommen wird. Vollkommen zu Recht wird von Fuchs (2001) darauf hingewiesen, dass Agency-Ereignisse in dieser Fassung zur soziologischen Residualkategorie verkommen oder als Ablenkungsmanöver von tatsächlich stattfindenden Strukturdynamiken (vgl. Loyal/Barnes 2001) dienen. Agency wird in einer derartigen Fassung erst dann zur Erklärung herangezogen, wenn Erklärungen über das Soziale an ihre Grenzen stoßen. Die Ironie besteht nun vor allem darin, dass sich Giddens als zentrale Referenz in der Einführung des Terminus in die Sozialtheorie auf eine Vielzahl an Autoren der philosophischen Tradition bezog, die sich gerade von diesen idealistischen und mentalistischen Vorstellungen abwendeten, namentlich dem Praxismarxismus im Gefolge Hegels, dem Existentialismus (vor allem über seine Aufnahme Heideggers) und pragmatistischen Denkern, vermittelt vor allem über Goffman und Garfinkel. Dieser breiten Denkbewegung ging es gerade um eine Hinwendung zum Vollzug und zur Praxis als Abgrenzungsbewegung zu einem Konzipieren des von einem freien Willen gesteuerten Handelns (Bernstein 1971: 5ff.). 
eingangs diskutierten Handlungs- und Institutionentheorien liegt ein solches Denken zugrunde. Giddens versucht mit dieser Agency-Bestimmung, die körperliche Bewegung in actu, in die beständig vergehende Praxis hinein in das Zentrum der Handlungstheorie zu rücken, und schließt sich dabei Autoren an, die die Entwicklung des Denkens als andauernden Prozess im Handeln begreifen.

Gerichtetheit ist für Davidson (1990a) weiterhin eine rationalisierbare. Giddens verallgemeinert diesen Gedanken und spricht von Reflexivität, wobei die Rationalisierung ein Teil dieser ist. ${ }^{98}$ Es wäre aber ein Fehler, Gerichtetheit daher per se, wie es bspw. Greshoff (2011: 85) formuliert, über eine Proto-Intentionalität und damit verbundenen, vorbewussten Zielorientierung zu beschreiben. In der hier vorgeschlagenen Interpretation der giddensschen Praxistheorie ist, so möchte ich argumentieren, vielmehr die prinzipielle Möglichkeit zur Selektion von Bedeutung. Wenn Menschen in der Lage sind, anders zu handeln, wird ein aktualisiertes Tun zu einer Selektion. Diese kann verschiedene Ursachen jenseits konkreter Ziele haben, etwa weil ein Tun plausibel scheint oder sich gut anfühlt. Zunächst ist es dabei hilfreich, Davidsons (1990b) allgemeinen Bestrebungen folgend, den Begriff der Absicht als Abgrenzungskriterium abzulehnen, um Handeln als spezifische Untergruppe von Ereignissen zu qualifizieren. Stattdessen wendet er sich dem Kausalitätsbegriff im Sinne von Ereigniskausalität (aus Ereignis A folgt Ereignis B) zu, einem Denken von Handeln jenseits der im Alltagsgebrauch üblichen Ursachenkausalität, die Handeln auf Gründe zurückführen möchte (Davidson 1990a: 81). Letztlich enden seine Ausführungen beim Bewegungsbegriff:

\footnotetext{
„Wir kommen nicht umhin, womöglich bestürzt und überrascht den Schluß zu ziehen, daß unsere Elementarhandlungen - also diejenigen, die wir nicht durch Ausführung etwas anderem vollziehen, mithin bloße Körperbewegungen - die einzigen Handlungen sind, die es gibt. Wir tun nie mehr, als unsere Körper zu bewegen; der Rest ist der Natur anheimgestellt" (Davidson 1990a: 96).
}

98 Auch die Beziehungen zwischen Giddens Konzeption von Agency und dem für die philosophische Debatte so prägenden Agency-Aufsatz von Davidson werden durch Giddens keineswegs offengelegt. Meines Erachtens nimmt er deutlich weitere Problemstellungen und Ansätze auf als es die wenigen Verweise belegen. Deutlich verwehren würde er sich sicherlich gegen den intentionalistischen Einschlag Davidsons. 
Wenngleich Giddens Davidson kritisch diskutiert, nimmt er dieses Verständnis von Primärhandlungen auf und plädiert dafür, eine strikte Trennung von Bewegung und Handeln aufzugeben (Giddens 1993: 80). Mit Davidson geht es ihm um ein Handlungskonzept, das die Möglichkeit absichtsvollen Handelns als komplexer Form explizit aufnimmt und zugleich die weniger komplexen Arten von Bewegungen eingrenzt, die noch als Agency-Ereignisse gelten können.

Das Konzept des Primärhandelns bietet somit eine Idee an, Agency nicht mittels Intentionen abzugrenzen und gleichzeitig nicht als bloßes Wirken (wie in der ANT) klassifizieren zu müssen. Zu dieser Abgrenzung kann folgendes Beispiel dienen:

\begin{abstract}
„Der Akkordeoneffekt lässt sich allerdings nicht einsetzen, wenn keine Absicht vorhanden ist. Drückt der Offizier auf einen Knopf in dem Glauben, damit wird nach dem Steward geläutet, der ihm eine Tasse Tee bringen soll, während er in Wirklichkeit einen Torpedo abfeuert, durch den die Bismarck versenkt wird, dann hat dieser Offizier tatsächlich die Bismarck versenkt; doch wäre er gegen den Knopf gefallen, weil er durch eine Welle aus dem Gleichgewicht gebracht wurde, dann würde er trotz Gleichheit der Konsequenzen nicht als der Handelnde gelten“"(Davidson 1990a: 88).
\end{abstract}

Im ersten Fall lässt sich in irgendeiner Hinsicht eine Gerichtetheit in irgendeiner Beschreibung finden, die sich jedoch weit von dem unterscheidet, was gewöhnlich als Intention verstanden wird. Diese basale Gerichtetheit ist gewissermaßen viel niedriger aufgehängt. Die Absicht oder der Grund für das Tun beruht vielmehr auf der Praxis selbst, dem kausalen Intervenieren als Ereignis. Sie setzt keine Bewusstheit der Konsequenzen, Pläne oder Handlungsentwürfe voraus, lediglich ein mögliches UnterlassenKönnen und eine basale Selektion. ${ }^{99}$

99 Giddens diskutiert den Ansatz von Davidson kritisch und nimmt zugleich zentrale Ideen auf: „But even the view that for an event to count as an instance of agency, it must be intentional only under some description or another is wrong. It confuses the designation of agency with the giving of act-descriptions; and it mistakes the continued monitoring of an action which individuals carry out with the defining properties of that action as such" (Giddens 1984: 9). Beiden Gegenargumenten kann man zustimmen und gleichzeitig einen ganz zentralen Beitrag Davidsons zur Agency-Diskussion aufnehmen, der von beiden nicht berührt wird: Bei einem unkontrollierten Fallen oder einem Verhalten unter bestimmtem physischem Zwang oder Drogeneinfluss haben wir es nicht mit einem möglichen Unterlassen-Können zu tun. Folglich handelt es sich nicht um ein Handeln. Dies ist das Kriterium (und nicht etwa Intentionen oder Gründe) das aus praxistheoretischer Perspektive angelegt werden muss, wenn wir von der basalen Gerichte- 
(iii) Neben Reflexivität und sozialer Anerkennung kennzeichnet Giddens (wie eingangs beschrieben) Handlungsfähigkeit zudem durch das Erzeugen eines Unterschiedes für ein aktuelles oder späteres Ereignis. Er nimmt damit Webers klasissches Thema der Kausaladäquanz auf. Diese Bestimmung ist als Ereigniskausalität im Sinne Davidsons (1990a: 87) zu verstehen:

„Die Kausalität ist von zentraler Bedeutung für den Begriff des Handelns, doch ist es die gewöhnliche Kausalität zwischen Ereignissen, um die es geht, und sie betrifft nicht die Ursache von Handlungen, sondern deren Wirkungen."

Das Tun des Akteurs als Ereignis wirkt auf aktuelle oder spätere Ereignisse ein, macht einen Unterschied, gleichwohl dieser nicht unbedingt so intendiert war. Ein praxistheoretischer Begriff der Agency startet sowohl von den Folgen und Konsequenzen als auch den Ursachen dieser. Wie schon bei Weber ist es bedeutsam, das Handeln einen kausalen Effekt für soziale Prozesse impliziert. Nicht jedes Tun im stillen Kämmerlein ist also automatisch Handeln, nichtsdestoweniger gibt es einsames Handeln, das für spätere Ereignisse hoch bedeutsam war und ist. ${ }^{100}$

\subsection{Die Reflexivität des Tuns vor dem Hintergrund des Nicht-Reflexiven}

Handeln impliziert weiterhin ein Spannungsverhältnis zwischen einem reflexiven Kern des Handelnden und den vorgefundenen sozialen wie physischen Bedingungen und Konsequenzen seines Tuns in Praxis. Auch in seinem Konzept der Reflexivität setzt Giddens seine Dezentrierung von Subjekt und Intention unter spezifischer Aufnahme der Webertradition fort. Handeln ist ein aktives Positionieren des Handelnden in der Welt. Weder bestimmen die Motive, Rationalisierungen und Betrachtungsweisen des Handelnden allein das Tun, noch ist es das kausale Relationieren in Praxis. Im Handeln entwickelt sich eine sinnliche Orien-

theit des Handelns sprechen. Denn hiermit verändert sich der analytische Blick auf das Prozessieren der Praxis, und wir müssen nach den praktischen Hintergründen für das so und nicht anders geartete Tun fragen. Diese müssen mit Intentionen oder Absichten keineswegs etwas zu tun haben und haben es doch häufig.

100 Die Sozialtheorie beginnt gerade erst, dies explizit zu thematisierten (vgl. Cohen 2015). Man denke nur an die einsamen Schreibstuben von Machiavelli oder Marx, die rückblickend sicher als zentrale Orte gesellschaftlicher Transformation bezeichnet werden können. 
tierung, die verstanden werden kann. Anders als Weber sieht er hierbei ein deutlich allgemeineres Konzept als einen subjektiv-gemeinten Sinn für angebracht: die Reflexivität des Handelns. ${ }^{101}$

Giddens' (1981: 36ff.) Bestimmung von Reflexivität ist jene im Sinne eines kontinuierlichen Erfahrens des eigenen In-der-Welt-Seins, des aktiven „Presencing“, wie er unter Verweis auf Heidegger bestimmt. Handeln in seiner allgemeinsten Definition umfasst damit auch das Sein im kontinuierlichen Fluss der „lived through experience“ (Giddens 1993: 81), meint, dass wir im Tun in Kontakt bleiben mit der Welt da draußen sowie mit eigenen Betrachtungsweisen, Motiven und Rationalisierungen dieser Welt aus unserer körperlichen Situiertheit heraus (siehe auch Windeler 2001: 136). Das bedeutet, die Situation vor dem Hintergrund des eigenen, kausalen Einwirkens sowie des Einwirkens anderer, für uns relevanter Symbole, Körper und Dinge zu beobachten. Giddens hält für diese Verbindung mit der eigenen Subjektivität die Vorstellung eines offenen Stratifikationsmodells des Handelnden bereit, um die untrennbare Vermittlung zwischen dem handelnden Selbst und seiner Umgebung im Handeln zu thematisieren. Er denkt Handelnde dabei nicht, wie etwa Luhmann (1988, 1995a), als eine nicht einsehbare Monade im Sinne der Romantik. Die Handelnden konzipiert Giddens über das reflexive Monitoring gerade als bis in ihre Begierden und Bedürfnisse hinein weltzugewandt.

Somit geht es ihm um eine Ko-Konstitution von Handelndem und Handlungssituation. Es gibt zwar verschiedene Schichtungen des eigenen Selbst, dennoch sind diese untrennbar miteinander verbunden, und zwar im Prozessieren der

101 Die bewusste Abgrenzung in der konzeptionellen Überführung des subjektiv-gemeinten Sinnes in die Reflexivitätsfigur ist hierbei deutlicher ausgeflaggt, als sie es tatsächlich ist. Die explizite Markierung der Sozialität und Materialität sowie der erwähnte antiintentionalistische Zungenschlag können allesamt auch in Webers Figur aufgenommen werden. Mit dem Motivbegriff scheint Weber (1972: 5) jedoch eine zu starke Betonung auf absichtsvolles Tun zu legen, relativiert dies aber gleichsam (ebd.) mit seiner Qualifizierung der Motive als Beobachterkonstruktion. Wogegen sich Giddens mit Recht wendet, ist die im Motivbegriff dezidiert angelegte Vorstellung einer dem Handeln vorgelagerten und dieses „,begründenden“ Sinnes. Dass Sinn erst im Handeln zum Handeln erzeugt wird, haben neben Giddens auch die pragmatistische und praxismarxistische Tradition betont. Hier unterschätzt die Handlungstheorie im Gefolge Webers die Parallelität von Entwurf und Wirken, die radikale Prozesshaftigkeit des Tuns. Dies ist für mich der vordringliche Grund, warum es Sinn ergibt, von einem reflexiven Kern des Handelnden zu sprechen, der sich im reflexiven Monitoring im Handeln und zum Handeln immer erst bildet. 
Praxis. Der Handelnde ist also eine durchaus komplexe und vielschichtige Menge wechselseitig vermittelter Prozesse:

\begin{abstract}
„What I call a stratification model of the acting self involves treating the reflexive monitoring, rationalization and motivation of action as embedded sets of processes. The rationalization of action, referring to 'intentionality' as process, is, like the other two dimensions, a routine characteristic of human conduct, carried on in a taken-for-granted fashion. In circumstances of interaction - encounters and episodes - the reflexive monitoring of action typically, and again routinely, incorporates the monitoring of the setting of such interaction." (Giddens 1984: 3f., Herv. RJ)
\end{abstract}

Unser Tun ist also gekennzeichnet durch ein beständiges und routiniertes Monitoring der eigenen Aktivitäten sowie der Aktivitäten uns relevant erscheinender Anderer und der materialen und sozialen Kontexte oder Settings, in denen wir uns gerade als Handelnde bewegen (Windeler 2014: 233). In Interaktionen betrachten wir nicht nur die Bewegungen der Anderen, sondern auch, was diese vor dem Hintergrund des sozialen wie physischen Settings und des eigenen Handelns bedeuten, also das, was nicht physisch präsent und dennoch in der Situation relevant ist. Diese Vergegenwärtigung informiert die kontrollierte Ausrichtung des Tuns, und allein dies macht eine basale „Intentionalität“ des Handelns aus.

Reflexivität meint, dass Akteure sich in ihrem Tun ,,mehr oder minder überlegt auf ihr eigenes, vergangenes, gegenwärtiges und zukünftig erwartbares Verhalten ebenso wie auf das anderer und auf die Strukturen des Handlungsfeldes“ (Ortmann et al. 2000: 317) beziehen. Wie in Abb. 3 eingeführt, sind die drei eingangs beschriebenen Aspekte des Einklammerns der Handlungssituation, der situierten Konstruktion eines Möglichkeitsraumes und der Realisierung einer Aktivität als Momente des reflexiven Monitoring des Handelns im Handeln zu verstehen. Diese Aspekte des Handelns sind im kontinuierlich beobachteten, kontrollierten und gerichteten Strom des Handelns in Praxis verortet. Sie gehen dem Handeln zumeist keineswegs als Entwurf, Entscheidung oder Planung voraus. 


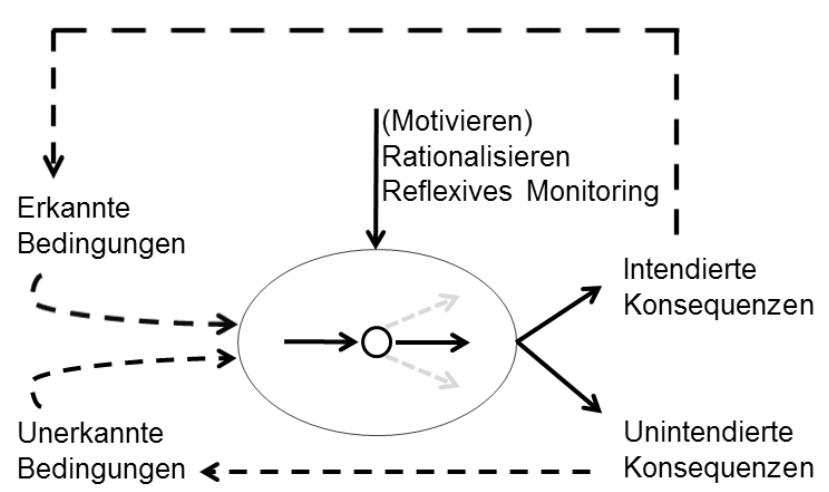

Abb. 3: Die reflexive Hervorbringung des Handelns in Anlehnung an Giddens (1984: 5)

Hierbei betrachten wir jede Situation zum einen vor dem Hintergrund bestehender, typischer Verfahrensweisen, die wir selbst und die Anderen (an-)wenden, zugleich aber auch als beständig neuartige Situation. Angedeutet wird dabei ein In-Kontakt-Bleiben mit den (und keineswegs ein Kontrollieren durch) eigenen Plänen und Motiven des Handelnden. Die Reflexivität impliziert vor allem ein Vergegenwärtigen der Kontexte des Tuns. Das, was Giddens als reflexiven Kern des Agenten bezeichnet, konstituiert sich dabei fortwährend als Vermittlung von Subjekt- und Systemreflexivität unter Verknüpfung von Gedächtnisspuren des Handelnden im Handeln in Praxis über soziale Praktiken (vgl. Windeler 2001: 271f.). ${ }^{102}$ Im und für das Handeln sind eben nicht nur individuelle, sondern auch umfassende Handlungszusammenhänge wie bspw. die Familie, die Position im Unternehmen oder gar die Einbettung in globale kapitalistische Verwertungszusammenhänge relevant. Handelnde nehmen über die in Interaktion aktualisierten sozialen Praktiken eine Beziehung zu Sozialsystemen auf, Systeme wiederum prägen ebenso systemische Formen der Motivation, der Rationalisierung und der Betrachtung von Welt aus, die im Handeln beständig auf subjektive aufge-

102 Systemreflexivität bezeichnet die Instanziierung von Prozeduren und Praktiken, die dazu dienen, allgemeine Bedingungen der System(re-)produktion so zu regulieren, dass Akteure im Sinne der systemischen Ordnung handeln (vgl. ebd. 215). 
pfropft ${ }^{103}$ werden, ohne sich je von ihnen abzulösen. Beide sind also ohne einander nicht denkbar und wechselseitig konstitutiv füreinander.

Diese reflexiven Informations- und Steuerungsversuche durch eine Melange an Subjekt- und Systembezügen lassen sich dabei vor dem Hintergrund von Deweys Konzept eines Wechselspiels aus offenen und geschlossenen Aspekten der Situation verstehen, das den stetigen Prozess des Erforschens immer wieder neu anregt. ${ }^{104}$ Es wird längst nicht immer gewusst, was zu tun ist und dennoch praktisch weiter gehandelt. Unbestimmte und offene Situationen sind für ihn Grundvoraussetzung jeder Forschung (Dewey 2008: 132). Forschen ist der basale Prozess des psycho-sozialen Prozessierens von Welt, die ,gesteuerte oder gelenkte Umformung" (ebd.: 131) einer relevant offenen (also ungewissen) in eine bestimmte (im und für das Handeln gewisse) Situation. Offene und bestimmte Situation sind dabei jeweils nur idealtypische Endpunkte eines Kontinuums, das viele Schattierungen kennt. Bedeutsam ist hierbei: Nimmt man Deweys Konzept auf, haben wir es in Praxis immer auch mit Aspekten der Situation zu tun, die als offen zu klassifizieren sind und mit denen wir dennoch praktisch umgehen. Das meint, die Handlungssituation

„,ist offen in dem Sinne, dass ihre Bestandteile nicht zusammenhängen.“ (ebd.)

oder auch:

„Die eigentümliche Qualität dessen, was die gegebenen Materialien durchdringt und sie zu einer Situation macht, ist nicht einfach Ungewissheit überhaupt; es ist eine einzigartige Zweifelhaftigkeit, die diese Situation zu genau der Situation macht, die sie gerade ist“" (ebd.: 132, Herv. RJ).

103 Pfropfung meint dabei stets eine Verknüpfung ohne Hybridisierung (vgl. Wirth 2011).

104 Die pragmatistische Tradition wird bei Giddens nur indirekt über Autoren aufgenommen. Eine Diskussion des Verhältnisses von Pragmatismus und Praxistheorie steht in systematischer Form meines Erachtens weiterhin aus. Nach vielversprechenden Ansätzen einer dezidierten Zusammenführung bei Joas (1992), Beckert (1997) und neuerdings Crossley (2013), Schubert (2016) sowie Strübing (2017), war den weiterführenden Ansätze etwa bei Schäfer (2012) oder Reckwitz (2008) eher an einer Aufnahme des Pragmatismus in ein großes Zelt der Praxistheorie gelegen. Reckwitz (2003, 2008) verfolgt diesen Ansatz der Verallgemeinerung des praxistheoretischen Programms sehr prominent, auch wenn dies auf der anderen Seite mit einem Verlust an Trennschärfe und Spezifik der Ansätze einhergeht. Ein derartiges Zusammenführen kann aber auch ein anderes Vorgehen inspirieren: die hier verfolgte Ausarbeitung einzelner Konzepte in einer bestehenden Perspektive unter Aufnahme anderer Ansätze der breiteren Denkbewegung der Praxistheorie. 
Mit Dewey gesprochen, versuchen Menschen, andauernd in ihrem Tun die Situationen in bestimmte Zusammenhänge zu bringen, die diese an sich unbestimmten und fluiden Kontexte nicht per se anbieten und denen sie sich beständig in ihrer Spezifik entziehen. Im Strom der Praxis begegnen wir ständig dem Unvorhergesehenen, müssen wir ständig erkunden, welche Elemente auf welche Art und Weise miteinander wirken. ${ }^{105}$

Wichtig ist zu betonen, dass nicht alle Aspekte der Situation diesem ,reflexiven Kern" des Handelnden zugänglich sind, es unerkannte Bedingungen wie Folgen des Handelns gibt (vgl. Giddens 1984: 5ff.). Hierauf verweist auch Abb. 3. Das für die Figur der Reflexivität im Handeln kennzeichnende Spannungsverhältnis eines wissenden und experimentierenden Umgehens mit Welt steht im Zentrum dieses Stratifikationsmodells des Handelnden. Vor uns liegen beständig unerkannte Bedingungen, und wir erzeugen permanent unvorhergesehene Effekte. Dennoch versuchen wir zugleich um die Welt zu wissen. Hier zeigt sich der Pragmatismus deweyscher Prägung als Wahlverwandter der giddensschen Handlungskonzeption. Beide versuchen, das Konzept des Handelns radikal zu prozessualisieren und in zwei zentrale Spannungsverhältnisse zu überführen: demjenigen zwischen offenen wie geschlossenen Aspekten der Situation und demjenigen zwischen Subjekt- und Systemreflexivität. Diese beiden Spannungsverhältnisse werden in allen drei Prozessen des Stratifikationsmodells (Monitoring, Rationalisierung und Motivation) vermittelt und kennzeichnen die KoKonstitution des reflexiv Handelnden und der Situation im praktischen Umgehen mit der konstant sich fortschreibenden Praxis in und durch soziale Praktiken. ${ }^{106}$

105 Jörg Strübing (2005: 61, Herv. i. Orig.) fasst die Grundposition unter Verweis auf ein Frühwerk (Dewey 1896) sehr treffend: „Im Kern besteht Deweys Argument darin, die Trennung von stimulus und response in zwei separate Einheiten des Handlungsablaufs zu kritisieren und anstelle einer bogenförmigen Verlaufsform eine zirkuläre anzunehmen: Die Handlung beginne nicht erst mit dem «response» auf einen «stimulus», vielmehr setze die Handlungsrelevanz des Reizes zunächst den Akt seiner Wahrnehmung voraus: Nicht der Reiz wirkt, sondern das aktive Wahrnehmen und Interpretieren des Reizes (hören, fühlen, sehen und verstehen) ist der erste Teil einer Handlungssequenz, dessen zweiter Teil aus dem aktiven Umgehen mit diesen Wahrnehmungen besteht, also aus deren handlungspraktischer Interpretation." Wir sehen also: Die radikale Prozessualisierung der Handlungstheorie war bereits für Dewey das zentrale Anliegen seines Wirkens und macht es zu einer bedeutsamen Quelle für die Schärfung der Praxistheorie.

106 So kann man für mein Dafürhalten Joas‘ (1992: 216) berechtigt kritische Nachfrage nach einer Fundierung der Reflexivitätsannahme in der Verhaltenskontrolle bei Giddens mit einem Verweis auf die sozialen Praktiken innwohnenden und mitschwingenden Formen der Reflexivität beantworten, die in ihrer praktischen Instanziierung das reflexive Monitoring genauso mitfun- 
Mit diesem Verständnis positioniert sich Giddens in der Gruppe soziologischer Handlungstheorien, die in Kritik an Parsons entstanden. ${ }^{107}$ Sein reflexives Handlungsverständnis speist sich dabei vor allem aus dem sogenannten Praxismarxismus (vgl. Lefebvre 1972, Heller 1978, Sztompka 1991). Diese Tradition bindet das Tun an bestimmte Bedingungen und den bedingten und aktiven Herstellungsprozess der Praxis. ${ }^{108}$ Fundamental geht es also zugleich darum, Praxis als gebundenen, aber nie komplett determinierten Prozess der rekursiven Hervorbringung von Welt durch kreative, reflexive und wissende Handelnde ins Zentrum der Agency-Debatte zu rücken. Praxis und Handeln sind für ihn komplementäre Konzepte (vgl. Cohen 1989: 47). Die handlungstheoretische Tradition muss unter Bezug auf einen Praxisbegriff neu gedacht werden. Die Praxis bildet für ihn das Scharnier, um die verschiedenen Stränge beweglich zu verbinden, denn

„,in der Praxis werden Denken und Sein, Bewußtsein und sinnliche oder stoffliche Natur, Intellekt und Spontaneität wieder zu einer Einheit“" (Lefebvre 1972: 47f.).

dieren wie die offenen Aspekte der konkreten Handlungssituation. Anders als Joas vermutet, müssen also nicht die anthropologischen Grundannahmen geklärt werden, sondern Reflexivität selbst nicht mehr vom Individuum, sondern von der Praxis und den sozialen Praktiken her gedacht werden.

107 In dieser kann man, Stones (2006: 4) Systematisierung weiterdenkend, drei grobe Linien aufzeigen, die allesamt für Giddens bedeutsam sind: eine, die den Begriff mit Reflexion, Reflexivität und Kreativität verbindet und stark im Pragmatismus und symbolischen Interaktionismus beheimatet ist, eine zweite Tradition des phänomenologischen Denkens, die den Begriff mit einem Wissen um den Aufbau der Sozialwelt verbindet und vor allem auf Alfred Schütz' Arbeiten aufbaut, sowie einer dritten, die die aktiven Kompetenzen und Fähigkeiten im Umgang mit Welt an Routinen und Ethnomethoden rückbindet und vor allem mit Garfinkel verbunden wird. Giddens strebt mit beindruckender Leichtigkeit, aber keineswegs immer nachvollziehbar, eine Synthese dieser Ansätze an.

108 Dieser Einfluss, vermittelt vor allem durch den Praxismarxisten Ilya Neustadt, durchzieht Giddens Werk sichtbar. Der Leitsatz seines gesamten Ansatzes stammt daher nicht zufällig aus dem 18. Brumaire: „Die Menschen machen ihre eigene Geschichte, aber sie machen sie nicht aus freien Stücken, nicht unter selbstgewählten, sondern unter unmittelbar vorgefundenen, gegebenen und überlieferten Umständen." (Marx 1960: 118). Es geht ihm, wie bereits in der Einleitung beschrieben, um ein rekursives und historisch gebundenes Handeln, das sich seiner Position im Prozessieren der Praxis nicht dauerhaft entziehen kann. Weiterhin ist der Mensch selbst im chaotisch Neuen, in der radikalen Umwälzung auf der Suche nach Antworten in den eigentlich vergangenen Routinen, versucht, sich stets stabil zu orientieren. Diese Neigung läuft gleichwohl als anthropologische Hintergrundannahme in der praxistheoretischen Perspektivität mit. 
Ganz im Sinne dieser praxismarxistischen Losung konzipiert Giddens alltägliche Praxis als Prozess, der von den Handelnden beobachtet und auf seine soziale wie materielle Kontextualität hin befragt wird. Diese Kontextualität ist zum einen durch ein Wissen um adäquates Handeln gekennzeichnet, gleichzeitig reicht dies allein nicht aus. Es braucht praktische Methoden und ein Vermögen, mit diesen Kontexten umgehen zu können, ein „know how to go on“ in situ. Dies alles passiert in historisch situierten Kontexten, also unter vorgefundenen Bedingungen. Giddens konzipiert den Handelnden als Praktiker, der beständig mit neuen Situationen umgeht und sich dabei meist erlernter Routinen und Prozeduren bedient.

\subsection{Die Anerkennung als Verursacher eines Effekts}

In verschiedenen Handlungskonzepten wird Handeln weiterhin als eine Aktivität konzipiert, deren Effekte von einem oder mehreren Beobachtern einem Verursacher zugeschrieben werden. ${ }^{109}$ Das bedeutet, dass die Realisierung einer Handlungsoption vor dem Hintergrund anderer Möglichkeiten im Sozialen als hervorgerufen durch eine individuelle oder kollektive Instanz betrachtet, gehandhabt und bewertet wird. Die Figur der Zuschreibung ist für eine praxistheoretische Analyse jedoch zu passiv formuliert. In der Regel bezieht sich eine Handlungszuschreibung in sozialen Prozessen auf ein Moment des aktiven Anzeigens von Verursachungsfähigkeit. ${ }^{110}$ Zuschreiben und Anzeigen können dabei voneinander entkoppelt werden. Zumeist entsteht zwischen dem Zuschreiben und Anzeigen von Verursachungsfähigkeit in sozialen Prozessen jedoch ein über soziale Praktiken vermitteltes Spannungsverhältnis zwischen Entkopplung und enger Verkopplung.

109 In der Soziologie besteht hier weitgehende Einigkeit. Selbst so unterschiedliche Traditionen wie Handlungs- (etwa Luckmann 1992, Schulz-Schaeffer 2007) und Systemtheorie (Luhmann 1984) weisen auf die konstitutive Dimension des sozialen Konstruierens einer Aktivität als Handlung hin.

110 Hierauf hat insbesondere die für Giddens so bedeutsame Tradition der Ethnomethodologie hingewiesen. Garfinkel führt hierfür den Begriff der „accounts“ ein und meint dabei eben jene Zweiheit aus einer Interpretation und der Darstellung des So-und-nicht-anders-Interpretierens im Handeln: „Garfinkel uses the nuances of English to express this equivalence between making sense of something and explaining that sense. The word ,account' carries this equivalence; to account for something is both to make understandable and to express that understanding" (Attewell 1974: 183). 
Der Terminus der Anerkennung als Verursacher eines Effekts vermag es meines Erachtens dieses Spannungsverhältnis zu fassen. Das allgemeine Konzept der Anerkennung kann mit Honneth (2010: 32) als Entgegensetzung zur Irrelevanz und Missachtung gedacht werden. Es geht hierbei um umkämpfte Prozesse der Aufnahme bestimmter Identitäten im Sozialen, die im Ringen um Aufmerksamkeit beständig mit einer Selbstbeschränkung eines Gegenübers einhergehen. Vor diesem Hintergrund kann meines Erachtens praxistheoretisch gewendet die Anerkennung von Handlungsverursachung als mitunter umkämpftes, meist routiniertes und stets relationales Geschäft verstanden werden. Die Anerkennung der Handlungsverursachung wird dann als aktiv hervorgebrachter sozialer Prozess vor dem Hintergrund alternativer Optionen betrachtet.

Dieser Prozess der Anerkennung umfasst hierbei Momente der Zuschreibung durch die Handelnden selbst und eines Publikums sowie des aktiven Anzeigens und Darstellens im Handeln. Verliert eine Instanz ihre soziale Anerkennung als Verursacher passenden Handelns, hat dies über die Zeit auch Konsequenzen für ihre faktische Handlungsfähigkeit, aber auch für das Vermögen zur Aufnahme von Welt als durch eigenes Tun veränderbar. Die Anerkennungsproblematik ist auf das engste mit Reflexivität und Handlungsfähigkeit verknüpft. Man denke nur an Krankheiten wie etwa Demenz, bei der den Betroffenen nach und nach eigene Autonomiespielräume entzogen und in Vormundschaften überführt werden (vgl. Meyer 2014). Ein ähnliches, sukzessives Entziehen von Handlungsspielräumen kann man für sanktionierte Staaten beobachten, die nur noch für Teile der Weltgemeinschaft in ausgewählten Bereichen als Verhandlungspartner anerkannt sind.

Praxistheoretisch geht die Anerkennung mit Prozessen der Wahrnehmung und Interpretation, praktischen Handhabung und Bewertung einer Instanz als Verursacher eines Effekts durch eine spezifische Aktivität einher. Wer hierbei als Verursacher gehandhabt, bewertet und gedeutet wird, kann wiederum in und zwischen verschiedenen sozialen Kontexten differieren. Stellen wir uns ein beherztes Eingreifen gegen ein Vordrängen an der Theaterkasse vor, so werden sowohl die Beteiligten als auch die Passanten sicherlich sagen, sie hätten als Gruppe gemeinsam gehandelt. Ein Gericht wird bemüht sein, jede Aktivität als Einzelaktivität zu dekonstruieren und Einzelne als Verursacher anzuerkennen. In diesem Sinne ist Giddens zuzustimmen, dass sich die häufig subtile, soziale Prägung dieser Anerkennung als Verursacher dort besonders eindrücklich zeigt, wo verschieden interessierte Gruppen offen um sie ringen: 
„Such ambiguities or blurrings between conduct for which agents are deemed responsible, and hence as potentially open to being asked for justifications, and that recognized as ,out of their hands' and sustain various forms of manoeuvre or deceit whereby people either seek to escape sanctions upon what they do, or conversely claim a particular outcome as an accomplishment of their own" (Giddens 1993: 78).

Anerkennung verweist also immer auch darauf, anzuzeigen, dass man ,passend“ in und für bestimmte Kontexte handelt, häufig geschieht dies routiniert und stumm:

„The idea of ,accountability' in everyday English gives cogent expression to the intersection of interpretative schemes and norms. To be ,accountable' for one's activities is both to explicate the reasons for them and to supply the normative grounds whereby they may be justified'. Normative components of interaction always centre upon relations between the rights and obligations ,expected' of those participating in a range of interaction contexts“ (Giddens 1984: 30)

Insofern reicht das Anerkennungsstreben oder das Vermeiden, als Verursacher zu gelten, bis hinein in die Motive für das Tun, die als eingebettet in einen sozialen Kontext des Handelns analysiert werden müssen. Die Vermeidung oder das Bestreben, als Verursacher zu gelten, beeinflusst sowohl die kontrollierte Gerichtetheit des Tuns als auch die reflexive Aufnahme von Welt. Gleiches gilt für die andere Seite der Anerkennungsproblematik: die Formen der Zuschreibung von Verursachung. Zumeist geschieht die Vermittlung zwischen Zuschreiben, Anzeigen und Darstellen von Verursachungsfähigkeit über reziprok typisierte Formen der Anerkennung, die, den Beteiligten zumeist praktisch bewusst, auf das engste mit erlernten sozialer Praktiken verknüpft sind.

\section{$1.4 \quad$ Ein erweitertes Modell der Agency}

Das Vermögen, einen Unterschied in Praxis machen zu können, basiert auf einem wechselseitigen Einander-Stützen sowie einer spezifischen Vermittlung von drei Aspekten: Einer Handlungsfähigkeit in Praxis; einer spezifischen Reflexivität des Handelnden; der Anerkennung der Aktivität als verursachendes Moment durch die Beteiligten und zumindest nachträglich auch durch Externe. Das wechselseitige In-Kraft-Setzen dieser drei Grundmomente von Agency in Praxis ist, wie in Abb. 4 zusammengeführt, der Kern eines praxistheoretischen Modells der Agency. Alle drei eingeführten Aspekte der Agency sind für die Spezifik des eingangs beschriebenen Realisierungsprozesses konstitutiv als auch wechselseitig konstitutiv füreinander. 


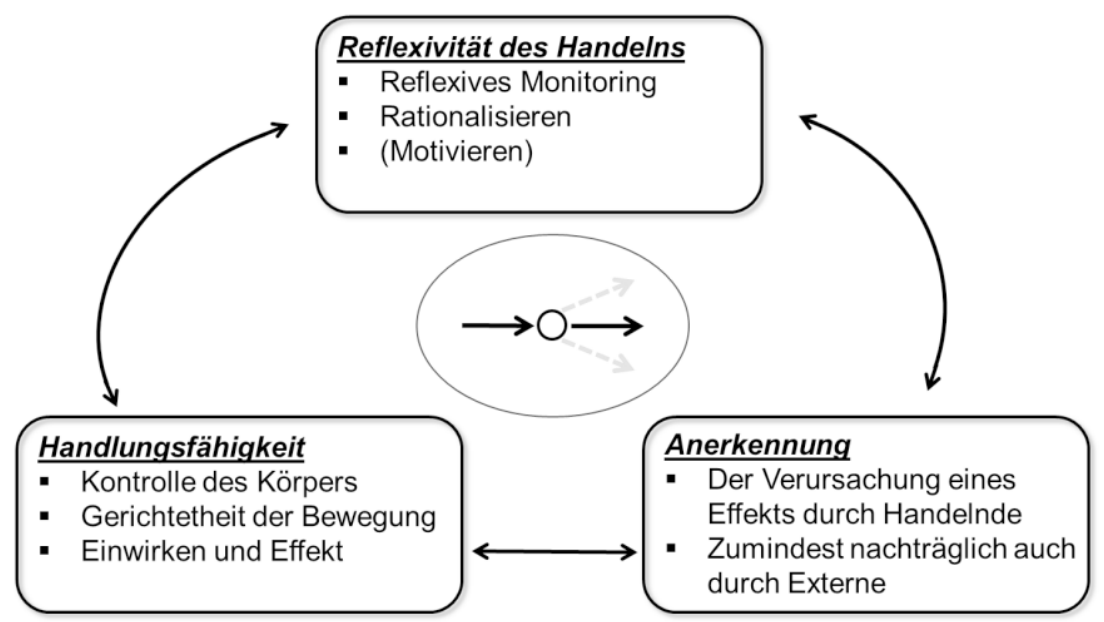

Abb. 4.: Ein erweitertes Agency-Modell aus praxistheoretischer Perspektive, eigene Darstellung

Wie Abb. 4 verdeutlicht, handelt es sich bei dem, was die Realisierung der Aktivität vor dem Hintergrund anderer Möglichkeiten erklärt, um eine prozessuale Vermittlung und ein wechselseitiges Stützen dieser Aspekte. Die basale Fähigkeit, zumindest zu einem gewissen Grade kontrolliert und gerichtet einen Effekt in Praxis zu erzeugen, prägt zutiefst die spezifische Aufnahme von Welt über den reflexiven Kern des Handelnden und ist zugleich durch die Reflexivität geprägt ist. Die Gerichtetheit fußt ganz fundamental in der beschriebenen Kontrollfähigkeit, gleichzeitig wird sie aber immer auch in der aktiven Positionierung des Handelnden in der Welt fundiert, die Giddens als reflexiven Kern der Agency versteht:

„Action is a continuous process [...] in which the reflexive monitoring which the individual maintains is fundamental to the control of the body that actors ordinarily sustain throughout their day-to-day lives" (Giddens 1984: 9).

So ist die Ausrichtung im reflexiven Monitoring das Scharnier zwischen dem reflexiven Kern und der tatsächlichen Kontrolle über den gerichtet erzeugten Effekt in Praxis. Ein ebenso ko-konstitutives Verhältnis zueinander besteht zwischen allen Aspekten des Handelns.

Giddens denkt die praktische Ausrichtung also beständig als zumindest zu einem gewissen Grad und in gewisser Hinsicht reflexiv informierte Gerichtetheit 
und Kontrolle, die allerdings stets und notwendigerweise auch nicht-reflexive (sowie auch nicht gerichtete und nicht kontrollierte) Momente beinhaltet. Andererseits ist es die körperliche Situiertheit und der spezifische Verlauf an Ausrichtungen, die diese spezifische Reflexivität, dieses In-der-Welt-Seins basal fundiert und rekursiv an bestimmte Bedingungen knüpft. Der reflexive Kern des Handelnden wird in Praxis erst in der rekursiven Folge körperlichen Einwirkens im individuellen Leben hin zum Tode instanziiert. Der reflexive Kern kann wiederum, wenn er in Praxis in relativ stabiler Form reproduziert wird, durchaus eine Wirkung auf die körperlichen Fähigkeiten zu handeln haben. Mit Simmel kann man dann von einer (lebenslangen) Kultivierung sprechen:

\footnotetext{
„Alle Kultivierung also ist [...] nicht nur die Entwicklung eines Wesens über die seiner bloßen Natur erreichbare Formstufe hinaus, sondern nun auch Entwicklung in der Richtung eines inneren ursprünglichen Kerns [....]; sie entsteht vielmehr durch deren Zusammenwirken mit den neuen teleologischen Eingriffen, die aber in jenen Anlagerichtungen des Wesens selbst erfolgen und insoweit seine Kultur heißen“ (Simmel 1993: 366, Herv. i. Orig.).
}

Dieses Verständnis der Kultivierung kann meines Erachtens fruchtbar auf das Verhältnis des reflexiven Kerns zum Körper übertragen werden. Setzt man das Körperliche mit dem Wesenhaften des Menschen gleich, so kann von einer Entwicklung spezifischer Fähigkeiten zu kontrollierten Bewegungen gesprochen werden, die einem stabil-reflexiven Kern als äußerer Form in Praxis entsprechen und von natürlichen Bewegungsformen abweichen. Hierbei kann der Leib über eine wiederholt gleichartige Bewegung in diesem Sinne überformt, trainiert und diszipliniert werden, ohne sein ursprüngliches Wesen zu verlieren. Die Gleichartigkeit kann dann weiterhin von einer spezifischen Reflexivität und sozial anerkannten Formen von Urheberschaft informiert werden. Diese Prozesse sind höchst voraussetzungsvoll, da sie insbesondere einer stabilen Reflexivität und stabiler Praxissituationen bedürfen. Nehmen wir an, wir kultivieren unseren Körper in der Form, dass ein Marathonlauf absolviert werden kann, so basiert dies nicht nur auf dem beständigen Verfolgen dieses Projektes, sondern ebenso der nötigen Zeit für das Training sowie von Bedingungen, die dieses Training ermöglichen. Nichtsdestoweniger passieren derartige Prozesse körperlicher Kultivierung jeden Tag, etwa indem wir uns im frühen Aufstehen üben, um rechtzeitig in die Kindergärten, Schulen oder Arbeitsstätten zu gelangen.

Weiterhin nimmt Giddens das philosophische Thema der Agency als kausaler Interventionen in Ereignisse hinein auf und wandelt es zugleich radikal ab. Davidson (1990a: 73) versuchte in dieser Debatte als spezifische Teilmenge von Ereignissen zu beschreiben. Auch Giddens plädiert für einen 
,account for agent causality, according to which causality does not presuppose ,laws“ of invariant connection [...], but rather (1) the necessary connection between cause and effect, and (2) the idea of causal efficacy. That action is caused by an agent's reflexive monitoring of his or her intentions in relation to both wants and demands of the 'outer' world" (Giddens 1993: 91, Herv. RJ).

Es geht Giddens, so interpretiere ich seine Ausführungen, um eine genuin soziologische Fassung des davidsonschen Themas der Ereigniskausalität als kausalem Einwirken auf Welt „durch“ die Bewegungen eines Akteurs. Giddens Konzept stellt nicht nur auf das Tun im Sinne des Handelnden, nach seinen Intentionen und Zielen ab, sondern nimmt sie als an Anderen und sozialen Formen von Urheberschaft ausgerichtetes und orientiertes Einwirken auf. Hierzu wählt er den zentralen Terminus des „reflexive monitoring“ als Scharnier, um sowohl die kausale Relationierung und Kontrolle in Praxis als auch die Ontologie der Potentiale (vgl. Cohen 1989), des virtuell Wirksamen miteinander zu verbinden. Hiermit sind konsequenterweise nicht nur die eigenen Intentionen gemeint, wie im Zitat angedeutet. Vielmehr geht es um das beschriebene Verhältnis des Anzeigens und Zuschreibens von Urheberschaft, einer Orientierung des Handelns an gesellschaftlichen Formaten der Urheberschaft.

Dieses Wechselspiel aus reflexiver Informierung und rekursiver Gebundenheit an körperliche Positionen sowie Fähigkeiten und situative Bedingungen ist kennzeichnend für Agency. Giddens betont mit seiner Theorie des Handelns als Agency, dass jedem sozialen Ereignis ein Charakter des spezifisch situierten, praktischen Ausführens unter vorgegebenen, nicht selbst gewählten Bedingungen innewohnt und dies nicht vorab von Interessen oder Zielen her gedacht werden kann. Er betont zudem, dass diese Handlungspraxis zutiefst geprägt ist durch die Rückbindung des Tuns an praktisch-bewusste, inkorporierte und routinierte Verfahrensweisen: soziale Praktiken. Diese sind konstitutiv für die Handlungsfähigkeit, die Reflexivität und die soziale Anerkennung des Tuns. Ich komme später noch darauf zurück (siehe III.1.). 


\section{Kollektives Handeln: Grundlegende Bestimmungen}

Als prominentester Warner vor einer Übertragung von individuellem auf kollektives Handeln kann wohl immer noch Max Weber gelten, der das Konzept einer „Kollektivpersönlichkeit“ (Weber 1972: 6f.) stets vehement ablehnte. ${ }^{111}$ Die Vorsicht vor zu schneller Übertragung bzw. gar Gleichsetzung vom Individuellen mit dem Kollektiven ist ernst $\mathrm{zu}$ nehmen. Insbesondere muss transparent gemacht werden, was der spezifische Unterschied zwischen kollektiver und individueller Agency ist. Hierzu nehme ich im Folgenden die bereits beschriebene, zentrale Bestimmung der handlungstheoretischen Debatte auf, dass der Sprung auf die kollektive Ebene Prozesse wechselseitiger Abstimmung und Koordination impliziert (vgl. I.2.1.). Gleichzeitig muss die Spezifik des Agency-Konzepts als eines Handlungskonzepts erhalten bleiben, das vom stetigen Fluss der Praxis her konzipiert ist.

Die Definition von Agency aufnehmend, spreche ich im Folgenden dann von kollektiver Agency als einem Geflecht von aktiv in Zeit und Raum hochgradig miteinander verbundenen Aktivitäten, die als spezifische Verbindung ${ }^{112}$ ein Vermögen zur Transformation von Praxis wirksam in Kraft setzen. Eine eingrenzbare Menge realisierter oder potentieller Aktivitäten von mehr als zwei Handelnden wird hierbei hochgradig aneinander gebunden, wechselseitig auf einen oder mehrere Aspekte von Welt hin mobilisiert; sie kann so in Verbindung

111 Die allgemeine Kritik an der Vorstellung einer Kollektivpersönlichkeit trifft sicher nicht das hier weder verfolgte Ziel noch die Mehrzahl der heutigen Ansätze. Sie war vor allem zur Abgrenzung von der Massenpsychologie in der Nachfolge von Le Bon geschrieben, die damals prominent wirkte und bspw. in der Bewegungsforschung noch lange nachhallte (vgl. hierzu Currie/Skolnick 1970).

112 Der Begriff der Verbindung wird schon bei Tönnies als zentraler Grundbegriff seiner Studie zu Gemeinschaft und Gesellschaft eingeführt: „Auf die Verhältnisse gegenseitiger Bejahung wird diese Theorie als auf die Objecte ihrer Untersuchung gerichtet sein. [...] Es besteht aus Förderungen, Erleichterungen, Leistungen, welche hinüber und herüber gehen, und als Ausdrücke der Willen und ihrer Kräfte betrachtet werden. Die durch dieses positive Verhältniss gebildete Gruppe heisst, als einheitlich nach innen und nach aussen wirkendes Wesen oder Ding aufgefasst, eine Verbindung“ (Tönnies 1887: 39, Herv. RJ). Diese Definition ist keineswegs unproblematisch, ist hier doch bereits der Gedanke eines einheitlich wirkenden Wesens und eine Verdinglichung impliziert. Sie wird mitunter als Gründungsfigur des Nachdenkens über Korporation angesehen (Vanberg 1982: 23ff.). Der erste Teil der Definition ist jedoch durchaus fruchtbar: Verbindungen sollen als Bündel aktiv miteinander verknüpfter Aktivitäten verstanden werden, die füreinander wechselseitig positiv relevant sind und in gewissem Maße Leistungen füreinander erbringen. 
auf Praxis einwirken. Ist die so hergestellte Verbindung von Aktivitäten dabei durch eine zu einem gewissen Grade ähnliche, reflexive Aufnahme des Aneinander-gebunden-Seins informiert und wird in Praxis als eigenständige, verursachende Instanz interpretiert, behandelt und bewertet, kann von kollektivem Handeln gesprochen werden.

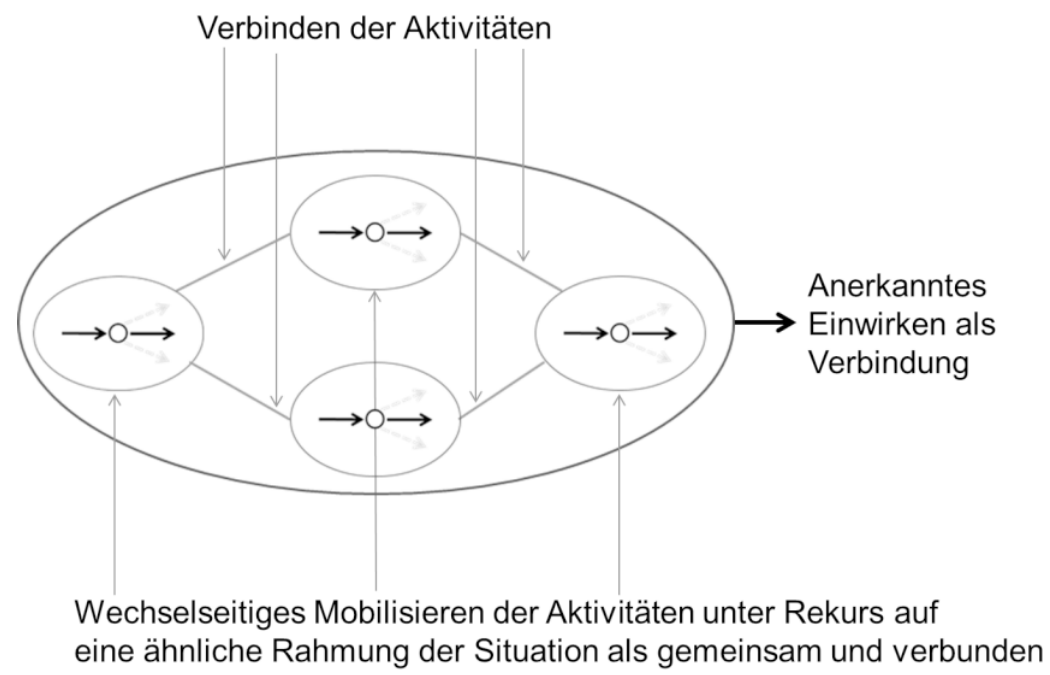

Abb. 5: Kollektives Handeln als Einwirken einer spezifischen Verbindung, eigene Darstellung

Wie Abb. 5 verdeutlicht, handelt es sich beim Kollektivhandeln um hochgradig einander bindende wie aneinander gebundene, für einander verbindliche und darüber spezifisch verbundene Zusammenhänge von Aktivitäten von mindestens zwei Handelnden. ${ }^{113}$ Über diese Verbundenheit können sie auf einen Aspekt der

113 Kollektives Handeln liegt hierbei vor, wenn mehr als zwei Aktivitäten unterschiedlicher Handelnder sich in der Form koordinieren, dass die drei Qualitäten der Handlungsfähigkeit in Verbindung, Rahmung und Anerkennung der gemeinsamen Verursachung entstehen. Die in Abb. 5 herangezogenen vier Aktivitäten sind aus Darstellungsgründen so gewählt. Kollektivhandeln impliziert ein Wechselwirken „mehrerer Individuen“, das bereits Simmel (1992: 17ff.) als kennzeichnend für Vergesellschaftungsprozesse ansah. Simmels Betonung der Trias (ebd.: 114ff.) kann weiterhin zugestimmt werden. Im Kollektivhandeln ist es um Konstellationen von mindestens drei Parteien bestellt. Selbst in Zweiergruppen ist im und zum Kollektivhandeln ein zumindest zu einem gewissen Grade geteiltes, handlungsleitendes Prinzip einer sozialen Prak- 
Praxis hin mobilisiert werden, sodass ein spezifisches Einwirken in die Praxis erfolgt.

Nehmen wir an, Moritz und Lene backen Plätzchen. Eine Aktivität ist es dann, dass Moritz zum Zeitpunkt t1 ein Rezept und die Zutaten heraussucht sowie den Teig zubereitet. Zum Zeitpunkt t2 kommt Lene hinzu. Während Moritz weiteren Teig zubereitet und auswalzt, sticht sie die Plätzchen aus. Dann muss Moritz zu einer weiteren Verabredung. Lene schiebt das Blech zum Zeitpunkt $\mathrm{t} 3$ allein in den Backofen und holt es nach einer Weile wieder heraus. Man kann hier eine Sequenz miteinander verbundener Aktivitäten rekonstruieren, die zu einem Gutteil auf denselben Aspekt hin mobilisiert waren. Die Plätzchen sind außerdem nur über die von Moritz und Lene miteinander verbundenen Aktivitäten entstanden. Dies bedeutet nicht, dass dasselbe Problem mitunter auch individuell bearbeitet werden kann. Beide wären sicher in der Lage gewesen, die Plätzchen allein zu backen. Sobald sie es aber gemeinsam angehen, involviert das Koordinationsprozesse, die eine hochgradige Bindung und Verbindlichkeit zwischen den Aktivitäten ermöglichen, sodass es zu einer realisierten Verbindung aus Aktivitäten, etwa des parallelen Teigbereitens und Ausstechens, kommt. Weiterhin führt diese wechselseitige Abstimmung im Kollektivhandeln dazu, dass die Verbindung durch eine zu einem gewissen Grade ähnliche Aufnahme der Situation informiert ist und auch als Verursacher anerkannt wird. In diesem Prozess berufen sich Lene und Moritz (explizit oder stillschweigend) auf verschiedene Praktiken des Backens.

Nehmen wir Luhmanns (1984: 272) Beispiel der Warteschlange an der Theaterkasse auf, so ist dieser Interaktionszusammenhang so lange nicht kollektiv handlungsfähig, wie es zu keinem Einwirken kommt, das auch als Einwirken in Verbindung ausgeflaggt wird. Unterhält man sich in der Schlange, wird dies in

tik unabdingbar. Ohne ein solches Prinzip wäre die Koordination beider Körper im Verlauf des Kollektivhandelns kaum vorstellbar. Somit haben wir es auch bei Zweiergruppen im Kollektivhandeln mit einer Dreierkonstellation aus der spezifischen Situiertheit der Handelnden und einem geteilten, von dieser Situiertheit abstrahierten Prinzip zu tun. Ein Sonderfall bildet das repräsentierende Handeln, in dem einzelne Aktivitäten von Repräsentanten symbolisch derart ausgeflaggt werden, sodass sie als Handeln einer dahinterliegenden, stabilen Verbindung an Aktivitäten verschiedener Handelnder interpretiert werden können, etwa einer Gruppe oder einer Organisation. Die in der Definition angesprochenen Grundprobleme der kollektiven Handlungsfähigkeit, Rahmung und Anerkennung sind hierbei nur zeitlich entkoppelt. Repräsentierendes Tun kann seine Wirkung nicht dauerhaft ohne dahinterliegende Potentiale tatsächlich kollektiver Handlungsfähigkeit entfalten. 
der Regel noch als Geselligkeit zwischen zwei Individuen behandelt. Wenn sich jemand vordrängt und einige der Wartenden ihn gemeinsam am Vordrängen hindern, wird dies hingegen wahrscheinlich als gemeinsames Einwirken verstanden. Dies involviert auch eine körperlich konzertierte Aktion, in der die Aktivitäten mehrerer Teilnehmer in der Schlange ihr Handeln derart aneinander binden, dass der Vordrängende aufgehalten werden kann. Kommt es zu einer derartig konzertierten Aktion, so wird dies in der Regel als ein nur in dieser spezifischen Verbindung ihrer Aktivitäten möglicher Effekt thematisierbar. Es wird nicht mehr nur gesellig interagiert, sondern kollektiv gehandelt. Wann eine solche Verbindung als kollektive Instanz der Verursachung anerkannt wird, differiert je nach sozialem Kontext. Sollten die Wartenden in der Schlange einem Täter gegenüber handgreiflich geworden sein und kommt es zu einem Gerichtsprozess, so würde jeder Einzelne verurteilt, obgleich in der Situation sowohl den Beteiligten, als auch den anderen Anwesenden wohl klar war, dass gemeinsam agiert wurde.

Dieses Einwirken ist, wie ebenfalls in Abb. 5 ersichtlich, weiterhin durch eine (zu einem gewissen Grade ähnliche) Aufnahme von Welt als Situation gemeinsamen Tuns, als eine gemeinsame Rahmung der am Handlungszusammenhang Beteiligten informiert. Jeder einzelnen Aktivität wohnt ein Moment der Agency inne, und dies impliziert auch Reflexivität. Doch im Falle des Einschreitens muss den Beteiligten klar sein, dass es sich um eine Situation handelt, in der das Tun der Anderen zur Prämisse des eigenen Tuns wird (ebd.: 273f.). Auch Moritz ist klar, dass das Produzieren von immer mehr Teig nur sinnvoll ist, wenn Lene parallel das Ausstechen übernimmt. Nur durch die Teigproduktion von Moritz ist es für Lene sinnvoll, sich auf das Ausstechen zu konzentrieren. Im Ergebnis entsteht eine spezifische transformative Kapazität des gemeinsamen Handlungszusammenhangs. Diese Kapazität wird erst durch die spezifisch realisierte Verbindung der Aktivitäten des Teigproduzierens und Ausstechens möglich. Das spezifische Vermögen der Verbindung kann prinzipiell zur Produktion des Neuen und zur Reproduktion des Bestehenden aktiv eingesetzt werden. Kollektives Handeln ist damit zugleich Produkt wie Produzent gesellschaftlicher Praxis unter Rekurs auf soziale Praktiken. Die Verbindung löst sich dabei nie vom Handeln der Beteiligten und relevanter Externer ab.

Prozesse kollektiven Handelns können dabei verschiedenartig ausgeführt werden. Hierbei lassen sich drei prinzipiell unterschiedliche Arten des Ausführens kollektiven Handelns unterscheiden: paralleles, sequentielles und repräsentierendes. Abb. 5 lässt sich als sequentiell verteiltes Handeln interpretieren, das 
sich über drei Situationen hinweg entfaltet, wobei es zum Zeitpunkt t2 zu einem Parallelhandeln kommt: Moritz macht Teig, Lene sticht aus. Paralleles Kollektivhandeln meint also ein gerichtetes und kontrollierbares Intervenieren mehrerer Handelnder in Kopräsenz in ein und derselben Situation. ${ }^{114}$ Das sequentielle Handeln verteilt sich auf verschiedene Situationen. Bei parallel ausgeführten kollektiven Interventionen ist dabei beobachtbar, dass es sich um ein Tun eines bestimmten Kollektivs handelt, wohingegen beim sequentiellen Ausführen der rote Faden gemeinsamer Rahmung, die gemeinsame Verbindung und Anerkennung gemeinsamer Verursachung erst verstanden und in ihrer kausalen Verbindung rekonstruiert werden müssen. Repräsentierendes Handeln bezieht sich auf ein Einzelhandeln, das mehrere abwesende oder potentielle Handlungen symbolisch verkörpert. Qua Position und Symbolisierung ist es beim repräsentierenden Handeln klar, dass sich hinter der Aktivität des Einzelnen eine Vielzahl abwesender Anderer verbirgt, obwohl sich nur ein Körper bewegt. ${ }^{115}$

Diese Ausübungsformate lassen sich über alle Qualitäten kollektiven Handelns hinweg finden, wobei durchaus bestimmte Affinitäten, bspw. des parallelen Handelns zur kollektiven Intervention oder des repräsentierenden Handelns zum Handeln als Kollektivakteur, bestehen. Dennoch ist es vor allem eine empirische Frage, welche Form der Ausübung unter welchen Bedingungen und in Bezug zu welcher Form des Kollektivhandelns entsteht. Man kann lediglich dahingehend einschränken, dass ein repräsentierendes Handeln stabilisierten Kollektiven und Kollektivakteuren vorbehalten bleibt, da es einer stabilen Kollektividentität bedarf, die repräsentiert wird.

Die Diskussion des Ausführens kollektiven Handelns verweist zudem darauf, dass neben Körpern und Dingen vor allem Zeichen oder Symbole als Trägermedium der Praxis kollektiven Handelns gesondert Beachtung geschenkt

114 Ich möchte hierbei mit Luhmann (1984: 231) zwischen Ereignissen und Situationen unterscheiden. Situationen sind dabei als spezifische Konstruktion von zusammengefassten Bündeln verschiedener Ereignisse zu verstehen.

115 Bourdieu (1985) hat hierbei treffend auf die ko-konstitutive Beziehung zwischen der stummen Gruppe der Abwesenden und dem repräsentierend Handelnden hingewiesen: „Die Gruppe wird durch den erstellt, der in ihrem Namen spricht und darin zugleich als Fundament der Macht erscheint, die er über jene ausübt, auf welche diese Macht doch tatsächlich zurückgeht. In dieser zirkulären Beziehung wurzelt die charismatische Illusion, die bewirkt, daß am Ende der Wortführer als causa sui erscheint: in den Augen der anderen, wie in den eigenen" (ebd.: 38). Siehe zum repräsentierenden Handeln aus praxistheoretischer Perspektive auch Ortmann (1995: 70ff.) am Beispiel Helmut Kohl. 
werden muss. Kollektivhandeln ist immer auf spezifische Art und Weise auf eine spezifische Verknüpfung von Zeichen, Körpern und Dingen verteilt. ${ }^{116}$ Hier kann verschiedenen Autoren der Science and Technology Studies zugestimmt werden. ${ }^{117}$ Wir müssen somit nicht nur nach den technischen Infrastrukturen schauen, die eine Form des Kollektivhandelns prägen und ermöglichen (vgl. Pollock/Williams 2010, Dolata/Schrape 2014). Es geht vielmehr allgemeiner um eine spezifische Verteiltheit kollektiven Handelns auf verschiedene Trägermedien (Rammert 2012: 94). Die inhärente und unentrinnbare Materialität und Symbolik der Praxis kollektiven Handelns wird damit ebenso aufgenommen wie die unausweichliche Rolle aktiver, menschlicher Interpretation. Beides ist nur im Zusammenspiel zu denken.

Hierfür muss jedoch zunächst ein Verständnis der Trägermedien der Praxis kollektiven Handelns expliziert werden. Dabei kann an die pragmatistischen Bestimmungen Rammerts angeschlossen werden, der Trägermedien über spezifische materiale Eigenschaften bestimmt: ${ }^{118}$

„Ein Medium kann also ganz allgemein als ein Stoff charakterisiert werden, der seine materiellen Eigenschaften problemlos für eine Prägung von außen hergibt, der auf der einen Seite seinen Widerstand dagegen verringert und der auf der anderen Seite den Formen ihren manipulierbaren und sichtbaren Ausdruck ermöglicht, ohne ihn durch seine eigenen Züge zu trüben. Der feinkörnige Sand macht es zum Beispiel leicht, Burgen zu bauen oder Zeichen einzuritzen; aber diese Artefakte, Gebäude wie Geschriebenes, zeigen nicht genügend Härte und Beständigkeit“" (Rammert 2016: 75, Herv. i. Orig.).

Diese Bestimmung verweist auf die Differenz zwischen Medium und Form, wie sie bspw. Luhmann (1997) prominent in die soziologische Diskussion eingebracht hat. Sie bezieht diese jedoch auf die Materialität der Praxis. Auch in der Praxis kollektiven Handelns ist es dabei nie um ein entweder symbolisches oder vor allem in actu performativ-wirkendes Geschehen bestellt. Bedeutsam ist es

116 Siehe Rammert (2016: 75ff.) für diese Typisierung in Bezug auf die Praxis der Technisierung.

117 Siehe zu einem derartigen Begriff der Verteiltheit klassisch Hutchins/Klausen (1996) und zur Verteiltheit in Bezug zu kollektivem Handeln Garud/Karnoe (2003).

118 Giddens (1990a: 22) verweist (in Anlehnung an Simmel) am Beispiel des Geldes auf die umfassende Transformation der Gesellschaft über generalisierte Symbole und Zeichen als Treiber der Entbettung und De-Lokalisierung, die einer Re-Lokalisierung bedarf (siehe bereits Luhmann 1975, Kittler 1985, Elias 1992). Windeler (2001:248) spricht von Sprache/Schrift, Geld, Technik und Expertise als Mitteln der Systemregulation. Das hier angesprochene, pragmatistische Medienkonzept ist diesen Diskussionen einen Schritt vorgelagert und adressiert die stoffliche Verteiltheit der Praxis. 
vielmehr, nach der spezifischen Verbindung beider $\mathrm{zu}$ fragen (siehe Feldman/Pentland 2003 unter Bezug auf organisationale Routinen). ${ }^{119}$ Insbesondere für das repräsentierende Handeln ist wichtig, dass das Symbolische als eigene Qualität entsteht. Neben seiner sichtbaren Materialität muss hier auch auf raumzeitlich Abwesendes verwiesen werden. In diesem Verweis auf Potentielles, aber in situ Abwesendes, liegt das Besondere der symbolischen oder zeichenhaften Trägermedien:

„Zeichen sind ein Stoff ganz besonderer Art. Sie bilden einen dritten Bereich zwischen den beiden anderen Welten. Materialität und menschliche Praxis sind zwar erforderlich, um sie in Erscheinung treten zu lassen. Aber Zeichensysteme, wie das Alphabet oder die Arithmetik, können vollständig von den Verhaltenskontexten und den physikalischen Bezügen, in denen sie entstanden sind, losgelöst werden (vgl. Krämer 1988). Sie benötigen selber wiederum einen medialen Träger, auf dem sie deutlich dargestellt und in dem sie dauerhaft gespeichert werden können. Und sie sind auf menschliches Deutungshandeln, das sich in Konventionen der Verwendung zeigt, angewiesen“ (Rammert 2016: 77f., Herv. RJ).

Das Zeichenhafte ist als spezifisches Medium von herausragender Bedeutung für das repräsentierende Handeln, da dieses erst qua Symbolisierung miteinander verbundener Aktivitäten zu einem Kollektivhandeln wird. Erst unter Nutzung generalisierter Zeichen wird es im raum-zeitlich entfernten repräsentierenden Handeln möglich, eine umfassendere Verbindung mehrerer Aktivitäten in situ auftreten zu lassen. Dies gelingt bspw. dadurch, dass qua Titel, Stelle, Rangabzeichen oder etwa dem rein körperlichen Erscheinen eines akzeptierten Vertreters im Medium des Symbolischen die Form einer konkreten Repräsentation miteinander verbundener Aktivitäten geprägt wird. Hierfür sind wechselseitig typisierte Identitäten des Kollektivs aufseiten des Repräsentanten und des Publikums eine Voraussetzung. Das repräsentierende Handeln ist daher auf die stabilisierten Kollektive und Kollektivakteure beschränkt.

Nach diesen grundsätzlichen Bestimmungen werden nun die bereits knapp eingeführten Aspekte kollektiven Handelns weiter expliziert und zu einem pra-

119 Hierbei ist Hirschauer zuzustimmen, dass es in den meisten Praktiken um „den gekonnten Einsatz des sozialisierten Körpers, den geschickten Gebrauch von Dingen, und den korrekten Gebrauch von Zeichen [geht]. Es sind Dimensionen, die in den meisten Praktiken verschmelzen, deren Hervortreten aber auch für eine einfache deskriptive Typologie genutzt werden kann: Es gibt Praktiken, in denen das körperliche Agieren (etwa der Kampf), das Hantieren mit Dingen, oder das Kommunizieren (der Gebrauch von Zeichen) im Vordergrund stehen" (Hirschauer 2016: 46f.). Auch Kollektivhandeln kann folglich auf Praktiken basieren, die eine dieser Dimensionen hervorheben. 
xistheoretischen Modell kollektiven Handelns verbunden. Dies bildet die Basis für eine Diskussion der Abgrenzungen zu anderen Phänomenen im Sozialen.

\subsection{Kollektives Handelns als spezifisch koordinierte Praxis}

Wie die handlungstheoretische Debatte schon lange thematisierte, beziehen sich Prozesse kollektiven Handelns im Unterschied zu Einzelhandlungen auf die Koordination und Abstimmung zwischen Handlungen selbst. Das heißt, sie können nicht nur aus der praktischen Motivation, Rationalisierung und dem reflexiven Monitoring der Individuen allein verstanden werden (auch wenn sie sich nie von diesem ablösen), sondern implizieren stets auch ein Moment der Handlungsabstimmung. Hier kann Tarrow (1994: 9) und Oliver (1993) zugestimmt werden, dass Kollektivhandeln ein multiples Koordinationsproblem ist. Dieses rekurriert auf verschiedene Praktiken und Praktikenbündel, wie der Diskurs um kollektives Handeln in der Bewegungsforschung schon lange betont hat (siehe vor allem Melucci 1996: 25ff.). Wenn gemeinsam eine Differenz erzeugt wird, ist eine spezifische Qualität der Koordination von Körpern und Dingen notwendig. Dies impliziert: Wir haben es mit einer Agency zweiter Ordnung zu tun, die auf der prinzipiellen Agency der Handelnden basiert und stets an diese gebunden bleibt.

Dabei muss Coleman (siehe I.2.1.) und auch Luhmann (1984: 271) zugestimmt werden, die stets davor warnten, jedwede Form der Koordination und Systembildung als kollektives Handeln auszuflaggen. Beide plädierten dafür, eine bestimmte Qualität an koordiniertem Handeln als Kollektivhandeln zu bezeichnen. Ich gehe nun davon aus, dass uns die vorher entwickelten Elemente von Agency helfen können, um die spezifische Art und Weise zu bestimmen, wie kollektives Handeln koordiniert ist. Dies impliziert zunächst: Wir haben es mit einem mehrfachen Koordinationsphänomen zu tun, denn für jedes der drei Elemente von Agency muss es diesem Argument folgend ein Äquivalent im kollektiven Handeln geben: eine spezifische Übertragung auf die Koordination zwischen Handlungen. Damit handelt es sich um ein Problem der Handlungsintegration à la Giddens:

\footnotetext{
„,Integration' may be understood as involving reciprocity of practices (of autonomy and dependence) between actors or collectivities. Social integration then means systemness on the level of interaction. System integration refers to connections within those who are physically absent in time or space. The mechanisms of system integration certainly presuppose those of social integration, but such mechanisms are also distinct in some key respects from those involved in relations of copresence" (Giddens 1984: 28).
} 
Ganz allgemein geht es praxistheoretisch im Kollektivhandeln um ein Phänomen der Handlungsabstimmung. Aus dieser entsteht eine wechselseitige Verschränkung der in Praxis aktualisierten sozialen Praktiken. Hierbei kann sich entweder auf physisch Anwesendes (Sozialintegration) oder auf physisch Abwesendes mit einer gewissen Relevanz (Systemintegration), vor allem die angesprochenen Ordnungen, aber auch abwesende Akteure und Dinge, berufen werden.

Die Koordination kollektiven Handelns erweist sich so als dreifache Qualität in der Koordination zwischen Handlungen in Praxis, die beständig unter Aktualisierung und Reproduktion sozialer Praktiken im individuellen Tun hergestellt wird und Struktureigenschaften von Sozialsystemen bzw. Institutionen involviert. Im Folgenden ist es also um eine Qualifizierung derjenigen Momente von Koordination bestellt, die aus der vorgestellten Definition folgen. Jedem der angesprochenen Elemente kollektiven Handelns lassen sich, in Anlehnung an das vorgestellte Modell der Agency, bestimmte Teilaspekte zuordnen. Diese Momente verweisen auf alte Grundfragen, die bereits bei den Klassikern theoretisch bearbeitet wurden (siehe I.1.). Auch eines der bisherigen Zentren der Debatte um kollektives Handeln, die Forschung zu sozialen Bewegungen, hat bemerkenswerterweise bereits eine Vielzahl an Konzepten etabliert, die mit den hier aus individueller Agency hergeleiteten Aspekten korrespondieren. ${ }^{120}$

\subsection{Die Fähigkeit zum Handeln in Verbindung}

Die Fähigkeit ein Geflecht von Aktivitäten in Raum und Zeit aneinander zu binden und durch eine so entstehende Verbindung von Aktivitäten einen Effekt zu erzeugen, ist von zentraler Bedeutung, um von kollektivem Handeln im hier verfolgten Sinne sprechen zu können. Dies wiederum impliziert drei verschiedene Momente: die Bindung, die Mobilisierung und das Erzeugen eines kausalen Effekts in Verbindung:

120 Bisher stehen sie jedoch unverbunden und teilweise unbegründet nebeneinander, betonen selten auch die negativ folgenreichen oder durch radikale Abhängigkeiten entstehenden kollektiven Hand-lungslinien, fokussieren stark solche des Aufbegehrens sowie der Abweichung und selten die der Reproduktion des Bestehenden. 
(i) Ohne eine gewisse Einheitlichkeit und Kontrollierbarkeit in der Bewegung zwischen den Handlungen, die bei unseren Körpern qua erlernter Fähigkeiten häufig unbemerkt Voraussetzung für unsere Teilhabe am Sozialen sind, kann von einer kollektiven Agency nicht gesprochen werden. Im Individuellen kann man sagen, unsere Lippen und unsere Zunge „gehorchen“ uns, wenn wir ,Hallo“ sagen wollen und es tun. Anders als bei diesem Beispiel basiert die Möglichkeit zum „Gehorchen“ zwischen verschiedenen Handelnden aber bereits auf einer wechselseitigen Abstimmung. Hierbei ist die Bindung zwischen Aktivitäten (vgl. Luhmann 1984: 272f., Windeler 2001: 225f., 2014: 254ff.) und die Verbindlichkeit von einzelnen Handlungen für das Kollektiv von zentraler Bedeutung. Das Thema der Bindung wurde in spezifischer Ausdeutung schon in der Nachfolge von Weber zum Kernthema der Debatte um kollektives Handeln (siehe I.1.1.), etwa bei Parsons (siehe I.2.) und ihm nachfolgend Coleman (siehe I.2.1.). Hierbei stand aber die Verbindlichkeit kollektiver Normen (Parsons) oder einer vertraglichen Ordnung (Coleman) für das einzelne Handeln im Zentrum und gerade nicht das Wie in der Entstehung der konkreten Bindungen zwischen Aktivitäten.

Hier können wir schon rein sprachlich Ähnlichkeiten mit dem allgemeinen Ordnungskonzept in Giddens' Praxistheorie erkennen, welches das Binden von Raum und Zeit thematisiert (Giddens 1984: 181). ${ }^{121}$ Diese Fi-

121 Betrachten wir die Aktivitäten mehrerer Handelnder vor dem Hintergrund der Möglichkeit zur Kontrolle dieser Aktivitäten, kommen wir mit dem basalen Moment jeder geordneten Koordination in Kontakt, dem Binden von Raum und Zeit. Sie ist Gegenstand aller drei hier vorgestellten Koordinationsprobleme kollektiven Handelns, jedoch nicht in ihrer allgemeinen, sondern vielmehr in spezifischerer Form. Es ist für Giddens die Basis von Ordnungsbildung im Sozialen und konstitutiv für sein Strukturverständnis:,,Structure thus refers, in social analysis, to the structuring properties allowing the ,binding' of time-space in social systems, the properties which make it possible for discernibly similar social practices to exist across varying spans of time and space and which lend them ,systemic' form" (Giddens 1984: 17). Das Binden von Raum und Zeit bezeichnet also die Stabilität und morphologischen Regelmäßigkeiten, die soziale Praxis häufig annimmt, und führt diesen Fakt zugleich auf bestimmte Struktureigenschaften, also eine Menge von Regeln und Ressourcen sozialer Systeme, zurück, die diesen Effekt regulieren. Verschiedene Situationen umspannend wird über einen Komplex an sozialen Praktiken eine spezifische Regelmäßigkeit des Sozialen (re-)produziert. Dies bezeichnet die allgemeine Figur der Bindung von Raum und Zeit. Sie steht im Zentrum jedweder auf Praktiken basierenden Form von Koordination. Das Thema der Bindung hat insgesamt eine lange Tradition in der Soziologie. Neben dem bereits erwähnten Parsons, ist hier noch Simmel zu nennen. Er spricht in seinem Text „Brücke und Tür“ (Simmel 1918) gar allgemeiner von der Fähigkeit zum Binden und Trennen als einem zentralen Charakteristikum des Menschen, die als anthropologische Begründung für die Spezifik menschlichen Zusammenlebens angenommen werden 
gur muss für das Kollektivhandeln aber deutlich spezifiziert werden. Windeler (2014) macht diese Koordinationsleistung in Anlehnung an Luhmann sogar zum zentralen Kriterium, um überhaupt von kollektiven Handlungen sprechen zu können, und bestimmt diese als

„Handlungen, die von mehreren individuellen Akteuren gemeinsam durchgeführt werden, die im Handeln ihre Handlungen zu einem hohen Grad aneinander binden und deren Handlungen darüber hochgradig aneinander gebunden sind" (ebd.: 255, Herv. i. Orig.).

Diese doppelte Bestimmung bedeutet zunächst, dass im kollektiven Handeln Koordinierungsleistungen erbracht werden, sodass die Aktivitäten am Kontext des kollektiven Handlungszusammenhangs orientiert werden:

„[...] kollektive Handlung heißt immer kollektive Bindung und dies heißt: daß die kollektive Handlung als Prämisse in den Sinn anderer Handlungen des Systems übernommen wird“"(Luhmann 1984: 273f.).

Man verpflichtet sich im Kollektivhandeln zur Orientierung an den anderen Handlungen im Rahmen des Handlungszusammenhangs, die so zur Prämisse des eigenen Tuns werden. Um ein Klavier zu tragen, benötigt man verschiedene Körper, und den Beteiligten ist klar, sollte eine Träger das Klavier nach rechts bewegen, so sollten die anderen Träger nicht nach links gehen. Man bindet seine Aktivität an das Handeln Anderer, hier bspw. über das Klavier selbst und das Projekt des gemeinsamen Tragens als temporärem Sozialsystem. Das eigene Tun wird als verbindlich, also hochgradig folgenreich für das der anderen Klavierträger aufgenommen. Dasselbe gilt für die Verbindlichkeit der anderen Handlungen für die eigenen. Die Aktivitäten sind so koordiniert, dass ein besonders hoher Grad an Interdependenz zwischen den beteiligten Handlungen (Giddens 1996: 104) entsteht. ${ }^{122}$

kann. Auch die naheliegenden freudschen Anleihen hat Giddens stets gesehen, gleichwohl aber nie konsistent diskutiert.

122 Eine radikale Form der Verbindlichkeit sind Zusammenhänge, in denen die einzelnen Aktivitäten so verkettetet sind, dass das Einzelhandeln unmittelbar abhängig vom Handeln der Anderen im Kollektiv ist. Mark Granovetter (1978) hat dies für das Einschreiten bei öffentlichen Gewaltphänomenen mittels Simulation eindrucksvoll aufgezeigt, indem er, selbst basierend auf Rational-Choice-Annahmen, die Auswirkungen der Wahrnehmung der Gruppenzusammensetzung von Einschreitwilligen bzw. Nichtwilligen auf die Entscheidung zum Einschreiten auf- 
Durch die sozial relevanten Bedingungen der Praxissituation des Klaviertragens und der Praktik des Tragens sind die Aktivitäten der Klavierträger hochgradig interdependent, miteinander auf das engste verknüpft und somit wechselseitig füreinander verbindlich.

Die Koordinierung dieser wechselseitigen Verbindlichkeit der Handlungen füreinander wird in einer derartigen Qualität hergestellt, dass in jedem Moment ein Unterlassen oder Abändern möglich wird. Dies ist eine zentrale Grundlage kollektiver Agency in Übertragung des AgencyKonzepts. Der Bezug zur Agencyfigur legt jedoch eine allgemeinere Bestimmung der Kontrolle kollektiven Handelns nahe: Die in Praxis entstehende Fähigkeit zur miteinander verschränkten, einheitlichen Bewegung. Es kommt auf eine wechselseitige Verbindlichkeit zwischen dem Handeln an, die in bestimmter Form hergestellt wird. Grundlage eines Kollektivhandelns im hier verstandenen Sinne ist es, dass ein gemeinsames Tun stets auch unterlassen werden könnte. Kollektivhandeln passiert also keineswegs reflexhaft, sondern muss permanent als solches aktiv fortgeschrieben werden. Hierzu sind weder ein Unterordnen unter kollektive Ziele, noch eine kollektive Intention oder geteilte Skripte des Handelns hinreichend bzw. mitunter sind diese auch nicht notwendig.

Ein instruktives Beispiel für ein koordiniertes Handeln, dem eben nicht jene Qualität gemeinsamer Handlungsfähigkeit innewohnt, gibt der in der Organisationsforschung prominente „Drop-your-Tools-Aufsatz“ (Weick 1996). Gezeigt wird in diesem Aufsatz, wie ganze Gruppen von Feuerwehrleuten bei Waldbränden ums Leben kommen, weil bspw. ihre professionelle Identität mit einem zutiefst institutionalisierten Deutungsmuster verknüpft ist, das besagt, dass man Feuer nicht mit den bloßen Händen löschen kann und die Löschgeräte so in keinem Fall abgelegt werden. Ein Befehl zum Wegwerfen und geordneten Rückzug durch den Vorgesetz-

zeigte. Die Wahrnehmung wechselseitiger Bindung, der hohen Wahrscheinlichkeit am Ende nicht allein dazustehen, ist also gerade in Bezug auf „risikobehaftete“ Situationen auch für die Motivation zur Teilhabe am kollektiven Handeln von Bedeutung. Praxistheoretisch würde man jedoch die Wie-Frage ins Zentrum rücken: Wie ist es möglich, dass sich verschiedenartige Körper in ihrem Tun wechselseitig miteinander verschränken. Die Antwort wird die sozialen Praktiken wie das Prozessieren der Praxis ins Zentrum rücken. Bei Granovetters Beispiel wären also die Praktiken des Anzeigens von und Verständigens über ein Einschreiten von zentraler Bedeutung. 
ten wurde von Teilen der Gruppe dadurch als nicht legitim erachtet. Die Gruppe war angesichts der Situation eben nicht fähig, derart koordiniert gemeinsam zu handeln, geordnet den Rückzug anzutreten, da die hierfür vorgesehene, formale Prozedur mit anderen Koordinationsmustern konkurrierte. Insbesondere die bereits erwähnte Qualität der hochgradigen Bindung und des daraus resultierenden ,Handelns in Verbindung' waren nicht vorhanden, aber auch die Rahmung der Situation als eingebunden fehlte, sodass auch in der Gruppe die Qualität der Handlungsfähigkeit nicht hergestellt werden konnte. Das Verharren im Löschen ist dennoch ein koordiniertes Tun über ein zutiefst institutionalisiertes Deutungsmuster, das aber gerade nicht die Form gemeinsamer Handlungsfähigkeit annahm. Die Gruppe konnte zudem die Ausrichtung des Tuns gerade nicht reflexiv unter Aufnahme der Situation derart kontrollieren, dass ein konzertiertes AndersHandeln möglich gewesen wäre.

Diese Koordination hochgradiger Handlungsinterdependenz erfolgt und umfasst weiterhin alle drei Ebenen des Sozialen. Sie muss als Koordination von Handlungsmöglichkeiten, von Kognition und Interpretation sowie Wertungen verstanden werden. Das meint sowohl, dass man eine hochgradige Interdependenz zwischen den eigenen Handlungsmöglichkeiten und -mitteln mit denen anderer produziert. Weiterhin werden Wahrnehmungen, Interpretationen sowie Wertungen miteinander abgestimmt. Die Herstellung der Handlungsinterdependenz erfolgt zugleich unter Rückgriff auf die drei Dimensionen des Sozialen (siehe III.1.), erfolgt unter Rekurs auf Muster der Handlungsmöglichkeiten, des Einsatzes von Handlungsmitteln, der Wahrnehmung und Interpretation sowie des Wertens.

(ii) Luhmann (1984: 272) hebt zudem die Möglichkeit einer Verbindlichkeit von einzelnen Handlungen für ein System hervor und argumentiert dafür, kollektives Handeln aus seiner Bedeutung für Sozialsysteme heraus in den Blick zu nehmen. Diese liegt in „Positionsgewinnen in Umwelt-Beziehungen“(ebd. 271). Was diese genau sind, wird bei Luhmann mit der Vorstellung ,einer kollektiv bindenden Entscheidungs- und Wirkungseinheit“ mit dem Potential zu „einheitlichen Aktionen“ (ebd.: 272) indes nur angedeutet. Diese Bestimmungen verweisen auf die Bedeutung von Bindungen in der Herstellung einer gebündelten Ausrichtung einzelner Aktivitäten, dem was ich im Folgenden als Mobilisierung bezeichnen möchte. Der Aspekt der Gerichtetheit individueller Tätigkeit war sowohl in der Möglichkeit zum Andershandeln in situ und der nicht-determinierten Situation konstitu- 
iert, als auch durch den reflexiven Kern des Agenten informiert. In der Übertragung auf eine kollektive Gerichtetheit kann man von Koordinationsprozessen ausgehen, die verschiedene Tätigkeiten auf eine konkrete Menge an Handlungsreferenzen hin ausrichten und so in einer hochgradig ähnlichen Ausrichtung sowie Bündelung dieser Tätigkeiten in Bezug auf einen oder mehrere Effekte resultieren. Die Referenz dieser Bündelung wandelt sich dabei im gemeinsamen Tun durchaus beständig.

Diese Bündelung wurde im Nachgang von Marx' Revolutionsanalysen (siehe I.1.3.) in der Bewegungsforschung als Mobilisierung bezeichnet. Als prominenter Ansatz kann hier die Ressource-Mobilization-Forschung (McCarthy/Zald 1977) gelten. Diese versucht, den Erfolg von Bewegungen oder auch bewegungsähnlichen Gruppen in Organisationen (Zald/Berger 1978) aus den Koordinierungsprozessen heraus zu verstehen, die diese in die Lage versetzen, die Handlungsressourcen verschiedener Individuen im Sinne von Zeit, Geld und Ähnlichem auf eine Form des Aufbegehrens hin zu bündeln. Problematisch ist hierbei sowohl die Einengung der Mobilisierung auf „unkonventionelle Politiken“ (Zald/Berger 1978: 830) des Aufbegehrens gegen einen oder mehrere Aspekte bestehender Ordnung als auch die nicht-relationale Vorstellung von Ressourcen als „Besitztümern“ der Menschen. Kollektivhandeln nimmt häufig sehr konventionelle Formen an und ist auf die Stabilisierung eines Status quo ausgerichtet. Ein ebenso klassisches, aber breiteres Konzept von Mobilisierung in der Bewegungsforschung liefert dabei Tilly aus einer historisch-prozessualen Perspektive:

„Mobilization is the process by which a group acquires collective control over the resources needed for action. Those resources may be labor, power, goods, weapons, votes and any number of other things, just so long as they are usable in acting on shared interests“( Tilly 1977: 1-10).

Auch in dieser Vorstellung bleibt Mobilisierung auf die Kontrolle von Ressourcen als Handlungsmittel bezogen, die zur Verfolgung eines bestehenden Interesses gebündelt werden.

Auch Baders (1991: 259) klassische und engere Definition des Begriffs zeigt dabei einige Fallstricke der Diskussion in der Bewegungsforschung:

„Mobilisierung nennen wir also jenen Prozeß, in welchem kollektive Aktoren bewußt und gerichtet die Kontrolle über jene Ressourcen steigern, welche sie für die Austragung von Konflikten für relevant halten, indem sie neue Ressourcen erschließen oder den Konversionsgrad steigern." (ebd.) 
In dieser Bestimmung zeigt sich die schlichte Setzung von Akteuren sowie Interessen als zentralen und bestehenden Motoren von Mobilisierung. Praxistheoretisch ist aber gerade die praktische Entstehung von Kollektivakteuren und von Interessen von zentraler Bedeutung, und erst in der Form, wie Mobilisierung im praktischen Vollzug geschieht, zeigt sich ihr Vorhandensein. Weiterhin ist auch die Bewusstheit in der Entstehung der Mobilisierung zu hinterfragen und zumindest in Richtung einer praktischen Bewusstheit auszudeuten. Eine Verallgemeinerung der Bündelungsfigur für die Bestimmung kollektiven Handelns erscheint mir vor dem Hintergrund der Erforschung der „neuen“ Kollektive sinnvoll. So müssten jenseits der Handlungsmittel, die Tilly anspricht, etwa die Mobilisierung bestimmter Normen und Werte, von Interpretations- oder Wahrnehmungsschemata explizit mit einbezogen werden. Weiterhin muss keineswegs ein- und dasselbe Interesse von allen Handelnden im Tun verfolgt werden.

Mobilisierung will ich (deutlich breiter als in der Bewegungsforschung üblich) als Koordinationsleistung verstehen, die zu einer Bündelung verschiedener Aktivitäten auf eine Menge von Handlungsreferenzen führt. Diese Bündelung kann dabei sowohl auf Reproduktion als auch auf Veränderung abzielen. Kollektives Handeln ist im hier verstandenen Sinne zu einem Großteil auch reproduzierendes Tun. Bedeutsam ist vielmehr die Frage, wie es in Praxis möglich wird, dass sich die beteiligten Aktivitäten auf eine bestimmte Menge von Referenzen hin orientieren lassen. Die Antwort beginnt mit den sozialen Praktiken. Sie koordinieren die wechselseitigen Verknüpfungen zwischen den beteiligten Körpern, Symbolen und Dingen, die eine praktische Kontrollierbarkeit des Kollektivs ermöglichen.

Die Referenzen kollektiven Handelns dürfen dabei zudem nicht vorab durch situative Umstände und Bedingungen festgelegt sein. Sie sind stets so oder auch anders möglich. In Konsequenz wird Mobilisierung so zu einer Form basaler Selektion des Handlungszusammenhangs, die nicht mehr nur auf individuelle Aktivitäten zurückgeführt werden kann, sondern hochgradig auf den wechselseitigen Interdependenzen zwischen den Handlungen basiert (vgl. Geser 1990 für Organisationen). Auch auf kollektiver Ebene handelt es sich also um einen Effekt, der über die gemeinsame Interdependenz und Bündelungsfähigkeit gemeinsam auch unterlassen werden kann. Dies ist insbesondere im kollektiven Handeln keine Trivialität. Nehmen wir wieder unser Beispiel des Klaviertragens. Auch hier muss es möglich sein, zu stoppen, bspw. wenn ein Gegenstand den Weg blockiert. In solchen Si- 
tuationen zeigt sich die Bindungs- und Mobilisierungsfähigkeit des Handlungszusammenhangs besonders deutlich darin, ob und wie es möglich ist, die verschiedenen beteiligten Körper zum Innehalten zu bewegen. Die empirische Frage ist dann, wie der Handlungszusammenhang so koordiniert wird, dass die beständige Möglichkeit zum Innehalten bzw. zur Richtungsänderung besteht.

Auch die Koordination der Bündelung von Aktivitäten auf eine eingrenzbare Menge an Referenzen hin fußt auf und umfasst weiterhin alle(n) drei Ebenen des Sozialen, als Koordination von Handlungsmöglichkeiten, von Kognition und Interpretation sowie Bewertungen. Das meint zunächst, dass man eine hochgradige ähnliche bzw. aufeinander abgestimmte Ausrichtung der eigenen und der anderen Handlungsmöglichkeiten und -mittel, Kognition und Interpretation sowie Wertungen herstellt. Ferner bedeutet es aber auch, dass eine Herstellung der geteilten bzw. abgestimmten Handlungsausrichtung unter Rückgriff auf alle drei Dimensionen des Sozialen erfolgt, also durch gemeinsame Kognitionen und Interpretationen, Wertungen, aber auch Handlungsmöglichkeiten und -mittel (siehe III.1.).

(iii) Die von Luhmann angesprochene, spezifische Leistung eines Systems in System-Umwelt-Beziehungen qua kollektiver Handlungsfähigkeit, lässt sich praxistheoretisch als kausales Einwirken in Praxis als spezifische Verbindung von Aktivitäten fassen. Ein spezifischer Effekt im Sinne eines ereigniskausalen Wirkens auf den Strom der Praxis kann nicht durch einzelne Handlungen, sondern erst durch hochgradige Bindung und Gebunden-Sein von Aktivitäten zustande kommen. Sicherlich kann es technologische Äquivalente zum Tragen des Klaviers über das Treppenhaus durch eine Gruppe geben, etwa eine Hebebühne. Nichtsdestoweniger lässt sich der spezifische Effekt auch in der Verbindung zwischen Aktivitäten erzeugen. Wirkungen sind unabdingbar, um von kollektivem Handeln sprechen zu können. Gleichwohl müssen diese keineswegs die mit ihm assoziierten oder intendierten Konsequenzen zeitigen.

Mitunter wird Kollektivhandeln dennoch von Individuen ausgeführt. Ein Beispiel ist das repräsentierende Handeln, etwa in Verhandlungen zwischen Staaten. Hier sind die Effekte jedoch nicht ohne die im Hintergrund dem Repräsentanten zur Verfügung stehenden, repressiven Sanktionierungsmöglichkeiten durch ein Militär oder restriktive Wirtschaftspolitik zu verstehen. Der Vertreter handelt keineswegs individuell, sondern vielmehr kollektiv, als ein ganzes Heer oder eine auf seine Anweisung ausgerichtete 
Exekutive in wirtschaftspolitischen Angelegenheiten in situ verkörpernd. Um von kollektivem Handeln sprechen zu können, muss also ein solches Erzeugen eines Effektes in und über eine Verbindung verschiedener (in situ aktualisierter oder potentieller) Aktivitäten erfolgen.

\subsection{Die Rahmung der Situation als gemeinsam und eingebunden}

Nicht zuletzt bedarf es der Koordinierung hin zu einer ähnlichen Reflexivität der Aktivitäten in Bezug auf eine gemeinsame Handlungssituation wie der Aufnahme eigenen Handelns als eingebunden in einen Kollektivhandlungszusammenhang. Es geht also um eine geteilte Rahmung der Aktivitäten als Aktivitäten, die in Verbindung einen Effekt erzeugen. In zugespitzter Art und Weise, nämlich als geteilte Weltsicht, wurde der Aspekt geteilter Rahmung schon seit Durkheim in die Soziologie kollektiven Handelns eingeführt (siehe I.1.3.). Die Geteiltheit ist zugleich ein schwieriges Thema. Bedeutsam ist die Bestimmung der Endpunkte eines Kontinuums verschiedener Grade geteilter Reflexivität. Welches Minimum reicht aus, damit wechselseitige Bindung und Mobilisierung der Aktivitäten sowie das Tun in Verbindung erfolgen können? Wo ist der Endpunkt von Geteiltheit, der Kollektivität weiterhin keineswegs mit einem homogenen Kollektiv als Einheit gleichsetzt? Letzteres lässt das andauernd instabile und ambivalente Prozessieren des Alltags sicher nie zu. Ich gehe davon aus, dass diese Fragen nicht sozialtheoretisch bestimmt werden können. In verschiedenen Kontexten bestehen erhebliche Unterschiede darin, was im Tun selbst noch als Kollektivhandeln gilt. Hier kann man nur abstrakte Bestimmungen wagen.

Die Minimalbestimmung geteilter Reflexivität im Kollektivhandeln meint insbesondere die Einbettung der einzelnen Aktivitäten in eine zu einem gewissen Grade ähnlich fokussierte Konkretheit der Handlungssituation sowie eine geteilte Aufnahme des in einen gemeinsamen Handlungszusammenhang eingebundenen Seins, das die beteiligten Aktivitäten informiert.

Giddens (1981: 36ff.) Konzept des „Presencing“ betont, dass jede Handlungssituation ein Konstrukt ist. Sie muss im Kollektivhandeln zunächst aktiv als ein gemeinsames In-einer-Situation-Sein produziert und koordiniert werden. Schließlich geht es meist um die wechselseitige Koordination von heterogenen individuellen wie kollektiven Orientierungen. Auch psychologische Forschungen haben immer wieder auf die zentrale Bedeutung einer ,mutual awareness ' oder einer ,shared gaze' für die Entwicklung von sozialen Verhaltensnormen hinge- 
wiesen (vgl. Metcalfe/Terrace 2013). Im Bewegungsdiskurs wurde die Bedeutung kollektiver Situationsdefinition, insbesondere im Collective-FramingAnsatz (Snow/Benford 1988, Benford/Snow 2000), unter Rekurs auf und in Abgrenzung zu Goffmans Rahmenkonzept, thematisiert. Hier haben kollektive Rahmungen eine zentrale Bedeutung für kollektives Handeln:

„Frames help to render events or occurrences meaningful and thereby function to organize experience and guide action. Collective action frames also perform this interpretive function by simplifying and condensing aspects of the ,world out there', but in ways that are ,intended to mobilize potential adherents and constituents, to garner bystander support, and to demobilize antagonists' (Snow/Benford 1988: 198). Thus, collective action frames are action-oriented sets of beliefs and meanings that inspire and legitimate the activities and campaigns of a social movement organization" (Benford/Snow 2000: 614). ${ }^{123}$

Das Bedeutsame an einem derartigen Rahmungsverständnis ist, dass die Aufnahme von Welt als ein aktiver Koordinierungsprozess hin zu einer ähnlichen Aufnahme von Welt dargestellt wird. Es handelt sich um eine Konstruktion einer gemeinsamen Situation, die eine hochgradig selektive und voraussetzungsvolle Basis für ein gemeinsames Tun darstellt. Damit weist der Ansatz auf einen zentralen Ausgangspunkt hin, nämlich darauf, dass es sich bei kollektiven Rahmungen keineswegs um rein kognitive Prozesse handelt: ${ }^{124}$

„A crucial feature that distinguishes collective action frames from schema and other related cognitive constructs is that, [c]ollective action frames are not merely aggregations of individual attitudes and perceptions but also the outcome of negotiating shared meaning' (Gamson 1992a:111)" (Benford/Snow 2000: 614).

Diese Abgrenzung von bloßen Schemata oder Deutungsmustern sowie dem bereits bei Coleman präsenten Thema der Aggregation ist insofern bedeutsam, als

123 Auch hier wird die bereits für die Mobilisierung beschriebene Verengung kollektiven Handelns auf Momente des Aufbegehrens in der Bewegungsforschung deutlich. Zudem wird die Rahmung in ihrer eigenen Bedeutung für kollektives Handeln herabgesetzt und insbesondere auf eine Mobilisierungs- und Legitimierungsfunktion in Bezug auf die Bewegungsinteressen verkürzt.

124 Nichtsdestoweniger halte ich die generelle Kritik an Goffman in diesem Ansatz für überzogen, beschreibt Goffman in seinem Konzept der primary frameworks doch nur eine spezifische und andere Form der Koordinierung geteilter Aufnahme von Welt, eine eben nicht vordergründig diskursive, sondern über die Naturalisierung von Situationen erfolgende (vgl. unsere Interpretation in Gläser et al. 2015). Dies wird später noch Thema sein und Einklang finden im Rahmen der Ordnungsbildung über Institutionen (siehe III.4.). 
dass wir es mit Prozessen gemeinsamen Handelns zu tun haben, die auch unterlassen oder andersartig mobilisiert werden. Wie das eingangs eingeführte Beispiel der im Feuer gestorbenen Feuerwehrleute verdeutlicht, reichen geteilte Deutungsschemata allein nicht aus um ein Kollektivhandeln zu ermöglichen. Die kollektiven Rahmungen müssen vielmehr auch den Hinweis umfassen, dass man in einen Handlungszusammenhang eingebunden ist. Bedeutsam ist zudem, dass potentiell auch ein Abändern der Situationsdeutung (auf Basis einer gewissen Verbindlichkeit der anderen Handlungen für das eigene Tun) ausgehandelt werden kann. Dies war den Feuerwehrleuten nicht möglich.

In Anlehnung an die pragmatistische Vorstellung der gerichteten Problematisierung der Konkretheit einer Situation kann nun die untere Schwelle des Grades ähnlicher Aufnahme von Welt in der kollektiven Rahmung spezifiziert werden. Sie meint zunächst nicht mehr als die Koordinierung einer ähnlichen Problematisierung in einer spezifisch offenen Handlungssituation (im Sinne Deweys). Die Beteiligten müssen eine zumindest zu einem gewissen Grade ähnliche Fokussierung im Erforschen der Welt aufweisen, um nicht in separaten Situationen zu handeln.

Mit Giddens geht es weiterhin, wie in Abb. 6 dargestellt, um die Koordination eines ähnlichen reflexiven Monitoring, Rationalisierens und gegebenenfalls Motivierens der konkreten Situation in den am Kollektivhandeln beteiligten Aktivitäten. Dies impliziert auch ähnliche unerkannte Bedingungen und Konsequenzen des Handelns in Verbindung, sowie ein Rekurs auf ähnliche Sets relevanter Regeln und Ressourcen. Gleichzeitig müssen die Beteiligten ihre Aktivitäten als eingebunden in einen spezifischen Handlungszusammenhang aufnehmen. Die Aktivitäten werden im Tun nicht nur als eigenes Tun verstanden. Sie werden darüber hinaus zu einem gewissen Grad als ein Tun aufgenommen, das in einen Kollektivhandlungszusammenhang eingebunden ist. 


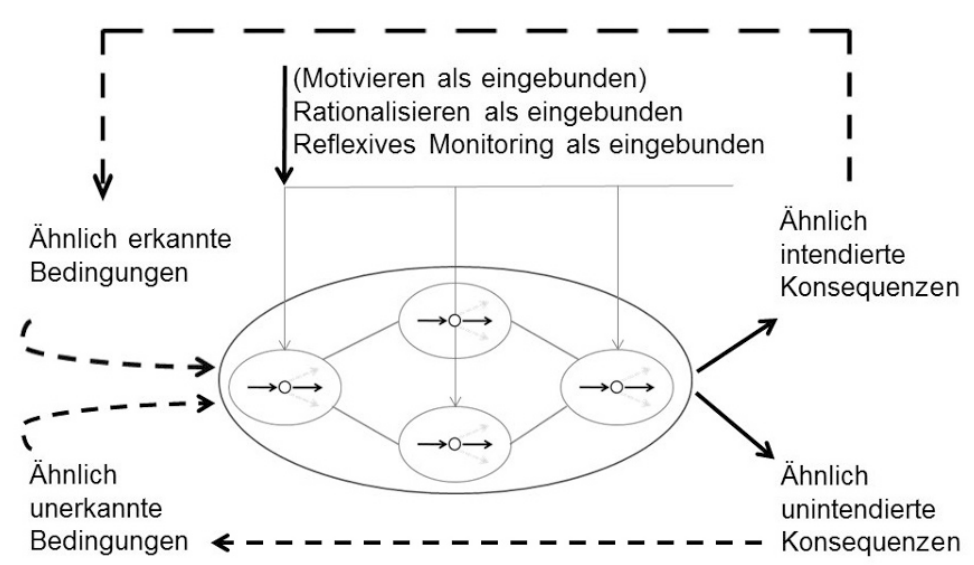

Abb. 6: Kollektive Rahmung als ähnliche Aufnahme der Situation, eigene Darstellung

Wie Abb. 6 verdeutlicht, bewegt sich jede einzelne Aktivität des kollektiven Handlungszusammenhangs zu einem Gutteil in derselben Situation. Dies ist keineswegs ein automatischer Prozess. Er umfasst dabei Ähnlichkeiten in der Fokussierung auf in situ relevante kognitive Schemata, Normen und Werte, aber auch Artefakte und relevante Akteure sowie der Aufnahme all dieser Aspekte als relevante Aspekte für das Kollektivhandeln. Daraufhin lassen sich die einzelnen Aktivitäten vor dem Hintergrund einer gemeinsamen Handlungssituation rationalisieren und motivieren. Dies ist in vielerlei Hinsicht Grundvoraussetzung für komplexe Formen von Kollektivität, die später Thema sein werden. Überführt man dieses Grundthema in einen Prozess, wird aber auch eine geteilte Rationalisierung (und Motivierung) im naiven Sinne möglich (vgl. Thompson 2011). Die Situation der Beteiligten wird mitunter mit einer anderen Situationen rationalisiert, da sie eine gemeinsame Handlungssituation ist: Wir holen die Segel ein, weil wir das wilde Schwingen der Baumwipfel am Ufer beobachten. Überdies kann das gemeinsame Tun sich an hochgradig als gewusst aufgenommenen Aspekten und Kontextualisierungen der Situation orientieren, also einer geteilten Schließung der Handlungssituation (im Sinne Deweys).

Bedeutsam für das Kollektivhandeln ist weiterhin, dass eine dominante Systemreflexivität oder ein spezifischer Komplex an Systemreflexivitäten des kollektiven Handlungszusammenhangs das Tun im Sinne einer handlungsleitenden Qualität informiert. Im gemeinsamen Tun wird dabei, in welchem Detaillierungsgrad auch immer, auf eine spezifische Menge an Regeln und Ressourcen 
systemischer Ordnungen Bezug genommen. Sobald dieser Bezug eine gebündelte Ausrichtung des Kollektivs dominant und spezifisch informiert, haben wir es mit einer handlungsleitenden Qualität zu tun. Dies bedeutet keineswegs, dass nicht eine Vielzahl anderer systemischer und institutioneller Ordnungen (bzw. individuelle Projekte) zugleich im Tun aktualisiert werden. Für einzelne Aktivitäten im Kollektiv können dabei auch ganz andere Ordnungen dominante Orientierungen sein, solange die Aktivität sich auch zu einem hinreichenden Grad an derjenigen Ordnung oder denjenigen Ordnungen orientiert, die das Handeln in Verbindung koordiniert. Handlungsleitend kann dabei auch eine spezifische Melange aus systemischen und institutionellen Ordnungen sein, wie es bspw. häufig für Innovationsfelder wie dem des Silicon Valley beschrieben wird (vgl. Saxenian 1994, Ferrary/Grannovetter 2009).

Welche Form das reflexive Moment des Kollektivhandelns auch immer dominant informiert und abstimmt: Kollektivhandeln ist nie denkbar ohne einen Koordinationsmodus und einen Ordnungsrahmen. Diese stimmen die hochgradig unterschiedlichen situativen wie situierten Aufnahmen von Welt im individuellen Handeln wechselseitig aufeinander ab. Insofern ist Kollektivhandeln immer auch Medium und Resultat der Reproduktion sozialer Systeme (siehe III.4.).

\subsection{Die Anerkennung gemeinsamer Verursachung}

Die Anerkennung eines Effekts als verursacht in Verbindung ist ähnlich prekär wie das Bild individueller Verursachung. Es gibt aber mindestens einen Unterschied: Die Bewegungen des Körpers sind im Individuellen ein zutiefst institutionalisierter Hinweis auf basale Handlungsverursachung eines Individuums, sie gelten in den vielfältigsten Kontexten als Basishandlungen, also als grundlegende Quellen einer Wirkung. Ein Äquivalent gibt es im Kollektiven nicht. Deshalb muss sich jedes Kollektivhandeln gegen die Anerkennung als basaler Körperbewegung eines Individuums behaupten. Geser (1990: 402) hat in Bezug auf das Handeln von Organisationen darauf hingewiesen, dass hier eine Zuschreibung von Verursachung meist nur gelingt, wenn eine Zuschreibung auf Individuen oder auch kleinere Subeinheiten ausgeschlossen werden kann. Welche Schwierigkeiten diese Zuschreibung auf Kollektive mit sich bringt, zeigen etwa die Problematiken der rechtlichen Behandlung kollektiven Protests, etwa in der Studentenbewegung der 1970er Jahre, auf die die Rechtsprechung mit der Suche nach individuellen Tätern reagierte (vgl. Kreissl 2000). 
Die Formalisierung von Urheberschaft im Recht hebt für Kollektive dabei häufig auf ein Äquivalent zu individuellen Personen ab. Dies kann man in der Figur juristischer Rechtspersonen, wie etwa Vereinen, Stiftungen, Unternehmungen oder Körperschaften des öffentlichen Rechts, beobachten, die sich im Zivilrecht oder im öffentlichen Recht finden lassen. Auch die Sozialwissenschaften folgen diesem Impuls der akteursorientierten Moderne zumeist (siehe auch I.2.1. und I.2.2.):

\footnotetext{
„Modern culture depicts society as made up of ,actors'-individuals and nation-states, together with the organizations derived from them. Much social science takes this depiction at face value, and takes for granted that analysis must start with these actors and their perspectives and actions" (Meyer/Jepperson 2000: 100).
}

Sicher ist das rationale Recht ein zentraler Taktgeber unseres Nachdenkens über Kollektive und prägt daher ganz bedeutsam die Formen der Entstehung kollektiven Handelns mit (vgl. Schulz-Schaeffer 2007: 337ff.), wie auch der westliche Rationalismus selbst diese Formen zutiefst prägt. Nichtsdestoweniger ist die im Zitat angedeutete Fixierung auf den Kollektivakteur insofern problematisch, als dass die alltägliche Praxis verschiedenste Formen kennt, in denen gemeinsame Verursachung durch die Beteiligten sowie durch Externe anerkannt wird.

Man denke etwa an unser Beispiel des Einschreitens in der Warteschlange, bei dem sowohl die Beteiligten als auch ein Publikum das Eingreifen gegen das Vordrängen durchaus als gemeinsame Intervention verstehen, es jedoch sicher jeden irritieren würde, vom Handeln eines Kollektivakteurs zu sprechen. Im kollektiven Handeln geht es also um die Wahrnehmung und Interpretation, praktische Handhabung und Bewertung einer spezifischen Verbindung von Aktivitäten als Verursacher eines Effekts. Die Instanz, die im Sozialen als Verursacher anerkannt wird, ist also der kollektive Handlungszusammenhang selbst. In welcher Form dieser anerkannt wird, bleibt eine empirische Frage.

Ich stimme dabei den neo-institutionalistischen Autoren (siehe I.2.3.) zu, dass die Anerkennung kollektiven Handelns als kollektives Handeln stets einen Prozess der sozialen Konstruktion bedeutet. Die Formate sozialer Agency zwischen Individuen und Kollektiven weisen dabei, wie die Autoren dieser Tradition stets betonen, auch erstaunliche Ähnlichkeit auf. Diese Formen der Zuschreibung von kollektiver Verursachung muss jedoch vor dem Hintergrund eines Moments des aktiven Anzeigens kollektiver Handlungsfähigkeit verstanden werden. Im Handeln selbst muss das Individuum dabei zunächst erst einmal die natürliche Attribution auf seinen Körper machtvoll durchbrechen, andeuten, dass es sich 
keineswegs um ein eigenes Tun handelt. Und: Um dies zu tun, stehen dem Handelnden je nach Handlungskontext verschiedene Mittel zur Verfügung. Die bedeutsame Frage Luhmanns lautete: „Wie weit kann dies Handeln gehen, ohne die kollektive Deckung zu verlieren und ultra vires als Handeln einer Einzelperson dazustehen?" (Luhmann 1984: 272). Sie ist nicht nur je nach Kontext, sondern auch im Verlauf der Praxis stets neu und andersartig zu beantworten. Selbst wenn eine zutiefst institutionalisierte Form gemeinsamer Produktion bereitsteht, etwa im repräsentierenden Handeln eines Vorstandsvorsitzenden, so bedarf es immer noch dem kompetenten, situierten Anzeigen, dass es sich um ein Handeln als Repräsentant der Firma handelt. Wird er eine Verhandlung mit den Worten „Wir freuen uns weiterhin auf eine gut Zusammenarbeit" beenden, werden die Beteiligten wissen, dass im Sinne des Unternehmens gesprochen wird. Wird stattdessen während des Meetings über das Essen beim letzten Aufeinandertreffen geredet, ist der Versuch angezeigt, das Gespräch auf Geselliges zu überführen.

Die juristische oder auch politische Konstruktion der Anerkennung kollektiver Akteure ist vermehrt und immer wieder mit verschiedenartigem Fokus analysiert worden (vgl. z.B. Dan-Cohen 1985, 1992, Matys 2011). Das alltägliche Konstruieren anderer Formen von Kollektivität hingegen ist bisher meines Wissens kaum explizit in den Blick geraten. Eine Ausnahme sind ethnographische oder konversationsanalytische Studien, etwa die eindrückliche Studie zum Präsent-Machen und Präsent-Halten der Organisation Ärzte ohne Grenzen im kongolesischen Arbeitsalltag eines führenden Koordinators und Repräsentanten dieser Organisation (vgl. Cooren et al. 2008). Auch konzeptionell bieten Cooren und Kollegen mit dem Konzept der „(Re-)Presentification“ ein interessantes Einfallstor an. Es muss nach dem aktiven Präsent-Halten eines Kollektivs als handlungsfähiger Instanz durch die Teilhabenden gefragt werden. ${ }^{125}$

125 Dieses Konzept wurde unter Rekurs auf Derridas und Gumbrechts Arbeiten zur Präsenz entwickelt. Zu lösen wären diese Arbeiten von ihrem ausschließlichen Fokus auf Kommunikation, hin zu einer Analyse, die auch die mit diesem Präsent-Halten einhergehenden Macht- und Herrschaftsprozesse, wie Wertungen dezidierter aufnimmt. 


\subsection{Ein erweitertes Modell kollektiven Handelns}

Die drei vorab angesprochenen Aspekte der Koordination sind wechselseitig konstitutiv füreinander. Wie Abb. 7 verdeutlicht, ermöglichen sie ausschließlich in ihrem Zusammenspiel Prozesse kollektiven Handelns. Dennoch können wir die Koordinationsprobleme analytisch trennen und fragen, wie eine zu einem gewissen Grade geteilte Rahmung oder die Fähigkeit zum Handeln in Verbindung bzw. die Anerkennung gemeinsamer Verursachung in Praxis hergestellt wird. Diese Abstimmungsaspekte können dabei durch verschiedene Praktiken und in Bezug auf unterschiedliche Ordnungen entstehen. Wir haben es nicht nur mit einem vielschichtigen Koordinationsprozess zu tun, sondern eben auch mit einem verschiedenartig koordinierten Prozess. Die analytische Aufgabe in empirischen Studien ist es nun, das Zusammenspiel verschiedener koordinierender Aspekte zu rekonstruieren, die Prozesse der Aktualisierung kollektiven Handelns ermöglichen (und so immer auch beschränken).

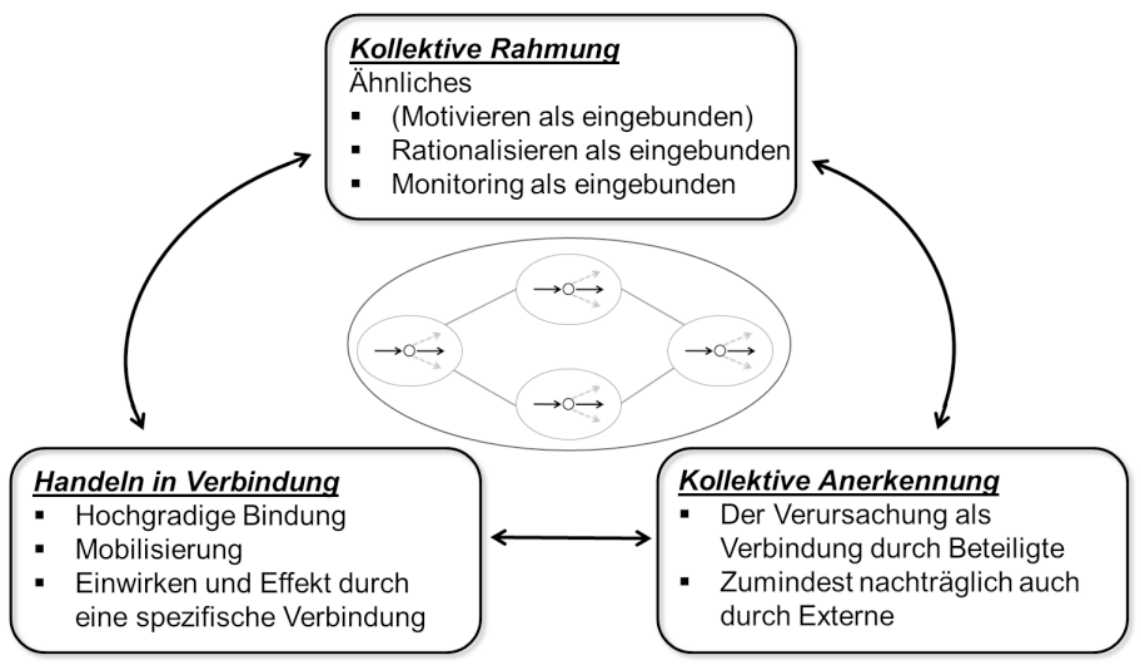

Abb. 7: Ein erweitertes Modell kollektiven Handelns, eigene Darstellung

Weiterhin stehen die drei Koordinationsprozesse in einer bestimmten Beziehung zueinander. Auch diese ist in Abb. 7 dargestellt. In Anlehnung an das erweiterte Agency-Modell (siehe II.1.1.) bildet die Bindung zwischen den Aktivitäten eines kollektiven Handlungszusammenhangs die Basis, um in einer spezifischen Verbindung von Aktivitäten gerichtet einen Effekt in und für Praxis zu erzeugen. Sie 
ermöglicht und beschränkt die praktische Fähigkeit zur gemeinsamen Mobilisierung auf Handlungsreferenzen hin. Gleichzeitig ist diese Verbindung durch eine spezifische und zu einem gewissen Grade ähnliche Rahmung des Handelns als gemeinsam und eingebunden in den Handlungszusammenhang informiert. Dies wiederum setzt voraus, dass die Verbindung von Aktivitäten selbst als Verursacher auf der Bühne des Sozialen auftritt, das Tun nicht als individuell, sondern gemeinsam anerkannt wird. Ohne eine solche Anerkennung der Verursachung in Verbindung sowie der reflexiven Aufnahme des Tuns als eingebundenem Tun ist die Erzeugung hochgradiger Bindung und das wechselseitige Gebunden-Sein schwerlich in einer Weise möglich, in der das Einwirken in Verbindung jederzeit unterlassen werden kann.

Dies zeigt sich bei den Feuerwehrleuten, die die Befehle nicht aufnehmen konnten und ihre Werkzeuge nicht fallen ließen. Ihr Handeln orientierte sich an einer hochgradig ähnlichen Deutung der Situation. Sie nahmen diese aber nicht als Situation auf, in der das Tun sich gemeinsam und wechselseitig aneinander ausrichtet, in einen Zusammenhang gemeinsamen Tuns eingebunden ist. Ihre Aktivität wird als alleiniger Kampf gegen das Feuer gerahmt und anerkannt, aber eben nicht als eingebundenes Tun, das über die hierarchischen Befugnisse des Gruppenleiters wechselseitig aneinander gebunden ist.

Jedes einzelne dieser drei Aspekte kollektiven Handelns kann also für eine gewisse Zeit isoliert bestehen, doch im Prozessieren der Praxis selbst wird es früher oder später zu einer wechselseitigen Verschränkung kommen müssen. Wird ein Tun dauerhaft nicht als kollektiv verursacht anerkannt, wird ein kollektiver Handlungszusammenhang die Fähigkeit zum Handeln in Verbindung früher oder später verlieren. Auch die Anerkennung als Instanz gemeinsamer Verursachung wird ohne tatsächlich erzielte Effekte nicht lange bestehen, wie etwa Phänomene des Verlustes der Handlungsfähigkeit von Staaten während einer Revolution immer wieder aufzeigen.

Die zentrale Scharnier- und Vermittlungsposition zwischen den drei Aspekten kommt im Kollektivhandeln den in Praxis aktualisierten sozialen Praktiken zu. Da es sich um Phänomene der Handlungsabstimmung handelt, müssen sie auch von relevanten Anderen versteh- und nachvollziehbar sein, zumindest soweit, dass ein paralleles oder zeitlich nachgeordnetes Anknüpfen möglich wird. Dabei geht es keineswegs immer um eine explizite Aushandlung eines (konsensfähigen) Handlungsziels. Dies zeigt sich in den Kooperationsformen, die im Alltag (fast) ohne direkte Anknüpfungspunkte zwischen den Beteiligten auskommen und daher in der Wissenschafts- und Technikforschung unter dem Slo- 
gan der „Kooperation ohne Konsens“ beschrieben werden. ${ }^{126}$ Diese basieren häufig auf Routinen, die bereits vor den Beobachtungen ihres alltäglichen Prozessierens aufeinander abgestimmt und ausgehandelt wurden. Es sind diese Routinen, die in ihrem spezifischen Anschließen, Voraussetzen und Verknüpfen mitund aneinander das beobachtete, stumme Kooperieren möglich machen, die im Alltag als Bewegungen Hand in Hand gehen und wechselseitig miteinander verschränkt sind. Die Verschränkung selbst geschieht häufig materiell oder auch symbolisch vermittelt und wird zu einem Zeitpunkt der Eingerichtetheit der kooperativen Lebensform als verknüpft und koordiniert über ein „Grenzobjekt“, etwa einer Krankenakte, beobachtet.

Bedeutsam für eine derart vermittelte Kooperation sind aber die flexiblen, nie gleichartigen und dennoch aufeinander abgestimmten Bewegungen der Körper sowie die Bedeutungskonstruktionen und Wertungen in sozialen Praktiken. Beispielsweise sind die aus einer Krankenakte entnommenen Informationen erst in ihrer Interpretation relevant, und auch die Inhalte von Dokumentationen müssen ausgehandelt und abgesprochen bzw. erlernt werden. Erst die Verbindung mit professions- oder organisationsbezogenen Praktiken macht die Akte zu einem zentralen Bündel von Medien der Kooperation. Auch wenn Ärzte und Pflegepersonal je Unterschiedliches mit der Akte verbinden und sie ihr alltägliches Tun nicht dezidiert aufeinander abstimmen, so ist die kooperative Wirkung dennoch in der spezifischen und stabilen Relation ihrer Praktiken und dem repetitiven Charakter der Praxis fundiert. Die in einer stabilen Praxis wiederkehrend ähnlich aktualisierten Praktiken ermöglichen die Verbindung wie Verbindlichkeit verschiedener Körper und Dinge füreinander und somit die praktische Ausrichtung des Handlungszusammenhangs aus Ärzten und Pflegenden. Dabei ist die direkte Interaktion durch die vorab ausgehandelte Abgestimmtheit ihrer Praktiken nicht mehr nötig. Dennoch geben sie dem gemeinsamen Tun im Alltag eine Richtung und sind sich durchaus ihres Eingebunden-Seins in ein Kollektiv gewahr: dem der Bewältigung verschiedener Anforderungen eines modernen Krankenhausalltags über die Krankenakte. Am Werke ist ferner eine spezifische Melange an Systemreflexivitäten, bspw. der ärztlichen wie pflegerischen Professionen oder der Krankenhausorganisation selbst.

126 Vgl. klassisch Star (2004); für einen Überblick Strübing et al. (2004), Meister (2011). 
Über eine bestimmte Periode kollektiver Praxis kann so auch eine Art der „Kultivierung“ eines stabilen Kollektivs entstehen, das auf der Ausbildung von Systemwissen (Windeler 2001: 186) und in sozialen Praktiken generalisierten Formen des Könnens basiert (vgl. Windeler 2014). So können im Kollektiv stabil geteilte wie miteinander verschränkte Körpertechniken entstehen. ${ }^{127}$ Hervorzuheben bleibt dennoch, dass die situierte Praxis der wechselseitigen Verschränkung von Aktivitäten, die, sozial anerkannt und reflexiv aufgenommen, gemeinsam in situ einen Effekt erzeugt, all dies erst ermöglicht. Diese eingerichteten Praktikenbündel sind die Basis für das stumme und nur scheinbar ohne Berührungspunkte auskommende Kooperieren.

127 Marcel Mauss greift hierbei mit dem spezifischen Marschschritt englischer Soldaten, die sich einfach nicht der französischen Marschmusik anpassen können (Mauss 1989: 201; vgl. auch Schüttpelz 2010), ein Beispiel der Differenz zwischen einem Koordinationsmodus und kollektiv erlernten Körpertechniken auf, die in ihrer spezifischen Verschränkung von Körpern und Dingen eine praktische Ausrichtung eines Kollektivs erschweren. 


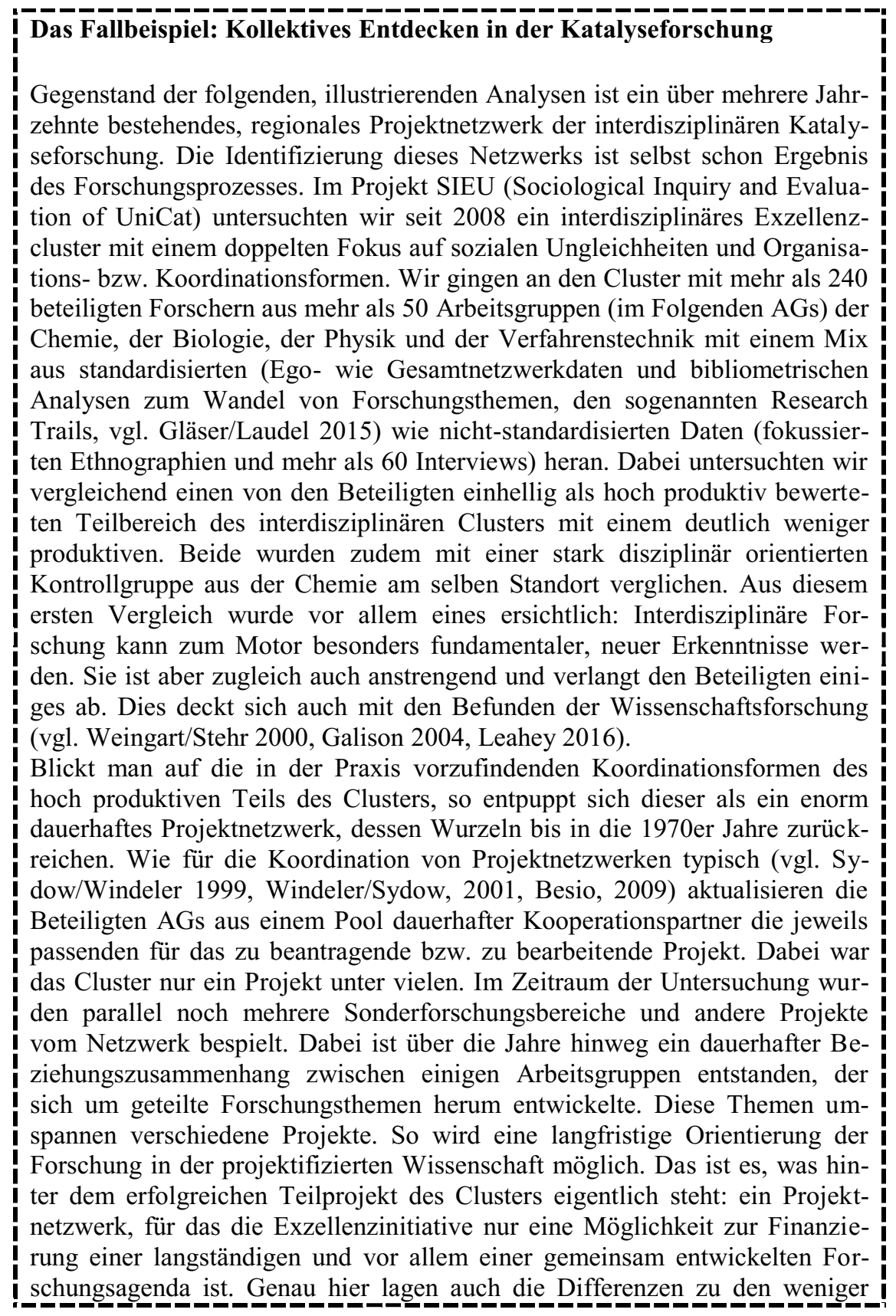


produktiven Bereichen, die sich thematisch erst mühsam finden und koordinieren mussten.

In der Folge wird am Beispiel der Entstehung, Aufrechterhaltung und VeränI derung kollektiven Entdeckens in den Laboren die konkrete wissenschaftliche Praxis dieses erfolgreichen Netzwerks beleuchtet. Der im vorherigen Kapitel entworfene Analyserahmen wird in Aktion gezeigt. Im Zentrum steht eine Analyse von Formen kollektiven Handelns in den Forschungsprozessen des Netzwerks, die auf einer vielschichtigen und subtilen Überlagerung von reflexiv (an-)gewendeten Prozeduren im wissenschaftlichen Alltag beruhen. Hierzu wird zu Beginn zunächst noch einmal kurz in den Netzwerkkontext eingeführt. Nach dieser kurzen Einordnung folgt eine Illustration des entworfenen Modells am Beispiel eines zentralen Prozesses kollektiven Entdeckens, der auch im weiteren Verlauf ausführlich analysiert wird.

Was hinter dem Fall steckt: Große Projekte, kleine Hilfen und ein robustes AG-Netzwerk

I

Will man die enorme Produktivität des Netzwerkes verstehen und erklären, so fallen insgesamt fünf Aspekte auf, die allesamt auf einen enorm stabilen Beziehungszusammenhang verweisen, den Windeler (2001) als zentralen Koord dinationsmodus von Netzwerken kennzeichnet. Die Netzwerkbildung kann sowohl als Reaktion auf zunehmende Projektifizierungs- und Vernetzungsanforderung in der Wissenschaftsförderung, als Reflexion auf die experimentellen Möglichkeiten von Konkurrenten und als Ausdruck historisch gewachsener, konkreter Geflechte persönlicher Beziehungen verstanden werden. Der wissenschaftliche Erfolg des Netzwerkkontexts ist dabei auf fünf besonders bedeutsame Strukturmerkmale zurückzuführen:

(1) Zunächst wäre eine inner- wie außerhalb des Netzwerks performativ wirksame, ikonische Erzählung über eine gemeinsame Agenda zu nennen. Dabei muss zunächst festgestellt werden, dass es mehrere überlappende Interpretationen gemeinsamer Forschungsprobleme und Themen gibt. Diese unterscheiden sich in ihrer Spezifik und ihrem Geltungsbereich im Netzwerk. Man kann dennoch sagen, dass es ein Grundthema der Forschung im Netzwerk gibt, das immer wieder behandelt wird: Es geht darum, die Struktur und Funktionsweise der Sauerstofftoleranz einer bestimmten Enzymklasse aufzuklären. Dieses Thema wirkt zum einen als motivierende Erzählung über den interdisziplinären Ansatz, aber auch als gemeinsame Klammer, um die sich spezifischere Fragestellungen gruppieren, die dann aber nur noch für Teile des Netzwerks relevant sind.

Insbesondere die immer wieder herausfordernde Verknüpfung von Erkenntnissen der verschiedenen Experimente und Fragestellungen bietet einen der 
zentralen Mechanismen an, die das Innovationspotential des Netzwerks erklären. Die Experimente sind keineswegs miteinander abgestimmt, schon gar nicht hierarchisch. Die Verknüpfungsleistungen erfolgen meist in den für den Netzwerkkontext typischen Gruppensitzungen zur Auswertung konkreter Experimentreihen, in dem jemandem einfällt, dass dazu ja schon einmal etwas durchgeführt wurde. Diese Treffen sind ein zentraler Motor, der in anderen Bereichen nicht zu finden war. Sie sind seit langem eingelebt. Hierbei kommt vor allem denjenigen Professoren und Postdocs eine zentrale Bedeutung zu, die als Methodiker oder Instrumentalisten an einer Vielzahl von Experimenten beteiligt sind. Diese können im Detail nicht unbedingt etwas zur Strukturaufklärung in den Enzymen sagen, haben aber häufiger das „breite Bild“ vom Netzwerk, leisten bedeutsame Verknüpfungen.

(2) Ein weiterer zentraler Punkt für die Stabilität des BeziehungszusammenI hangs ist die ähnliche Reflexion über die lokalen Forschungsbedingungen und das gemeinsam kumulierte Wissen. Das Netzwerk hat sich weltweit anerkannte Alleinstellungsmerkmale in Bezug auf die Enzyme erarbeitet. Eine zentrale Position für dieses Thema kommt einer biologischen Arbeitsgruppe (im Folgenden AG) zu, die auf jahrzehntelange Erfahrung mit diesen speziellen Proben zurückgreifen kann. Um diese Proben herum gruppieren sich verschiedene auf Methoden und Instrumente ausgerichtete AGs, die mit „Fuhrparks“ ausgestattet sind, die durchaus mit dem weltweiten Spitzenniveau mithalten können. Die AGs haben komplementäre Expertisen und sehen keine Probleme mit einem Wissensabfluss untereinander. Dieser Punkt wird insbesondere I dann hervorgehoben, wenn die Forscher die Kooperationen im Netzwerk mit denjenigen mit direkt konkurrierenden AGs vergleichen, die es durchaus auch gibt. Diese Komplementarität führt insbesondere zu einer tiefergehenden Diskussion zukünftiger Ideen. Dabei werden diese Ideen nicht nur offengelegt, sondern zugleich die Möglichkeiten und Fertigkeiten der anderen AGs in I diese mit einbezogen. Insgesamt lassen sich sieben der neun im Teilbereich des Clusters involvierten AGs als Kern des Netzwerks identifizieren, hierbei gibt es bei den Befragten keine Differenzen bezüglich der dazugehörigen AGs, die in Abb. 8 dargestellt sind. D.h. alle Befragten nannten uns dieselben AGs. 


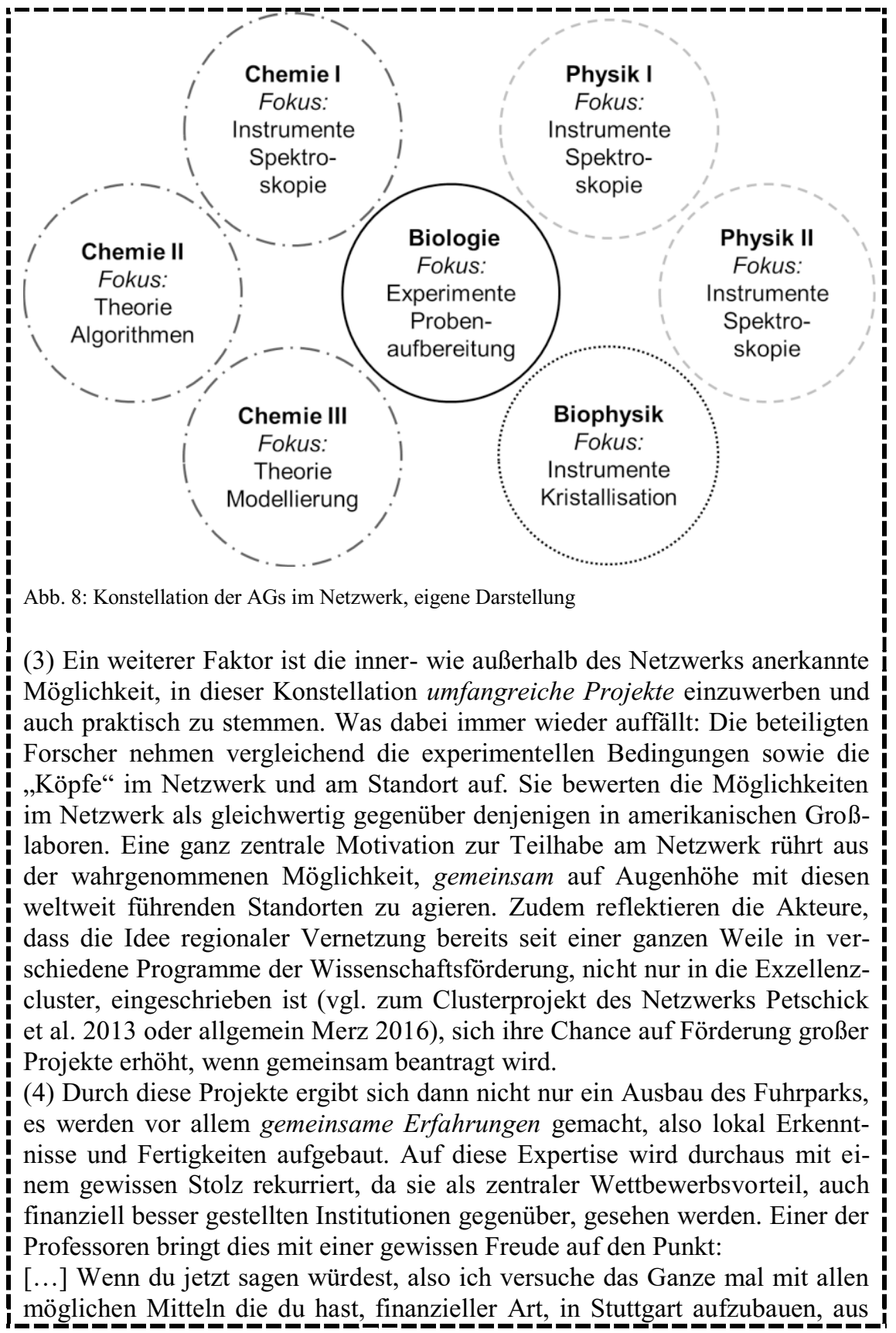


i dem Nichts heraus, dann hast du also einen enormen Rückstand sowohl die entsprechende Manpower und Expertisen da zusammenzustellen als auch die Geräte zum Laufen zu bringen [...]. Also diesen Rückstand würdest du so I schnell nicht aufholen können. Selbst mit viel Geld kannst du es nicht erschlagen. Diese Erfahrung, genau, und eben auch das Knowhow.“ (Interview 55, Prof. Chemie)

Von zentraler Bedeutung ist die lang anhaltende Verknüpfung von verschiedenen Expertisen, von Proben und von Laboren mit ihren „Fuhrparks“ in der alltäglichen Praxis des Experimentierens, aber auch die gemeinsame Diskussion von Ideen in der Datenauswertung. In all diesen Aktivitäten kann immer wieder auf eine gemeinsam erfahrene Geschichte des Kooperationszusammenhangs zwischen den verschiedenen AGs rekurriert werden. Diese Erzählungen sind zumeist leidvoll und geprägt von vielen Rückschlägen, werden aber mit einem „Happy End“ in Verbindung gebracht: Am Ende war man noch immer erfolgreich. Immer wieder sträubten sich die Befragten, in diesen Erzählungen einzelne Arbeitsbereiche in ihrer Bedeutung herauszuheben. Die teuer erkauften, gemeinsamen Erfahrungen und das gemeinsame Lernen aus diesen sind also, neben den seit Jahrzehnten aufeinander abgestimmten LaboI ren mit ihren Einrichtungen, das zentrale Moment für die Produktivität des Netzwerks. Sie resultieren in und aus einem wechselseitig als niedrigschwellig I erreichbar wahrgenommenem Pool an Expertisen und Ressourcen. Die lokale Konzentration wird somit als ein hoher Grad an „presence availability“ der AGs füreinander über den dauerhaften Beziehungszusammenhang des Netzwerks immer wieder aktiv hergestellt (vgl. Schmidt 2013).

(5) Von besonderer Bedeutung gerade für radikal neuartige Erkenntnisse sind auch kleinere Projekte abseits der offiziellen Experimentlinien. Hierfür müssen die in den Laboren arbeitenden Doktoranden, Assistenten und Postdocs durchaus auch für kleinere Projekte ,nebenbei“ zu haben sein. Ob des enormen Zeitdrucks und der Arbeitslast ist das keineswegs eine Selbstverständlichkeit. Häufig sind dabei neben den geteilten, positiven Erfahrungen auch generalisiert reziproke Beziehungen zwischen zentralen Positionen im Netzwerk bedeutsam (siehe III.4.). Dies ist nicht nur auf professoraler, sondern auch auf Ebene der Postdocs und Doktoranden gegeben, die für die praktische Realisierung kleiner Zusatzprojekte besonders bedeutsam ist.

Diese für die Produktivität im Netzwerk so bedeutsamen Strukturmerkmale I des Netzwerkkontextes waren allesamt im weniger produktiven Teil des Exzellenzclusters nicht gegeben. Die durch den Antrag definierte Forschungsagenda zeigte sich als zu unspezifisch. Konkretere Themen mussten erst mühs sam erarbeitet werden. Das Teilprojekt wurde weiterhin von vielen beteiligten AGs nicht als die zentrale Möglichkeit angesehen, ihre eigenen ForschungsI bedingungen zu verbessern. Eine häufig wiederzufindende Einschätzung war, dass ein ordentlicher Sonderforschungsbereich deutlich attraktiver ist. Mitun- 


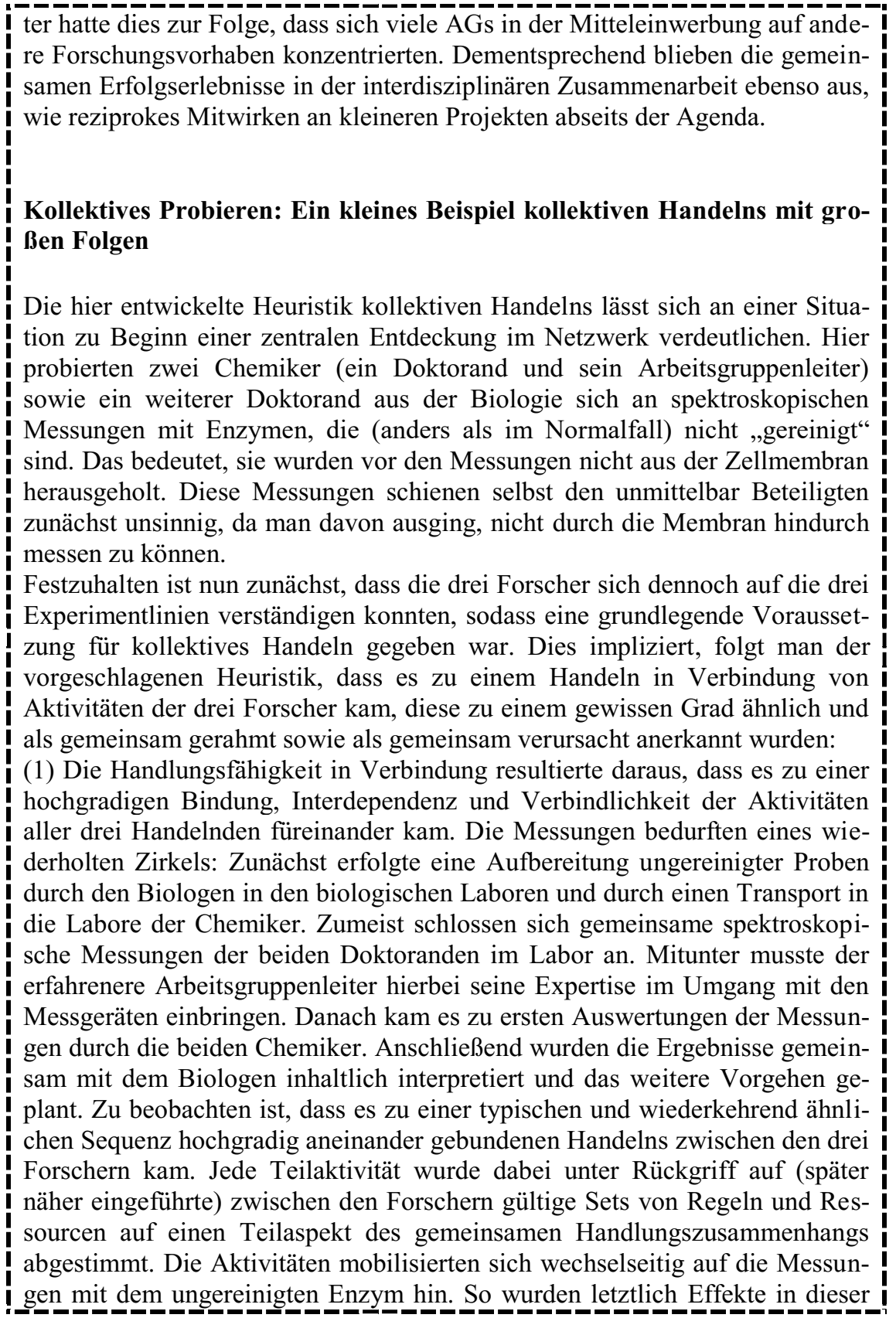




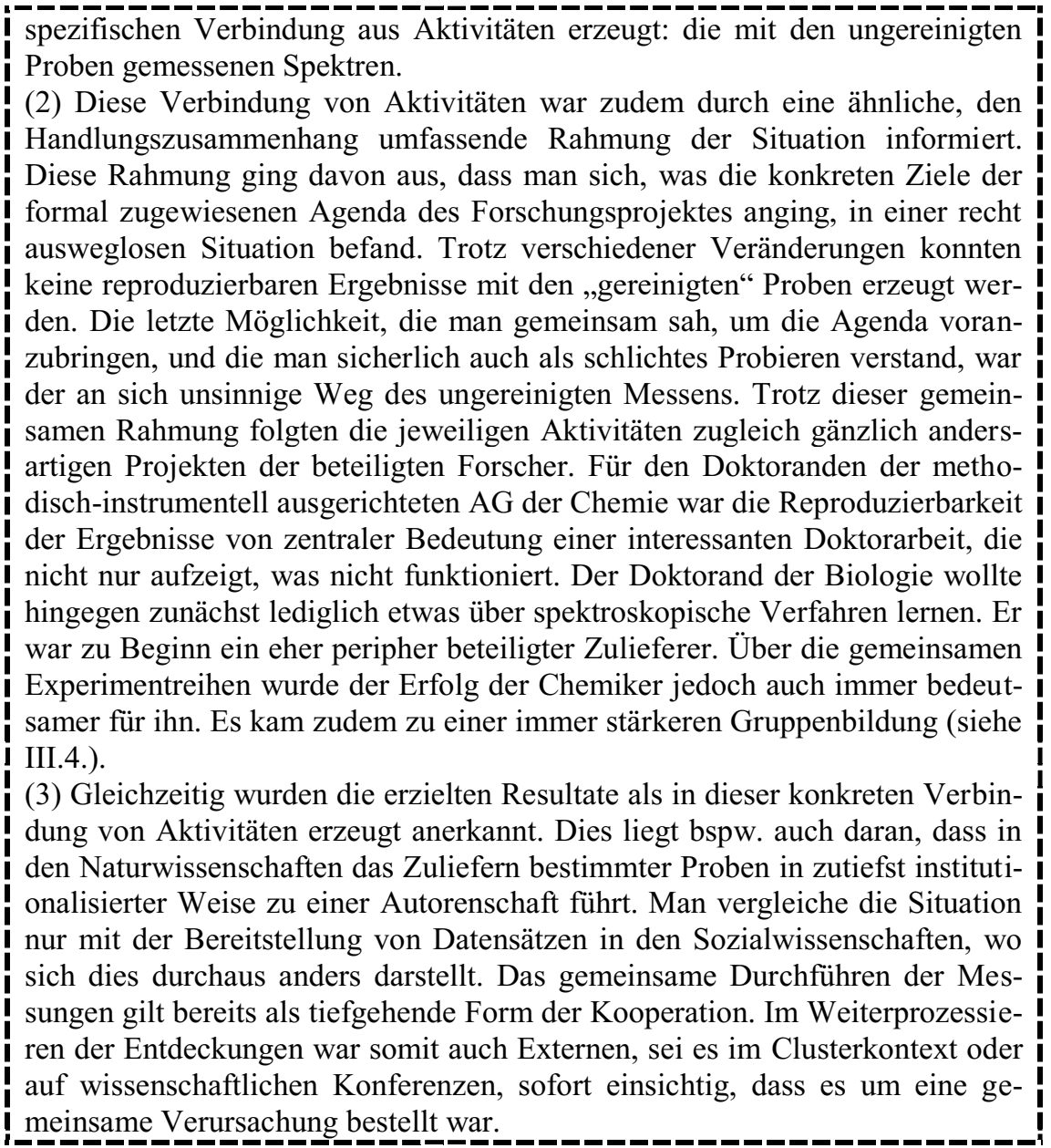

\section{Kollektives Handeln: Abgrenzung und Ausdifferenzierung}

In der sozialtheoretischen Debatte um kollektives Handeln finden sich zum einen Ansätze, die mit einem breiten Begriff kollektiven Handelns arbeiten. Hier wird alles koordinierte Handeln bis hin zum sozialen Handeln als Kollektivhandeln thematisiert. Zum anderen bestimmt eine Vielzahl an Ansätzen das Phänomen kollektiven Handelns in zugespitzter Form, reserviert den Begriff etwa für das Handeln korporativer Akteure oder für kollektiv-intentionales Handeln. Wie 
Abb. 9 verdeutlicht, ist die hier eingeführte Definition von kollektivem Handeln zwischen diesen beiden Extremen angesiedelt. Sie thematisiert kollektives Handeln als Spezialform sozialen und koordinierten Handelns, die verschiedene Ausprägungen annehmen kann, bspw. das Handeln als Kollektivakteur.

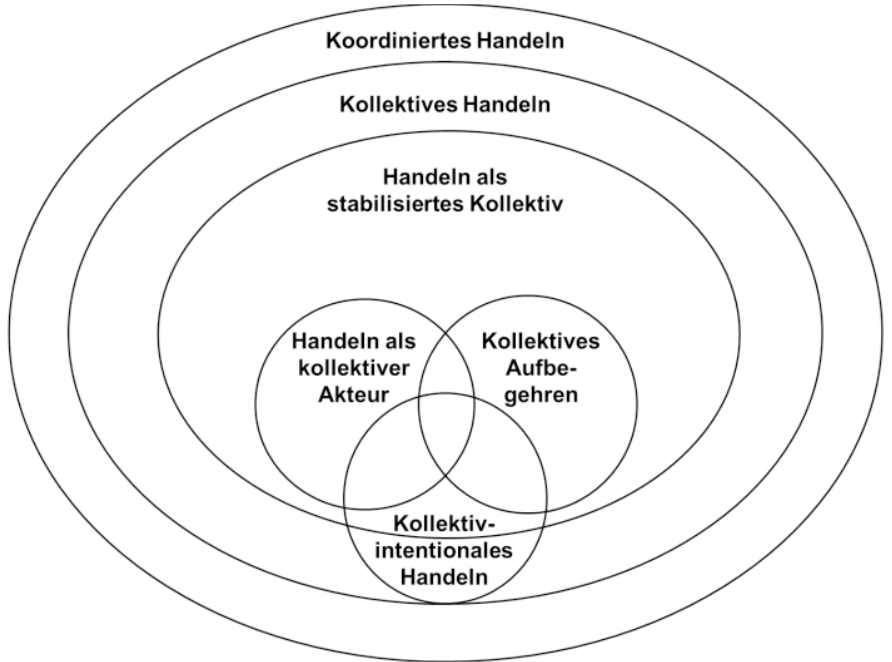

Abb. 9: Relation verschiedener Konzepte des Zusammenhandelns, eigene Darstellung

Wenn Kollektivhandeln als ein Geflecht von aktiv in Zeit und Raum miteinander hochgradig verbundenen Aktivitäten konzipiert wird, die von einer zu einem gewissen Grade ähnlichen Rahmung informiert und in ihrer Verbindung als Verursacher eines Effekts anerkannt werden, haben wir es mit einem Handeln und keinem Verhalten zu tun. Hierbei kann, wie schon bei Max Weber, die spezifische Reflexivität, also eine sinnhafte Orientierung, als zentrales Abgrenzungskriterium herangezogen werden:

„Bestimmte Arten des Reagierens werden durch die bloße Tatsache, daß der Einzelne sich als Teil einer ,Masse ' fühlt, erst ermöglicht, andre erschwert. Infolgedessen kann dann ein bestimmtes Ereignis oder menschliches Verhalten Empfindungen der verschiedensten Art [...] hervorrufen, welche bei Vereinzelung nicht (oder nicht so leicht) als Folge eintreten würden, - ohne daß doch dabei (in vielen Fällen wenigstens) zwischen dem Verhalten des einzelnen und der Tatsache seiner Massenlage eine $\mathrm{s}$ i $\mathrm{n} \mathrm{h}$ a f $\mathrm{t}$ e Beziehung bestände. Ein derart durch das Wirken der bloßen Tatsache der ,Masse' rein als solcher in seinem Ablauf nur reaktiv verursachtes oder mitverursachtes, nicht auch darauf sinnhaft b e z o g e n e s Handeln würde begrifflich nicht ,soziales Handeln“ [...] sein“ (Weber 1972: 11, Herv. i. Orig.). 
Wie bereits ausgeführt, ist es für ein Kollektivhandeln unabdingbar, dass die Beteiligten ein zumindest ähnliches Verständnis davon haben, gemeinsam in einer Situation und in einen Handlungszusammenhang eingebunden zu sein. Erst hierdurch wird auch die Intervention insofern kontrollierbar, dass ein Einwirken durch das Geflecht miteinander verbundener Aktivitäten stets auch unterlassen werden kann. Somit ist jede Aktivität im Rahmen eines Kollektivhandelns auch soziales Handeln im Sinne Webers, da es sich sinnhaft an seiner Verbundenheit mit den anderen Aktivitäten im Handlungszusammenhang orientiert. Die hier vertretene Form der Praxistheorie sieht sich, anders als etwa die Studien der ANT (siehe I.2.3.), der Trennung von Verhalten und Handeln also weiterhin verpflichtet.

\section{(A) Kollektivhandeln als spezifische Form koordinierten Handelns}

Soziales Handeln kann auch koordiniertes Handeln implizieren. Dies ist dann der Fall, wenn es zu einer minimalen Form der Wechselseitigkeit in der Orientierung aneinander kommt. Was Weber als soziales Handeln beschreibt, (re-)formuliert Giddens als spezifischen Teil einer Grundkonstante des Handelns des Menschen als sozialem und umweltbezogenem Wesen, als Teil des basalen reflexiven Monitoring des Handelns:

„Actors not only monitor continuously the flow of their activities and expect others to do the same for their own; they also routinely monitor aspects, social and physical, of the contexts in which they move" (Giddens 1984: 5).

Ein Teil dieses Monitoring als In-Kontakt-Bleiben mit den eigenen Aktivitäten sowie der physischen und sozialen Umwelt in Interaktionen ist eben die kontinuierliche Anpassung und Abänderung der eigenen Aktivitäten (und mitunter auch Interessen) in Auseinandersetzung mit anderen Anwesenden und antizipierten Abwesenden. Handeln im giddensschen Sinne ist also stets soziales Handeln.

Die hier angedeutete Konzeption kollektiven Handelns geht zudem von einem Verständnis der wechselseitigen Orientierung aneinander aus und erfasst kollektive Handlungsfähigkeit als spezifische Ausprägung koordinierten Handelns. Polanyi (1962: 1) grenzt in seiner Beschreibung von Wissenschaftlern koordiniertes von individuellem Handeln ab, indem er es von einem idealtypischen Handeln ohne jegliche Form der Beeinflussung des Handelns durch Ande- 
re unterscheidet. Zur selben Zeit wartet er (ebd.) mit einem allgemeinen Verständnis von Koordination auf:

„This consists in the adjustment of the efforts of each to the hitherto achieved results of the others. We may call this a coordination by mutual adjustment of independent initiatives - of initiatives which are co-ordinated because each takes into account all the other initiatives operating within the same system. "128

Koordiniertes Handeln kann so als Handeln unter wechselseitiger Abstimmung ${ }^{129}$ in Zeit und Raum mit mindestens einem (anwesenden oder abwesenden) relevanten Gegenüber bestimmt werden. Bedeutsam ist, dass es sich auch um vermittelte Abstimmungsprozesse handeln kann, also sich jenseits der Kopräsenz, bspw. über die Anwendung eines allgemeinen Prinzips, abgestimmt wird. Im Kollektivhandeln geht es darüber hinaus um eine wechselseitige Abstimmung individueller Aktivitäten, die Aktivitäten bindend an anderen Aktivitäten orientiert, das entstehende Geflecht auf spezifische Referenzen hin ausrichtet, eine ähnliche Aufnahme der Situation als einer gemeinsamen impliziert und zudem das Handeln im Handeln als gemeinsam verursacht ausflaggt. Somit werden zusätzliche Kriterien bestimmt, die Kollektivhandeln als spezifische Koordinationsprozesse konzipieren (ähnlich Coleman, siehe I.2.1.).

\section{Kollektives Handeln als kollektiv-intentionales Handeln}

In der philosophischen Debatte wird mit dem Konzept des Kollektivhandelns vor allem die Frage behandelt, ,was es heißt, dass Individuen jene intentionalen Handlungen, welche sie als Subjekte auszeichnen, auch gemeinsam einnehmen bzw. teilen können“ (Schmid/Schweikard 2009: 21a). ${ }^{130}$ Die behandelte Frage

128 Wenngleich man die allgemeine Bestimmung aufnehmen kann, bleibt zu hinterfragen, ob koordinierte Handlungssysteme nicht deutlich heterogener gedacht werden müssen. Zu hinterfragen wäre, ob jede Aktivität unmittelbar auf alle anderen rekurrieren muss.

129 Die Übersetzung kann hier ebenso in Richtung eines wechselseitigen Anpassens geschehen. Dies ist allerdings nur in speziellen Kontexten der Koordination der Fall. Praxistheoretisch basiert Koordination vielmehr auf einer Aufnahme von Aktivitäten als relevante Aktivitäten im reflexiven Monitoring der Handelnden.

130 Das Problematische an dieser Debatte für die Sozialwissenschaften ist der zumeist strikt individualistische Zugang zur Problematik, der bereits in dieser Fragestellung anklingt. Kannetzky (2007) arbeitet diesen unzureichenden Startpunkt anhand grundlegender Vertreter der Debatte 
nach der Konstitution kollektiven Handelns verwandelt sich so zumeist in eine noch spezifischere, in diejenige nach den Bedingungen und Möglichkeiten von kollektiven Intentionen. Verschiedene Autoren der analytischen Handlungstheorie (für einen Überblick siehe Schmid/Schweikard 2009b) fragen nach dem Unterschied zwischen parallelem Handeln und kollektivem Handeln (Schmid/ Schweikard 2009a: 11). Weitergehend beantworten sie (bei allen Differenzen) diese Frage unter Berufung auf die spezifische „Struktur der leitenden Absicht der Beteiligten“ (ebd.: 13). Bei allen Differenzen würden viele Autoren dieser Debatte auf die Frage, was kollektives Handeln ausmacht, geteilte Intention zur Beantwortung heranziehen. Aus der hier verfolgten praxistheoretischen Perspektive ist dagegen einzuwenden, dass nicht jedes Kollektivhandeln geteilter Intentionalität bedarf. Kollektiv-intentionales Handeln ist aus der hier vertretenen Perspektive ein Spezialfall des Kollektivhandelns.

Dies hängt selbstredend mit dem giddensschen Verständnis von Intentionen zusammen. Für ihn sind intendierte Phänomene keineswegs der Normalfall im Sozialen. Sie müssen von der allgemeineren Figur der Agency unterscheiden werden:

„[...] we have first of all to be clear how ,intentional' should be understood. This concept I define as characterizing an act which its perpetrator knows, or believes, will have a particular quality or outcome and where such knowledge is utilized by the author of the act to achieve this quality or outcome. If the characterization of agency given above is correct, we have to separate out the question of what an agent ,does' from what is ,intended' or the intentional aspects of what is done. Agency refers to doing" (Giddens 1984: 10; ebenso Giddens 1993: 83)

Intentionen sind dabei keineswegs irrelevant. Giddens weist ihnen nur keine prinzipiell konstitutive Rolle für Agency zu, wie es eine Vielzahl anderer Autoren tun (siehe prominent Emirbayer/Mische 1998). Für ihn ist Intentionalität nur

(namentlich Tuomela, Gilbert, Bratman und Searle) heraus und verbindet dies mit einer scharfen Kritik: Die ontologische Problemstellung der Debatte würde sich auflösen, wenn man die grundlegend soziale Natur von Intentionen ernst nehmen würde, wenn man aufhörte, Intentionen als exklusive Besitzgüter der Subjekte zu behandeln. Einen weiteren Einwand formuliert Schmid (2005: 105): „Nicht deshalb können wir gemeinsam Denken und Handeln, weil wir gemeinsames Denken und Handeln zum Gegenstand unseres Bewusstseins machen und ihm zustimmen können, sondern umgekehrt: Die Tatsache, dass wir gemeinsam denken und handeln können, ist Voraussetzung dafür, dass wir unser gemeinsames Intendieren reflexiv zum Thema unseres individuellen Bewusstseins machen können." Weite Teile der Literatur in der Philosophie starten also von einem sozialwissenschaftlich erstaunlich wenig plausiblen Ausgangspunkt. 
in besonderen Situationen von Bedeutung, in denen von den Akteuren im Handeln als zutreffend angenommene Ursache-Wirkungs-Ketten angelegt werden.

Diese Entkopplung von Agency als Ausführen und eines dahinterliegenden, angewendeten Wissens um die Erzeugung eines Ergebnisses nimmt er aus zwei Gründen vor: zum einen um die unintendierten Konsequenzen des teils intendierten Tuns thematisieren zu können, die aus einer Entfernung dieser Konsequenzen vom unmittelbaren Handlungskontext und den unmittelbar erzielten Effekten herrühren, ${ }^{131}$ zum anderen um die beschriebenen Verhältnisse von Prinzipal und Agent aufnehmen zu können (siehe I.2.1. für die Argumente von Coleman für diese Trennung), wobei der Prinzipal das intendierte Handlungsprodukt planen und erreichen kann, ohne es notwendigerweise selbst auszuführen. Das Ausgeführte kann auch anderen Interessen entspringen als denen des Ausführenden und andersartig intendiert sein. Was intentionale und intendierte Aspekte von Agency sind, muss erst empirisch herausgestellt werden. Entkopplungen kollektiven Handelns von kollektiven Intentionen sind nicht nur möglich, sondern ein regelmäßiger Bestandteil des Kollektivhandelns.

Für kollektive Intentionalität bedeutet diese Bestimmung, dass nur dasjenige kollektive Handeln auch kollektiv intendiert ist, von dem alle Beteiligten in hochgradig ähnlicher Weise ein bestimmtes, ähnliches Produkt als Ziel ihres Tuns ausmachen und daraufhin ein hochgradig ähnliches Wissen und Können einbringen um dieses Produkt zu erzeugen. Einige Ansätze definieren Kollektivhandeln generell über eine „erwartete gemeinsame Wirkung koordinierten Handelns“ (Scharpf 2000: 101). ${ }^{132}$ Dennoch wird das kollektiv-intentionale Handeln,

131 Beispielsweise wenn wir einen Kaffee trinken und darum wissen, dass er uns wach macht, dieses Ziel auch erreichen, zugleich unintendiert jedoch die miserablen Arbeitsbedingungen in den Anbaugebieten und die ökologische Schäden mit ins Leben rufen (siehe Giddens 1999: 4f.).

132 Mitunter wird auch Kooperation als Sonderform kollektiv-intentionalen Handelns diskutiert. Dies geschieht vor allem dann, wenn der Begriff nicht generell mit einem Zusammenhandeln oder Kollektivhandeln gleichgesetzt wird. Bei Bratmans (2009: 177) allgemeiner Bestimmung wäre die Mindestanforderung für kooperatives Handeln dann das Verfolgen ein und desselben Ziels, ohne dass dabei jeder dieselben Gründe (oder Interessen, wie Laudel 1999: 32 vorschlägt) für die Verfolgung haben muss. Weiterhin ist das Gewähren von Hilfestellung und Unterstützung kennzeichnend, ebenso wie die wechselseitige Vereinbarung zum gemeinsamen Handeln und das explizite, bewusste Aufeinander-Eingehen. Sennett (2012: 17) fügt dem noch hinzu, dass es sich um einen Austausch handeln muss, von dem alle profitieren (oder zumindest zu profitieren scheinen), und verweist damit auf eine positiv-normative Komponente, die mit der Kooperationsthematik auch verbunden ist. Andere (Popitz et al. 1976: 43) verweisen 
dem eine geteilte Absicht zugrunde liegt, im hier entworfenen Konzept zu einem hochgradig voraussetzungsvollen Spezialfall kollektiven Handelns. Die analytisch-philosophische Handlungstheorie in der Nachfolge Anscombes stellt dabei einen klaren und hilfreichen Bezugspunkt heraus:

„People are acting together intentionally if and only if their actions can all be straightforwardly instrumentally rationalized by the same action" (Laurence 2011: 282, Herv. i. Orig.).

Diese Aussage kann verstanden werden, wenn wir annehmen, dass sich die individuellen Aktivitäten nur dann an einer geteilten Erzeugung eines Ergebnisses qua als richtig angenommener Ursache-Wirkungs-Kette orientieren können, falls sie sich auf dieselbe, wechselseitig typisierte Handlungsweise beziehen. Die Beteiligten müssen dieselbe Prozedur oder soziale Praktik vor Augen haben und aktualisieren. In diesem Sinne kann man die schützsche Trennung von Handeln und sozialer Handlung praxistheoretisch in eine zwischen Handeln und sozialen Praktiken überführen. Nur unter Rekurs auf eine Praktik können alle Beteiligten auch geteilt annehmen, sie würden einen Effekt auf eine bestimmte Art und Weise erzielen. Nimmt man Beispiele kollektiven Handelns auf, sieht man, dass dies nicht immer der Falls ist. Im bereits erwähnten Beispiel des über die Krankenhausakte koordinierten Handelns müssen die Ärzte keineswegs alle Aktivitäten des Pflegepersonals kennen und wissen, wie ihre Arbeitsabläufe aussehen, um in Verbindung Effekte zu erzeugen. Nicht jedes Kollektivhandeln ist über eine geteilte Repräsentation des gemeinsam realisierten Handlungsablaufs charakterisierbar. Einige Beteiligte wissen mitunter nicht einmal, wie ihre Aktivitäten konkret „eingebunden“ sind. Dies war bei einigen „Zulieferern“ von Proben in der Katalyseforschung der Fall. Dennoch nehmen Ärzte und Pflegende sowie die Katalyseforscher reflexiv auf, dass sie in Verbindung handeln, behandeln bestimmte Effekte ihres Arbeitens als in Verbindung erzeugt. Sie koordinieren ihr

zudem darauf, dass eine bestimmte Kollektivleistung in diesem Austauschzusammenhang arbeitsteilig erbracht wird. In dieser Bestimmung wird das kooperative Handeln dann eben zu einer Sonderform kollektiv-intentionalen Handelns, die nicht nur durch geteilte Absichten, sondern die geplante und häufig auch organisierte Erzielung eines Effekts ausgerichtet ist. Die Beteiligten klären vorab, wie sie das gemeinsame Ziel arbeitsteilig erreichen. Mitunter wird diese arbeitsteilige Vorgehensweise wiederum von Kollaboration unterschieden, also einer Zusammenarbeit, die nicht verteilt, sondern parallel erzeugt wird. Die begrifflichen Verästelungen lassen sich noch weiter fortführen, ohne dass eine (zumindest ansatzweise) geteilte Sprachregelung erkennbar ist. 
Handeln etwa durch einen Systemzusammenhang, der auf einer arbeitsteilig ausgestalteten Trennung der Aktivitäten verschiedener Professionen basiert.

Man kann sicher annehmen, dass Kontexte stabilisierter Kollektive und von Kollektivakteuren durchaus häufig ein kollektives Handeln auch in kollektivintendierter Form ausüben. Hier stehen bestimmte Formen des sytemreflexiven Monitoring, der Rationalisierung und Motivierung sowie stabile Systempraktiken zur Verfügung (Windeler 2001). Bei kollektiven Interventionen bedarf es genauer Aushandlungen oder dem Verweis auf wechselseitig erlernte Prozeduren, um kollektiv-intentional zu handeln. ${ }^{133}$

\section{(C) Kollektives Handeln als Handeln eines stabilisierten Kollektivs}

Das hier angestrebte Begriffsinstrumentarium legt zunächst ein möglichst vorrausetzungsloses Verständnis an, das kollektives Handeln nicht an bereits bestehende Kollektive, seien es mit einer stabilisierten Knowledgeability ausgestattete Kollektive oder Kollektivakteure, bindet. Der Unterschied zwischen dem allgemeineren Begriff des Kollektivhandelns zum Handeln stabiler Kollektive besteht darin, dass es nicht in jedem kollektiven Handeln auch zu der bereits angesprochenen „Doppelattribution“ des Handelns kommt. Nicht jedes Handeln in Verbindung wird automatisch neben einer individuellen auch auf eine kollektive Identität zugeschrieben. Dies ist aber für eine Vielzahl an Autoren Voraussetzung, damit von einem Kollektivhandeln eines stabilen Kollektivs gesprochen werden kann. ${ }^{134}$

133 Kollektive Intentionalität ist weiterhin zu unterscheiden von kollektiv motiviertem Handeln. Giddens verweist beständig darauf, dass Intentionen nicht mit Motiven zu verwechseln sind: „Motives tend to have a direct purchase on action only in relatively unusual circumstances, situations which in some way break with the routine. For the most part motives supply overall plans or programmes - , projects', in Schutz's term - within which a range of conduct is enacted. Much of our day-to-day conduct is not directly motivated" (Giddens 1984: 6). Kollektiv motiviertes Handeln wäre dann ein kollektives Handeln, das auf hochgradig ähnlichen Projekten und Plänen eines kollektiven Handlungszusammenhangs aufsetzt. Dennoch geht Giddens davon aus, dass unser Tun in aller Regel nicht direkt aus diesen Motiven erklärt und verstanden werden muss, solange es eingelebten Prozeduren des Sozialen folgt. Von kollektiv motiviertem Handeln auszugehen, ist sodann analytisch sinnvoll, wenn ein Bruch mit diesen Prozeduren aus in einem kollektiven Handlungszusammenhang geteilten Begierden, Projekte und Plänen folgt.

134 Siehe neben den bereits ausführlich diskutierten Handlungs- und Institutionentheoretikern etwa so avanciert argumentierende Autoren wie Teubner (1987, 1992), Ortmann (2010, 2014: 39), 
In der Bewegungsforschung wird seit den 1970er Jahren vor allem die planvolle und deutend sinnhafte Komponente kollektiver Aktionen des Aufbegehrens fokussiert. ${ }^{135}$ Dabei rückten Koordinierungsproblematiken spätestens seit den 1970er Jahren in das Zentrum der Debatte der Bewegungsforschung vor allem verbunden mit den Arbeiten von Tilly und Zald. Insgesamt wird seit Ende der 1990er Jahre versucht, kollektives Handeln aus einem Zusammenspiel von Mobilisierungsstrukturen, kollektiver Rahmung und politischen Gelegenheiten (McAdam et al. 1996) heraus zu erklären. Dabei gerät immer stärker die aktive Rolle von sogenannten „Bewegungsentrepreneuren“ in den Blick, die eine Passung zwischen den drei Ebenen produzieren. Mit dem Terminus werden hier aber vor allem spezifische Phänomene kollektiver Protestaktionen bezeichnet. Diese Eingrenzung ist ein häufiges Phänomen im englischsprachigen Diskurs über das Kollektivhandeln.

Kennzeichnend für die Art und Weise der konzeptionellen Behandlung in der Bewegungsforschung kann die folgende Definition eines prominenten Protagonisten dieses Forschungsfeldes gelten:

„The term ,collective action' is hopelessly broad. Taken at face value, it could plausibly refer to all forms of human social action involving two or more people. Suffice to say, consideration of such a broadly inclusive category would be well beyond the scope of this entry. But there is a far narrower subset of human action to which the term has been applied and which will be the focus here. For our purposes, collective action refers to emergent and minimally coordinated action by two or more people that is motivated by a desire to change some aspect of social life or to resist changes proposed by others" (McAdam 2007: 574).

Hier wird die generelle Fokussierung des Bewegungsdiskurses auf Prozesse koordinierten Aufbegehrens deutlich. ${ }^{136}$ Der Term des kollektiven Handelns selbst kann viel breiter verstanden werden, wie McAdam selbst klarstellt (siehe

Felsch (2010) oder Sydow (2014), die sich allesamt auf Kollektivakteure beziehen. Siehe für eine Ausnahme die neueren Bemerkungen von Windeler (2014: 257 in Fußnote 42), der Kollektivhandeln und den Status des Kollektivakteurs dezidiert voneinander trennt.

135 Dies vor allem in Abgrenzung zu Ansätzen, die das Tun der Einzelnen zu einem bloßen Agieren als reflexartigen Ausdruck der Gruppenlage bestimmen (etwa dem relative DeprivationAnsatz bei Gurr 1970), die klar auf den Schultern der Massenpsychologie Le Bons steht (siehe etwa Currie/Skolnick 1970).

136 Für eine Ausnahme siehe die systematische Darstellung kollektiven Handelns bei Melucci (1996), der diese Fokussierung nicht aufnimmt. 
hierzu kritisch Bader 1991: 22), um bspw. auch reproduzierendes kollektives Handeln eine Bedeutung beizumessen, ohne damit jegliches soziale Handeln einzuschließen. ${ }^{137}$ Weiterhin stehen zumindest minimal stabilisierte Kollektive oder Kollektivakteure im Zentrum der Debatte, also etablierte oder gerade in Entstehung begriffene Bewegungen. Im Rahmen des hier vorgeschlagenen Konzeptes kollektiven Handelns thematisiert die überwiegende Mehrzahl an Konzepten aus dem Bewegungsdiskurs spezielle Formen kollektiven Handelns: kollektive Aktionen des Aufbegehrens eines Kollektivs.

137 Dieses Argument bildet auch den Ausgangspunkt für die neuerliche Wiederbelebung der Begegnung von Organisations- und Bewegungsforschung (insbesondere in Davies et al. 2005 sowie Fligstein/McAdam 2012). 
Open Access Dieses Kapitel wird unter der Creative Commons Namensnennung 4.0 International Lizenz (http://creativecommons.org/licenses/by/4.0/deed.de) veröffentlicht, welche die Nutzung, Vervielfältigung, Bearbeitung, Verbreitung und Wiedergabe in jeglichem Medium und Format erlaubt, sofern Sie den/die ursprünglichen Autor(en) und die Quelle ordnungsgemäß nennen, einen Link zur Creative Commons Lizenz beifügen und angeben, ob Änderungen vorgenommen wurden.

Die in diesem Kapitel enthaltenen Bilder und sonstiges Drittmaterial unterliegen ebenfalls der genannten Creative Commons Lizenz, sofern sich aus der Abbildungslegende nichts anderes ergibt. Sofern das betreffende Material nicht unter der genannten Creative Commons Lizenz steht und die betreffende Handlung nicht nach gesetzlichen Vorschriften erlaubt ist, ist für die oben aufgeführten Weiterverwendungen des Materials die Einwilligung des jeweiligen Rechteinhabers einzuholen. 